\title{
Knots that Strain \& Threads that Bind: NGO-Grassroots Dynamics in the Movement Web Challenging Canadian Resource Extractivism
}

\author{
by
}

Maximilian Chewinski

A thesis submitted to the Faculty of Graduate and Postdoctoral Affairs in partial fulfillment of the requirements for the degree of

Master of Arts

in

Sociology

Carleton University

Ottawa, Ontario

(C) 2015, Maximilian Chewinski 


\begin{abstract}
The predominant NGOization thesis typically describes NGO-grassroots relationships as disconnected, with the former engaging in hegemonic social formations, the apolitical delivery of services, and shifting accountability structures that alter agendas for social change. By utilizing a hermeneutic phenomenological approach, and in conducting nine in-depth and semi-structured interviews with two NGOs and two grassroots groups working within this field, the objective of this thesis is to complicate theories of NGOization by magnifying the threads and knots that comprise the social movement web challenging Canadian resource extractivism. In light of five knots that create tensions and feelings of ambivalence between NGOs and grassroots groups, my findings suggest that they are bound together in this web through five main threads. This thesis asserts that studies on NGOization would benefit from the relational understanding of collective action provided by social movement studies, including the conceptual tools offered through resource mobilization and framing theories.
\end{abstract}




\section{Table of Contents}

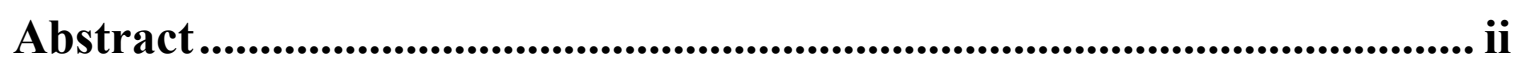

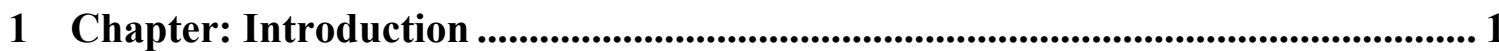

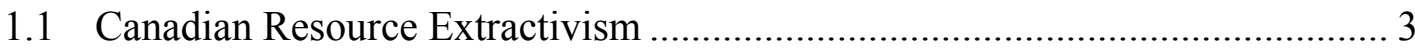

1.2 Theoretical and Methodological Approaches ………………………............ 8

1.3 Findings \& Project Map ............................................................................ 10

2 Chapter: NGOization and Social Movement Theory ............................................... 16

2.1 Theorizing the Component Parts of NGOization:............................................. 18

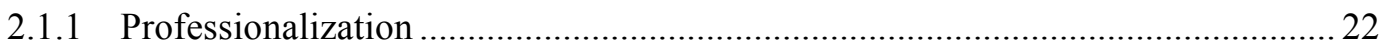

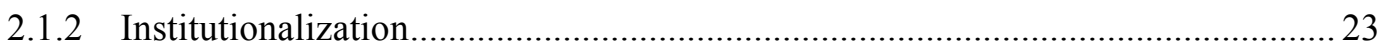

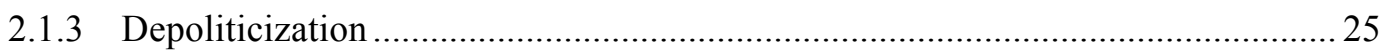

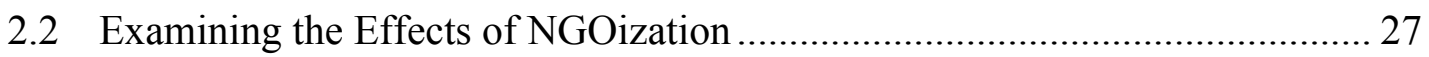

2.2.1 Engaging in Hegemonic Social Formations........................................................ 28

2.2.2 Shifting Accountability \& Changing Movement Agendas .................................... 31

2.2.3 Institutionalization and its Discontents: Apolitical Service Delivery ..................... 34

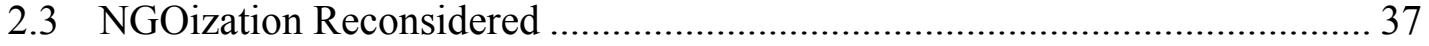

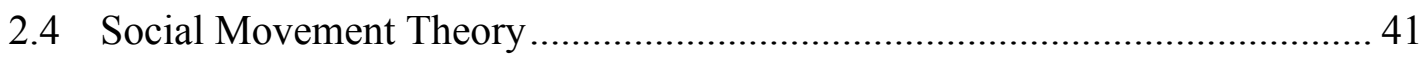

2.4.1 Resource Mobilization .................................................................................. 44

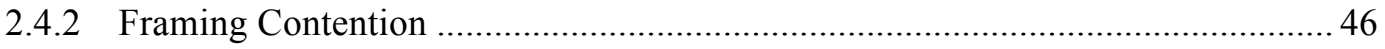

2.5 Conclusion: Identifying Limitations, Gaps \& Bridging Theories..................... 48

3 Chapter: Methodology............................................................................................. 51

3.1 Methodology: Hermeneutic Phenomenology ………………......................... 52

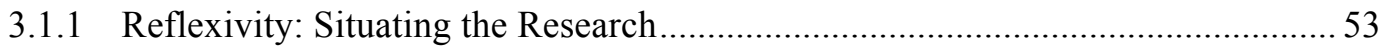

3.1.2 Asking Phenomenological Questions …………………………….................... 55 
3.2 Rationale for Selected Participants/Organizations ...................................... 57

3.3 Methods: The Interview Process and the Space Between...............................6 60

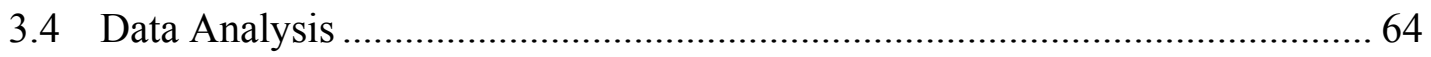

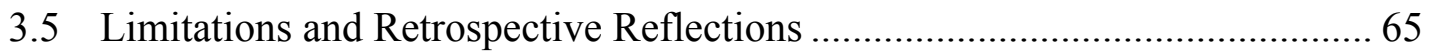

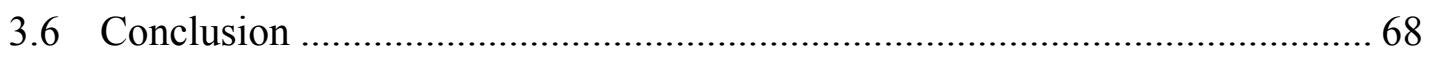

4 Chapter: Shared Values and Frames of Contention ........................................... 69

4.1 Shared Values: Self-determination and Accountability .............................. 69

4.1.1 Self-determination, Community Agency and Free, Prior and Informed Consent. 70

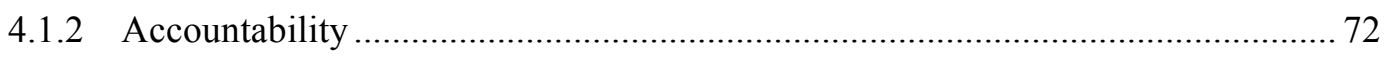

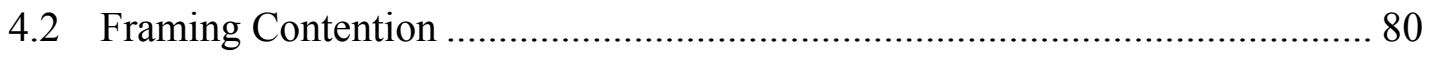

4.2.1 The Environmental Justice Movement and Framework .................................... 81

4.2.2 Environmental Justice \& Resource Extraction in Canada .................................. 82

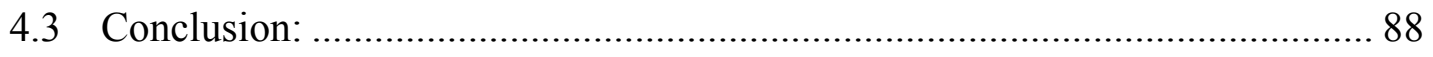

\section{Chapter: Strengthening Threads \& Navigating Knots: Resources, Goals \&}

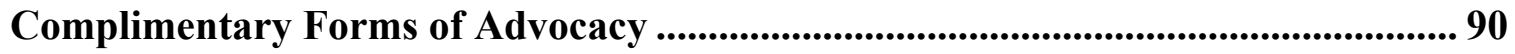

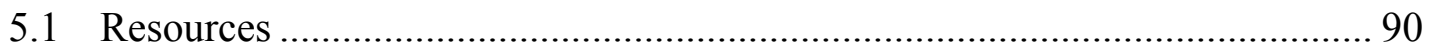

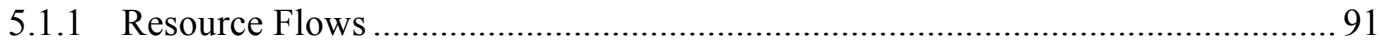

5.1.2 Resource Sharing \& Pooling: Strengthening Networks and Coalitions................ 92

5.2 Capacity Knots: Understanding Tensions and Strains ............................... 96

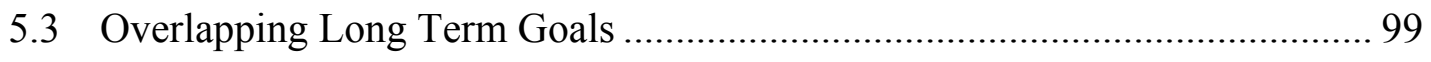

5.3.1 Educating Publics: Cultivating a Critical Consciousness ….............................. 100

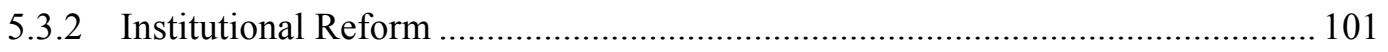

5.4 Complimentary Forms of Advocacy: Diversity of Tactics \& Division of

Labour 103 
5.4.1 From Each According to Their Strength, To Each According to Their Need .... 104

5.5 Linking Knots: Depoliticization and Institutionalization............................ 109

5.6 Conclusion: ....................................................................................... 114

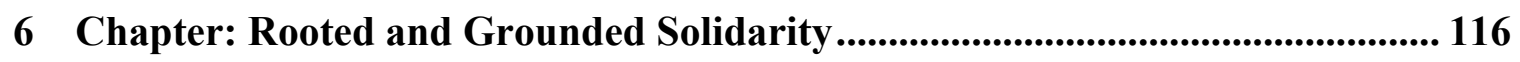

6.1 Rooted Solidarity: Bridging the Local and the Global ............................. 116

6.1.1 Requirement 1: Community Driven Advocacy.............................................. 118

6.1.2 Requirement 2: Establishing Long-Term Relationships ................................ 120

6.1.3 Collaborating with Communities: Engaging in Strategy Formation................... 122

6.1.4 Threads that bind North-North Collaboration ................................................ 123

6.2 “These organizations are dangerous, man!”: Examining Rootlessness ......... 127

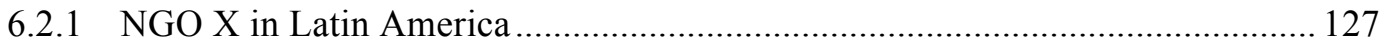

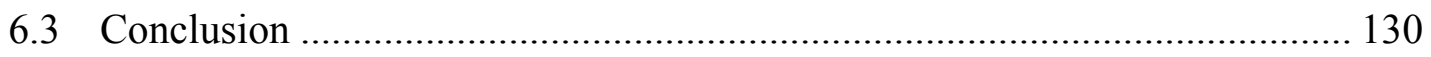

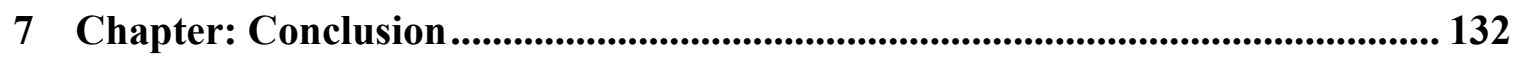

7.1 Theoretical and Methodological Foundations......................................... 133

7.2 Research Findings: NGOization and the Complexity of Movement Webs ... 136

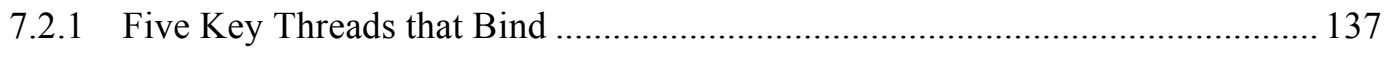

7.2.2 Five Knots that Strain Relationships \& the Capacity to Enact Change .............. 140

7.3 Implications and Future Areas of Inquiry …........................................ 142

Appendices ........................................................................................................144

Appendix A Grassroots Group, NGO and Union Profiles .................................................. 144

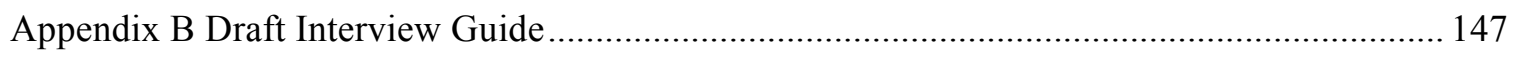

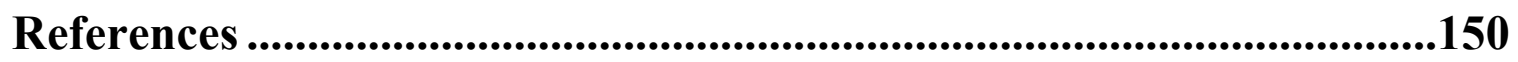




\section{Chapter: Introduction}

As of 9:30 in the morning on Wednesday April 24 ${ }^{\text {th }}, 2013$, dozens of environmental justice activists gathered outside of the Metro Toronto Convention Centre in the rain to welcome shareholders to Barrick Gold's Annual General Meeting (AGM). A group of us, including myself, made our way into the AGM to hand out an alternative annual report to shareholders entitled Debunking Barrick. ${ }^{1}$ After only speaking to a few uninterested shareholders - some confrontational - we were escorted by security under threat of being charged for trespassing. Around the same time, two Greenpeace activists from Argentina were arrested in Toronto for "unfurling a banner condemning the Pascua Lama mine" (Saunders 2013). Following this action, now former Chairman Peter Munk "blasted NGOs, environmental regulations and the governments of countries hosting his mines", only to be called out by said NGOs and speakers from the Dominican Republic moments later - in front of a hall full of investors attending the Toronto AGM- about Barrick Gold's treatment of mining affected communities and the activists that organize against the world's largest gold producer (Saunders 2013). Meanwhile, outside, activists holding banners and a 14-foot effigy of a Pinocchio nosed Peter Munk with blood on his hands chanted enthusiastically, with a hint of anger, "Divest, Divest, Divest from Barrick Gold!" as police officers lined the sidewalk, preventing protestors from accessing the building.

${ }^{1}$ This report sought to challenge the mainstream narrative of Barrick Gold as an organization committed to Corporate Social Responsibility (CSR) by highlighting the lived realities of largely Indigenous communities dispossessed of their land and/or facing water contamination and health issues as a result of gold mining projects in countries such as Tanzania and Papua New Guinea. 
This protest, as a practice of contentious politics, is illustrative of the diversity of tactics, the constellation of actors, and the different types of voices that comprise, borrowing Alvarez's (1997) apt metaphor, the movement web challenging Canadian resource extractivism. For Alvarez (1997: 87), social movement webs include "inter- and intramovement networks" and the power knots that are representative of the tensions, contradictions and feelings of ambivalence that are always evident and give shape to complex webs. NGOs, grassroots groups, and other organizational forms consist of nodal points with ties between nodal points constructing the web (Alvarez 1997). I prefer to think of ties as threads that intricately and precariously bind actors together. ${ }^{2}$ This metaphor is indicative of the need to move away from a conceptualization of groups and organizations as "discrete, or isolated actors, somehow pure and disconnected [from the] social and political actors that surround them," instead stressing the relational character of social movements (Alvarez 1997: 89). It is because of this thoughtful metaphor and its attention to the relationality of collective action that I adopt it to frame an analysis which seeks to complicate predominant theories of NGOization - specifically those that articulate the NGOization thesis - that have a tendency to render unintelligible the relational aspect of actors operating in any given web.

In order to do so, I ask the following questions: (1) What factors explain the relatively high level of collaboration between NGOs and grassroots groups working to challenge Canadian resource extractivism? (2) Are there elements of NGOization

${ }^{2}$ One qualification must be made clear: the concept of binding is not meant to suggest that threads are permanent or that the threads that bind nodal points rest on a symbiotic relationship. In fact, like in most webs, threads can be loosened, tightened, or disappear entirely, without devastating individual nodes - hence the precariousness of them. 
occurring within the movement that is critical of Canadian extractive operations? and (3) what effect does NGOization have on the movement's capacity to enact change in this sector? The remainder of this chapter is set up to both contextualize these research questions and explicate the theoretical and methodological foundations that inspire them. In the first section, I contextualize the project by situating Canada's political-economic reality in a strong commitment to resource extractivism and briefly draw attention to the nascent resistance movement challenging this model of development. In the second section, I provide an overview of NGOization theory and the predominant NGOization thesis before discussing the hermeneutic phenomenological approach that shapes this project, the methods that I adopt to explicate and interpret the phenomenon, and the role of social movement theory in magnifying the threads that bind interaction between NGOs and grassroots groups. Finally, I provide an overview of my findings and a project map that orients my thesis.

\subsection{Canadian Resource Extractivism}

The resource extraction sector - from cod fisheries in the East to logging in the West - has a rich history in Canada. Today, Canada continues its centuries-long reliance on extractivism as a driver of economic growth, employment, and fiscal revenues (Veltmeyer and Bowles 2014). In the context of this thesis, I focus on mineral and oil development, as they are representative of the Canadian and global resistance movements to extractivist imperialism ${ }^{3}$, and are the two industries targeted (to varying degrees) in the

\footnotetext{
${ }^{3}$ Veltmeyer $(2012 ; 2013)$ coined the term extractivist imperialism to highlight the role of the Canadian state apparatus, under the Harper regime in particular, in actively using its powers to support the flow of financial capital around the world. The mechanisms used to do this are explained on page five.
} 
social movement web I examine in this study. Oil development - in the form of the Alberta tar sands (and its associated pipelines) - and mineral extraction at home and abroad contribute significantly to Canada's economic performance. The tar sands and the production of bitumen play a dominant role for Alberta's GDP, as investment in 2009 was believed to be a total of $\$ 10$ billion with estimates for 2010 to 2035 forecasting capital investment at $\$ 250$ billion (Bowness and Hudson 2014).

The mining sector is equally compelling and revealing of a national commitment to resource extractivism as a development model. In 2012, the GDP generated from mineral extraction was valued at \$53 billion (Natural Resources 2013: 14). In 2011, the mining industry contributed $3.9 \%$ to Canada's overall GDP, and it is suggested that contributions will steadily increase (Natural Resources 2013: 14). This contribution to Canada's GDP may not seem significant, but the value of mining to Canadian economic growth is made evident when examining exports. In 2012, it was calculated that $\$ 89.5$ billion is generated in merchandise exports, accounting for a total of $20.9 \%$ in overall exports (Natural Resources 2013: 7). The historical and contemporary economic importance of staples production (oil and minerals), has significant implications for Canada's development and foreign policies, which is overwhelmingly in support of extractivist models of development with no political party - including the Green Party calling for a wholesale shift from this paradigm.

The Canadian state's commitment to oil and mineral development takes several forms. For oil and mineral development nationally, it is most evident in cutting the redtape of Federal and provincial environmental regulations, captured with the passing of 
Bills C- $-38^{4}$ and C- $-45^{5}$ without substantive policy review, no public debate, and both of which were passed with a single vote (Kirchhoff \& Tsuji 2014). In addition to this neoliberal assault on the environment and communities (both Indigenous and nonIndigenous) in close proximity to extractive operations, there has been a corresponding shift in government foreign policy and the development agenda, both of which provide political opportunities and threats for engaging in contentious politics that challenge the resource extractivist regime.

The Canadian state's foreign policy in the mineral and oil industry in particular is characteristic of extractive imperialism, with its governance arrangements at home and abroad securing Canadian multinational domination (Veltmeyer 2014). The mechanisms invoked take many forms, including: a national commitment to voluntary Corporate Social Responsibility (CSR) principles that have been found to be inadequate in responding to social, environmental and cultural harms experienced by impacted communities (Coumans 2012; Veltmeyer 2014); the aggressive lobbying of foreign governments by Canadian Embassies and their ambassadors to accept extractive projects

${ }^{4}$ Bill C-38, the Jobs, Growth, and Long-term Prosperity Act, was introduced in April 2012 as a budget bill, despite including many changes to legislation that have nothing to do with the adjudication or source of federal monies. Bill C-38 includes changes to legislation such as the Fisheries Act, the Species At Risk Act and most significantly, the Canadian Environmental Assessment Act - all changes that run counter to the claim of assuring long-term prosperity and which cut the red tape of environmental protection laws.

${ }^{5}$ Bill C-45, the Jobs and Growth Act, was introduced in a similar manner as Bill C-38 in October 2012. This bill included changes to over 60 acts and regulations, with the most important allowing corporations to escape responsibility for pipeline or mineral tailings pond spills (or other risks involved with the extraction and processing of these natural resources); it also includes changes to the Navigable Waters Protection Act. The new Navigable Protection Act represents a significant loss to water protection policies as an astounding 99\% of Canadian waterways are no longer under federal protection (Kirchhoff \& Tsuji 2014: 111). 
(Dirty Business 2007); the launch of Canada's Global Markets Action Plan (2013) which encourages economic diplomacy to secure Canadian commercial interests in foreign natural resource markets; the use of Canada Revenue Agency (CRA) audits on environmental NGOs in particular to "determine if they comply with guidelines that restrict political advocacy" -- a move many organizations have interpreted as a tactic to silence criticism of Canadian state practices (Solomon and Everson 2014); the use of the former Canadian International Development Agency (CIDA) to alter foreign mining laws, favourably aligning them according to the interests of extractive capital (Mining Watch 2013); and turning CIDA "into an agent of financial support for Canadian mining companies in their overseas operations" (Veltmeyer 2014: 85) by folding the organization into the Department of Foreign Affairs, Trade and Development (DFATD).

This last and most recent mechanism promotes public NGO and private corporate partnerships that effectively market extractive operations as development projects according to the ideology of "inclusive growth" (Veltmeyer 2014: 85), guided by a "whole of government" approach (Blackwood and Stewart 2012). This move has restructured Canada's former institution for foreign aid to serve the private sector, and reflects the Canadian state's commitment to using civil society for economic ends. In fact, two NGOs that supported grassroots resistance to Canadian extractivism abroad Development and Peace and KAIROS - "have lost, respectively, 50 and 100 percent of their development project funding" (Veltmeyer 2014: 86). This disciplining action acts as a warning to NGOs and attempts to silence the voices that are critical of an extractivist model of development. The immediate options for most NGOs in Canada are quite clear: either they support the industry and receive additional funding (as is the case for NGOs 
like World Vision), adopt a neutral or complacent position in regards to this industry; risk losing funds for a more principled position; or continue to advocate for environmental and social justice according to an alternative funding model.

The political-economic forces described above paint a troubling picture for the potential of contentious politics and the formation of strong social movement webs that remain resilient in light of the lack of political opportunities and state threats of defunding. However, despite the risks involved (defunding for NGOs and the criminalization of dissent of all actors involved), there continues to be a vocal and nascent movement in Canada that challenges the Canadian resource extractivist model of development. Although historically, Indigenous and individual communities have been affected by mineral and oil development in Canada and organized themselves in opposition, it has not been until the twenty-first century that a sustained social movement web began to take shape. The origins of the movement against mining in particular, for example, can be traced to early 2005-2006 when a coalition of NGOs, in the absence of grassroots groups organizing against the industry at this time, began to participate in national roundtables to bring about legal reform to Canada in light of increasing concerns about corporate abuses abroad (Kamphuis 2012). Grassroots groups eventually began to mushroom across the country to work on these issues - either on their own or in tandem with NGOs - and both sets of actors continue to collaborate in coalitions such as the Canadian Network for Corporate Accountability.

A movement against the tar sands, including resistance to pipeline expansion and other forms of oil mobility is "on the rise and gathering steam" (Annis 2012; Veltmeyer 2014), and is being led by Indigenous communities and settler allies across the country. 
The movement against the tar sands includes Indigenous activists and organizations as well as NGOs and grassroots activists and groups working in solidarity with tar sands affected communities and collaborating in coalitions such as British Columbia's Defend our Coast (Annis 2012) or the mobilization in Toronto against Line 9. NGOs and grassroots groups/activists use a variety of tactics and avenues for change to resist the environmental injustices that the Canadian state systematically upholds.

\subsection{Theoretical and Methodological Approaches}

The frequent and typical alliances formed by grassroots groups, NGOs, and Indigenous groups in support of common goals against resource extractivism (Veltmeyer and Bowles 2014) stands in contrast to the theoretical projections and dominant empirical examples of NGOization as it appears in the literature. This observation begs the question: what is NGOization? Lang (2013: 7-8), in an overview of research on NGOization, has provided three explanatory concepts that describe the contemporary operating conditions of NGOs in particular: (1) "the NGOization of civil society," understood as a shift from loosely organized groups towards vertically structured and professionalized NGOs to meet the needs of businesses, states, and private donors; (2) "the institutionalization of advocacy," which results in NGOs withdrawing a critical voice from public discourse and action in an effort to maintain institutional leverage and finally; (3) "NGOs acting and being perceived as proxy publics."

In the first two points, Lang (2013) addresses common criticisms of NGOs: they are professional and depoliticized organizations that shift from activism to the realm of acceptable advocacy vis-à-vis institutional structures. Indeed, this view argues that the process of NGOization undermines social movements in favour of state and corporate 
interests, and this claim is well established in the literature (Africa, 2013; Barry-Shaw \& Jay, 2012; Choudry, 2013; Gill 1997; Kapoor, 2013; Petras, 1997; Petras \& Veltmeyer, 2011; Stavrianakis 2012). This understanding of NGOization as co-opting grassroots struggles is a popular theme, and in addition to acknowledging a shift in accountability from the grassroots to donors, and the delivery of apolitical services, forms the crux of the NGOization thesis.

Less explored are studies that attempt to account for instances in which NGOs do not extinguish a vibrant social movement and the associated claims made by grassroots actors. This stream of research has demonstrated that, although NGOization is occurring, NGOs: engage in important movement work (Alvarez 2009); play a role in expanding the political space for organizing (Nazneen and Sultan 2009; Tsikata 2009); and in particular cities, NGOization does not represent a direct shift from a horizontal grassroots structure to a vertical NGO model, but rather a process that is dialectical and includes both actors operating at once and at different and varying degrees of influence (Lavalle \& Bueno, 2011), presenting movements with both opportunities and costs (Choudry \& Kapoor, 2013; Lang, 2013). This area of inquiry is an attempt to address the "tensions, contradictions and ambiguities which can help to problematize overly binaristic, generalized characteristics of 'co-opted NGOs' vs. 'radical social movements"' (Choudry \& Kapoor, 2013, p. 19).

In light of attempts to refrain from over-essentializing NGOs and their relationships within movements, existing research generally does not address instances of collaboration or the factors that influence collaboration in spite of NGOization. Scholars instead resort to the traditional NGOization thesis, which posits a disconnect between 
NGOs and social movements (Choudry and Kapoor 2013), obscuring the threads that may bind NGOs and grassroots groups within a given movement web.

In seeking to appreciate the complexity of social movement webs, I want to understand why they connect in light of a literature that predominantly describes the opposite. In order to do so, I magnify the threads that comprise the phenomenological "isness" or essence of the web (Finlay 2014). By adopting a hermeneutic phenomenological approach to this research, which is concerned with describing and interpreting the texts of life - the lived experiences and meanings individuals attach to a particular phenomenon (Creswell 2013; van Manen 2014) - I discern the essence or is-ness of the phenomenon experienced. To describe a phenomenon's essence, research must address "what" participants are experiencing and "how" they have experienced the phenomenon (Creswell 2013). In the context of this thesis, this includes the phenomenon of NGOgrassroots relationships (the "what") and the five threads and knots that inform the phenomenon ("how"). The essence of the phenomenon is accessed through nine in-depth and semi-structured interviews with two NGOs and two grassroots groups; all four of these groups are actively engaged in the solidarity movement challenging resource extractivism, and can provide valuable insight into NGOization.

\subsection{Findings \& Project Map}

In answering my research questions, I place the social movement web - the movement challenging the Canadian extractivist regime - under a magnifying glass. By doing so, I argue that despite the five knots (praxis, capacity, institutionalization, depoliticization and rootlessness) that typify processes of NGOization and may disconnect movement actors from one another, the NGOs and grassroots groups in this 
study are bound together by five key threads: (1) shared values and frames (2) sharing or pooling scarce resources (3) overlapping long-term goals (4) complimentary forms of advocacy marked by a diversity of tactics and a division of labour and finally (5) a rooted and grounded form of solidarity. Additionally, the knots that appear in this web affect the ability of groups to enact substantive changes in the industry as a result of: the scarcity of resources (capacity knot); the lack of sustained and mass public mobilization, in part due to the institutionalization of advocacy in a context in which political opportunities are disappearing; and the apparent depoliticization of large NGOs who receive many crucial resources. The project map below includes the main arguments and findings of this study as they appear throughout the thesis.

In chapter 2, I draw on theoretical conceptualizations of institutionalization, professionalization and depoliticization to render intelligible the component parts of NGOization theory. I proceed to engage in a detailed discussion on the state of empirical research on NGOization, examining separately the two prongs that typify the research on NGO-grassroots relationships: the NGOization thesis and the literature that nuances NGO-grassroots relationships. I argue in the final section of this chapter that the literature on NGOization can be improved if it were to adopt theoretical and conceptual tools provided by social movement theory, including resource mobilization and framing, which together emphasize the relational character of social movement webs that are often obscured by the NGOization thesis.

The purpose of chapter 3 is to illuminate the hermeneutic phenomenological approach utilized for this research project. I begin by discussing what this approach looks like, drawing on Finlay's (2014) phenomenological attitude marked by reflexivity and 
bracketing as a practice to engage in through the duration of any given study. The following two sections explain phenomenology in practice: by asking phenomenological questions and engaging in bracketing and reflexivity, the latter of which highlights how my experience in this movement shapes my own epistemological and ontological assumptions. In the last three sections of the chapter, I provide an explanation and rationale for my methods, including the creative interview process that allowed me to disclose to participants my location in a space between insider and outsider and discuss my strategy for analyzing the data. In the final section of this chapter, I discuss three key limitations of the project and two key retrospective reflections.

In Chapter 4, I identify the first thread that binds actors together and the primary praxis knot that shapes the social movement web. The first thread I identify includes that of shared values and frames. In describing how participants work with other organizations, self-determination and (corporate and state) accountability are frequently described as values that are crucial in connecting nodal points (organizations). Each set of actors explains that recognizing self-determination in particular functions as a basis for cooperation. NGOs or grassroots groups that do not value self-determination are unlikely to tie actors together. Another element of this first thread is an overlapping but constantly evolving environmental justice frame that is situated in the present concerns for socioecological sustainability (marked by a commitment to decolonization) of communities and activists negatively affected by resource extraction projects. Collaboration with the grassroots is more likely to occur when NGOs adopt this frame.

Notwithstanding the importance of this first thread, I argue that a praxis knot appears that has to be carefully navigated by grassroots group actors in particular, but 
also some of the NGO staff as well. This praxis knot represents the complex and reflective exercise engaged in by activists, taking the form of a pause in collaboration. In this space, grassroots groups reflect on the meanings associated with involvement in institutional advocacy, and whether or not this represents a significant compromise of the more radical values and positions that grassroots groups hold. Although grassroots groups and some NGOs may favour more confrontational forms of public advocacy and activism, they cautiously engage in institutional advocacy so long as it is not seriously compromising. I argue that studies of NGOization should appreciate more explicitly that NGOs are heterogeneous and that the pull to institutional advocacy characteristic of NGOization is not always guaranteed and subject to a consideration of contextual factors. In Chapter 5, I highlight three additional threads that bind: sharing or pooling scarce resources, overlapping long-term goals and engaging in complimentary forms of advocacy marked by a diversity of tactics and a division of labour. In terms of the third thread - sharing or pooling scarce resources - I make two arguments: the availability of material, cultural and human resources determine whether or not collaboration will occur and more importantly, that resources flow between and across organizational forms according to a desire to increase mobilization and/or to strengthen networks and coalitions. In examining this thread with participants, I was able to articulate a capacity knot. The capacity knot has two components, both of which are resource tensions: scale of work and the lack of human resources to engage in coalitions. The fourth thread that binds actors together is overlapping long-term goals, which include educating publics and institutional reform. Since these goals are shared, and because resources are scarce, there is an incentive to collaborate on campaigns or in coalition spaces. 
The fifth thread includes complimentary forms of advocacy marked by a diversity of tactics and a division of labour. In this thread, movement actors argue that because resource extractivism is deeply embedded in the Canadian state and is itself a complex phenomenon, it is necessary to adopt a diversity of tactics approach based on the strengths of each group. An important finding in this section that complicates the NGOization thesis is that grassroots groups do not engage in a "holier than thou" (as mentioned by Lesley and Micah) discourse where confrontational approaches are more valued than institutional ones; in fact, they understand that multiple strategies are required, resulting in a division of labour between groups and NGOs within this social movement web.

However, two potentially significant knots may appear: an institutionalization knot and a depoliticization knot, both of which typically occur as a tension between small NGOs and grassroots groups and large NGOs - particularly those that engage in publicprivate partnerships with industry representatives. The institutionalization knot takes the form of a belief shared by grassroots groups that large NGOs are inflexible when it comes to adopting different strategies for social change. The more toxic depoliticization knot is a result of heightened levels of institutionalization evident in larger NGOs, and the belief that this results in a loss of activist voice in exchange for legitimacy and credibility, which ultimately serve to weakening demands. This critique derives from both NGOs and grassroots groups involved in this study, complicating the NGOization thesis, and again suggesting that NGOs are heterogeneous and can maintain activist voices in institutional spaces. 
Chapter 6 explores the final and fifth thread that binds NGOs and grassroots groups together: a rooted and grounded solidarity. A grounded and rooted form of solidarity is characterized by a participatory methodology that requires community driven advocacy and long-term relationships with communities. Although NGO or grassroots group activity is community driven, it often involves collaborating with communities and/or movements in the Global South in terms of strategy formation. One knot that was identified by both NGOs and grassroots groups is in response to large (and as Skylar frames it, dangerous) NGOs. I call this the rootlessness knot. To use an example of this in practice, the NGOs and grassroots groups in this study argued that a large human rights NGO (NGO X) did not take the correct approach to research in Guatemala, threatening to weaken the demands that organizations and movements in Guatemala are making by releasing a report that was (in their view) conducted without community input, representing the generation of knowledge from above. This, and other examples like it, create severe tensions between small NGOs and grassroots groups and larger organizations such as NGO X. Both NGOs and grassroots groups in this study navigate coalitions with caution when large NGOs are present. The rootlessness knot exemplifies the criticisms that comprise the crux of the NGOization thesis, and it appears that although elements of NGOization are evident in this movement, actors strategically deal with them as they calculate the opportunities and costs associated in collaborating with NGOized organizations.

In Chapter 7, I conclude by restating my findings, discussing the implications of my project for studies on NGO-grassroots relationships, as well as future areas of research. 


\section{Chapter: NGOization and Social Movement Theory}

NGOization as a concept and a theoretical model for understanding the relationship between NGOs and grassroots groups across time and space has entered the literature - as far as I can tell - in the 1990s. The origins of the concept are difficult to trace; Lavalle and Bueno (2011) suggest that Sonia Alvarez (1999; 2009) coined the term, but Alvarez's (1997) earlier work traces an analysis of NGOization to Lebon $(1993)^{6}$. As a theory, NGOization describes a shift from horizontally structured social movement formations to vertically structured NGOs marked by institutionalization, professionalization, and bureaucratization (Lang 2013), and it is this characterization of the process that I adopt in this study. The prevailing NGOization thesis in the literature explored in this chapter argues that the elements of NGOization often lead to the depoliticization and substitution of radical actors and movements with NGOs that engage in hegemonic social formations, apolitical service delivery and express accountability upwards to donors, changing movement agendas ${ }^{7}$ (Barry-Shaw and Oja-Jay 2012; Choudry and Kapoor 2013; Jacobsson and Saxonberg 2013; Lavalle and Bueno 2011). Lang (2013) asserts that the elements of NGOization include institutionalization

\footnotetext{
${ }^{6}$ Unfortunately, I could not gain access to the Lebon (1993) text to further trace the term's origins. However, Lang $(1997 ; 2013)$ has been writing on the theory as long as Alvarez (1997; 1999; 2009), with her most recent work (Lang 2013) being the first I could find in the English literature that outlines the component parts of NGOization. It is as a result of this that I use her work to describe the theory and processes involved in understanding NGOization.

${ }^{7}$ It is important to note that although they are similar, NGOization and the NGOization thesis represent two distinct concepts: the former describes a process while the latter represents a normative judgment on the effects of the process. Following Lang (2013: 7), when I employ NGOization, I do so to trace the pull to "incorporate and perform as NGOs." On the other hand, the NGOization thesis represents the pejorative slant in the literature described in the three themes above.
} 
(establishing durable institutions based on an established repertoire of routines and norms), professionalization (professionally trained staff engaging in institutional advocacy) and bureaucratization (external pressures encouraging formalization through accountability chains, functional hierarchies, etc.). Due to the prevalence of depoliticization in comprehending the effects of NGOization, I also include it as a phenomenon believed to be occurring when movements NGOize; it is part of the prevailing NGOization thesis.

The negative connotation associated with the term NGOization has been nuanced by recent scholarship that seeks to challenge the NGOization thesis as is, suggesting that the relationship between grassroots groups and NGOs is mired by complexity, with NGOs embodying hybrid identities as both professional staff and an integral part of social movements (Alvarez 2009; Lavalle and Bueno 2011; Nazneen and Sultan 2009; Tsikata 2009). The scholarship that nuances the prevailing NGOization thesis discusses NGOs as a component part of social movements, but rarely utilizes the conceptual toolkit offered by social movement theory to explicate the different ways in which NGOs and grassroots groups interact in social movement webs. Adopting some of the concepts offered by resource mobilization and framing theories may better position studies on NGOization to articulate descriptions of social movements that appreciate the complexity of NGO-grassroots dynamics, carefully identifying the threads of collaboration that comprise social movement webs as well as the knots that shape them.

This chapter is divided into four sections. First, I discuss the proliferation of NGOs and the rise of NGOization as a theory, focusing on its component parts (institutionalization and professionalization) and consider depoliticization as its main 
effect. The second section examines the empirical literature on the NGOization thesis, grouping the effects of NGOization into three themes: engaging in hegemonic social formations, shifting accountability structures and changing movement agendas, and the apolitical delivery of services. The third section examines the contribution of the literature that departs from the standard NGOization thesis, often providing a greater appreciation of the complexity of social movement dynamics and the need for nuanced narratives of NGO-grassroots interactions. Finally, I discuss how an integration of social movement theory - and concepts from resource mobilization and framing theory in particular - may augment examinations of NGOization as a process, highlighting the threads that bind NGOs and grassroots groups in a given social movement web.

\subsection{Theorizing the Component Parts of NGOization:}

With the rise of neoliberal policies in the 1980s and the subsequent retreat of the state from public service provision, NGOs have emerged all over the world to address this gap in services. In speaking of the NGO boom, Lang (2013) highlights the increase in NGOs in both individual nation states and the international arena. For individual nation states, we can look to the United States to demonstrate this growth: between 1982 and 2006 the number of NGOs almost doubled in size from 793,000 to 1,478,000 (Lang 2013: 13). In the international community, the number of NGOs registered with the UN Economic and Social Council increased from 41 in 1994 to 3,172 in 2009 (Lang 2013: 13).

This historic and continuous proliferation of NGOs alongside grassroots groups coincides with the implementation of neoliberal policies, with scholars noting this trend both in large geographical regions such as Latin America (Dagnino 2008; Petras 1997; 
Petras and Veltmeyer 2011) and in small nations such as Israel (Herzog 2008).

Scholarship in the fields of development studies, sociology, and political science theorizes the trajectory of social movements and the relationship between social movements and NGOs in a variety of countries and across a variety of issues (Africa 2013; Barry-Shaw and Oja-Jay 2012; Britton 2006; Brown 2014; Chahim and Prakash 2014; Choudry and Kapoor 2013; Choudry 2014; Choudry 2013; Choudry and Shragge 2011; Fogarty 2011; Ghosh 2009; Gill 1997; Gupta 2014; Hammami 2000; Jad 2007; Jalali 2013; Junge 2012; Kapoor 2013; Kuttab 2008; Martens 2006; Mitlin 2001; Mosser 2004; Mueller-Hirth 2009; Rahman 2006; Sinwell 2013; Stavrianakis 2012).

Despite the breadth of scholarship on this topic, NGOization as a concept (including the elements that define it) is rarely theorized, often appearing secondary to empirical and contextual accounts of how the elements of NGOization (institutionalization, professionalization, etc.) have positively or negatively affected social movements. However, in her recent work on NGOs and the public sphere, Lang (2013) theorizes NGOization. In this work, NGOization is defined as marking

a shift from rather loosely organized, horizontally dispersed, and broadly mobilized social movements to more professionalized, vertically structured NGOs. This shift not only has lasting effects for mission, goals, management, and discourse cultures of civic actors but it also influences advocacy strategies and ultimately the properties of the publics that NGOs seek out or try to generate (Lang 2013: 62-63).

As suggested in this definition, NGOization is a process that should be understood in light of the degree of institutionalization, professionalization, bureaucratization and depoliticization apparent within a particular context, meaning that social movements can be less NGOized or more NGOized. I utilize this understanding of NGOization, with a minor but conceptually significant alteration: it is a shift from loosely organized 
grassroots groups and networks to more professionalized NGOs. This distinction is necessary to make, because, as della Porta and Diani (2006), Diani (2003) and Tarrow (2011) suggest, social movements are comprised of dense networks (webs) and ties of interaction between different organizational forms. To accept this alteration is to avoid a simplistic binary of social movement versus NGO. With this clarification in mind, the effect of the interrelated elements of NGOization can be understand as a shift in focus to "policy-outcome-oriented organizations" that often engage in specific issues, service delivery and "marketable expert knowledge" (Lang 2013: 64). In effect, "emphasis is placed on organizational reproduction and on the cultivation of funding sources" which alongside a focus on policy, services, and expert knowledge - may often result in the deradicalization of movement messaging in order to engage in institutional advocacy as opposed to purely public forms of advocacy and dissent (Lang 2013: 64). The shift in focus to policy outcomes typical of many NGOs can be explained by a preference for institutional rather than public forms of activism.

NGOs that rely on institutional advocacy seek to "influence decision making by gaining some degree of insider status in institutions or in organizations that initiate, prepare, legislate, or execute policy change" (Lang 2013: 22). By engaging in such insider strategies (Fogarty 2011), organizations attempt to work within the system by gaining access to and cultivating relationships with actors involved in governance regimes. By participating in this form of advocacy, NGOs might secure legitimacy and gain a favourable reputation by sharing their expertise to gain leverage, using expert knowledge and lobbying to effect social and policy changes. 
In contrast to institutional advocacy, public advocacy/activism - in an effort to achieve social and policy changes - mobilizes and engages broader publics "while stimulating citizen voice and engagement in the process" (Lang 2013: 23). NGOs are able to accomplish this by "amplifying citizen voices," focusing on outreach and organizing publics as opposed to seeking insider status (Lang 2013: 23). As an outsider strategy (Fogarty 2011: 209), public advocacy turns "public opinion against the status quo system" through protest, demonstrations - marking a shift from a politics of collaboration and consultation typical of institutional advocacy to one of confrontation. Of course, institutional and public advocacy are not incompatible strategies, and NGOs can use both in an effort to achieve social or policy change. Lang (2013) asserts that it is important to note that research has shown that governments are selective in terms of the NGOs they invite to the table. The NGOs invited share a similar agenda, while NGOs with radical agendas are less frequently invited, which indicates: (1) the heterogeneous make-up of NGOs operating in civil society and (2) the tendency for NGOs engaging in institutional advocacy to depoliticize claims in favour of incremental changes. Notwithstanding the occasional propensity for some NGOs to mix advocacy strategies, they "are prone to prioritizing institutional over public venues in order to influence their environment" (Lang 2013: 18).

Together, the elements of institutionalization, professionalization, and bureaucratization consequently make evident another measure of NGOization: depoliticization (Britton 2006; Choudry 2014; Gill 1997; Hammami 2000; Kuttab 2008; Rahman 2006). Lang (2013) suggests that each of these elements (minus depoliticization, which is not examined in depth) "signals the onset of NGOization" (Lang 2013: 70). 
Professionalization, institutionalization and depoliticization have been identified in this study as elements of NGOization that produce knots in the web that comprises the movement challenging Canadian resource extractivism.

\subsubsection{Professionalization}

Borrowing from the sociologist Max Weber, Lang (2013: 71) describes professionalization as part and parcel of the modern project of rationalization, signifying "the authority of institutionalized expertise over the authority of other claims, be they coercive or moral in nature." The project of rationalization through authoritative knowledge has at least three characteristics according to Choudry and Kapoor (2013) and Choudry and Schragge (2011):

(1) "The centrality of paid staff": demonstrates an upward form of accountability towards donors and a board of directors, often directing daily operations, activities and goals.

(2) The centrality of professionally trained staff: In an NGOized organization, staff are rarely movement activists but from an educated elite class trained in university programs geared towards NGO management. This training adopts organizational models from the private sector to encourage accountability and efficiency in non-profits.

(3) The centrality of institutional advocacy: professionals spend their work hours representing the NGO at institutional roundtables, partnerships, etc. as opposed to in communities organizing and mobilizing activists (Choudry and Shragge 2011: 507, emphasis added).

As the above excerpt indicates, professionalization has significant impacts on individuals and the organizations that they work for. Organizational development is often framed as increasing monetary resources as well as the number of salaried staff employed, creating an expansive division of labour as well as increasingly hierarchical structures to support goals (Lang 2013). According to Smith (1987: 216-217), organizational changes use expert "knowledge to restructure collective non-capitalist forms of organization into hierarchical strata, detaching them from the movements they originate in and connecting 
them to the relations of ruling" (as cited in Choudry and Schragge 2011: 507). Related to this shift, individual NGO employees have to adapt "to institutional norms and structures as well as to a policy field's language in terms of trade" (Lang 2013: 72). In studying civil society in Japan, Pekkanen (2006) argues that the shift to adopt the norms of institutional structures operates as a pull to professionalize and engage in institutional advocacy (as cited in Lang 2013). The professionalization of activism has produced knots in the movement challenging Canadian extractivism, creating tensions in coalition spaces that are largely the result of paid vs. unpaid work, and the commitment to institutional advocacy as a preferred means of challenging the state and the industry in this sector. Although professionalization is evident, the experience of my participants is indicative of the ambivalent effects of - and ambivalence to - the supposed pull to professionalize which presents the movement with both opportunities and costs. This pull to NGOize becomes apparent in the processes of institutionalization explained below.

\subsubsection{Institutionalization}

A second element of NGOization includes the pull to institutionalize. As Lang (2013) argues, institutionalization is informed by the following: (1) the need to build durable institutions, and (2) the desire to expand political opportunities, particularly in governance arrangements (Lang 2013: 73). In regards to the first point, organizations become durable when they are able to stabilize themselves through the adoption of “consistent norms, functions, and routine so as to secure their survival" (Lang 2013: 73). Furthermore, institutionalization is established when the activities emerging from such norms, rules, and routines become "taken-for-granted" as "part of everyday social reality" (Schneiberg and Soule 2005: 122). In an effort to ensure survival, organizations 
may adopt: a fixed decision-making process that often takes the form of a charter; routinized and repetitive actions "engrained through institutional learning"; and measures to guarantee organizational survival beyond the involvement of particular key individuals (Lang 2013: 73). The tendency towards organizational building creates an openness to engage with government actors, with Take (1999) suggesting that with high degrees of institutionalization and bureaucratization (as a result of a charitable status), the greater the likelihood that organizations will co-operate with the state, as well as important international bodies (as cited in Lang 2013).

Take's (1999) finding suggests a second point on institutionalization: that it often results in a desire for organizations (NGOs) to expand political opportunities by engaging in governance arrangements (Martens 2006). In speaking about the general trend of NGO activity, Lang (2013) suggests that they engage in the practice of governance by participating in expert commissions and consultations at the national and/or international level. Participation can vary across scales: in regional terms, it can mean that NGOs sit on municipal boards; in a national context, NGOs are more likely to participate in legislative hearings; and internationally, NGOs attend meetings with large institutional players such as the World Bank or representatives from the United Nations. The motivation for this level of institutionalization is connected to the rewards accrued from it: "an organization's reputation can be enhanced by being visible institutionally; its members typically feel recognized and validated by decision makers; and there tends to be increased policy success associated with overt institutional voice, providing organizations with enhanced legitimacy to speak for certain claims" (Lang 2013: 73). However, this pull to institutionalize is not without its costs. By becoming more 
'credible' or 'legitimate', NGOs often have to adjust their agenda "from what is considered to be right to what is considered to be feasible" (Lang 2013: 73). Thus, it is assumed that NGOs tend to shy away from taking more principled positions in their advocacy work, accepting concessions in their demands so long as some progress however incremental - is made. In this process, NGOization through institutionalization "contributes to a refocusing of advocacy; it redirects advocacy from public arenas into institutional advocacy venues that have been opened up by new governance modes and enhanced by institutional allies" (Lang 2013: 74; see also Lounsbury 2005; Meyer and Tarrow 1998).

This dominant understanding of institutionalization as a shift from loosely structured grassroots groups and networks engaging in public activism/advocacy through mobilization to highly structured organizational forms delineated by rules and norms that engage in institutional advocacy precludes, if not renders invisible, an analysis and appreciation of the complexity and strategic decision-making involved in collective action. For example, it does not examine how political subjects navigate the terrain of social movements, preferring a particular mode of advocacy in response to (1) their own skill sets and expertise (2) the division of labour found within the movement and (3) the political context of the particular state in question. It is the assumed willingness of small or large NGOs to abandon (partially or completely) principles for incremental change that causes critics to argue that NGOs depoliticize social action.

\subsubsection{Depoliticization}

Prior to discussing depoliticization, it is important to have a basic understanding of its opposite: politicization. Blühdorn (2007) provides a typology of the three locations 
or sites of politicization: the politicization of issues, the politicization of people and the politicization of social organization and institutions (as cited in Mishra 2011). For the purposes of this study, the third site of politicization is most important. The politicization of social organizations and institutions occurs when previously apolitical organizations openly promote a particular political programme (as cited in Mishra 2011). In general, as Mishra (2011: 156) notes, "politicization is the realization that established social norms, social practices and social relations are contingent rather than sacrosanct; that citizens, individually and collectively, have political agency by means of which alternatives can be explored and implemented." In recognizing the contingency of the power structures within which they are embedded, agents - whether individually or collectively - spark "emancipatory-progressive movements... and politicization has been their key strategy" (Mishra 2011: 156).

Considering this understanding of politicization and its role in social movements, we can begin to grasp the nature of depoliticization: at the most basic level, it involves the shift from a political to less or non-political organizations and institutions. In this context, the "depoliticization of institutions and social organization implies that bodies ranging from environmental organizations [to] micro-credit societies... shed their ideological commitments and political agendas and focus on their 'core business' or the 'task at hand"” (Mishra 2011: 157). According to Mishra (2011), this transformation towards depoliticization is often guided by the principles of professionalization and institutionalization (organizational or economic efficiency; managerial best practice).

The depoliticized focus on the 'task at hand' through institutional advocacy has implications for NGO voices and strategies. Voice, and being vocal, requires that actors 
‘speak up’ rather then 'let go' (Lang 2013). Speaking up requires “active intervention and public communication over silent dissociation from political conflicts" (Lang 2013: 19). It is assumed that when organizations shed themselves of ideological commitments and political agendas when participating in institutional advocacy, they risk depoliticization by silencing their own voices. While this may hold true in some instances, it is not necessarily the case that critical voices are muted and depoliticized when participating in institutional advocacy. In fact, the participants in this study - all of whom engage in institutional advocacy to some degree - are able to maintain a critical voice, with some voices louder than others. When discussing depoliticization as an effect of NGOization, it is important to draw attention to the values and ideologies that guide the work and consequently the voice of movement actors. The literature described below constitutes the NGOization thesis, suggesting that the elements of institutionalization, professionalization and depoliticization create a tendency for NGOs: to engage in hegemonic social formations; to provide apolitical service delivery; and to remain accountable to donors as opposed to the communities they represent, changing movement agendas.

\subsection{Examining the Effects of NGOization}

Now that I have defined and described the theoretical foundation of NGOization, it is important to turn to empirical scholarship that studies the effects of NGOization and NGO-grassroots relationships more generally and the impacts of this process on social movement trajectories. The scholarship described in this section represents the three main themes that constitute the NGOization thesis: NGOs as engaging in hegemonic social formations; tracing accountability shifts, including corresponding changes in agendas; 
and the apolitical nature of institutionalized service delivery projects. In each section, I select vignettes from the literature to demonstrate, compare, and contrast the different forms and contexts in which NGOization occurs - as well as its associated effects.

\subsubsection{Engaging in Hegemonic Social Formations}

In the opening pages of NGOization: Complicity, Contradictions and Prospects, Choudry and Kapoor (2013: 1) explore "whether or not NGOs open up political space or represent specific forms of regulation and containment in the interest of a contemporary capitalist (re)colonization" by asking: "what political, economic, social and cultural interests do these trends [the rise of NGOs and the associated process of NGOization] serve?" The attempt is to move beyond the simple dichotomy of radical social movement and reformist NGO by taking into consideration the tensions, ambiguities, and contradictions involved in movement dynamics. In spite of calling for a nuanced analysis in which NGOs are no longer over-essentialized and NGO-social movement dichotomies are transcended, all of the authors in the volume "argue that NGOs - and the process of NGOization - frequently undermine local and international movements for social change and environmental justice and/or oppositional anti-colonial and anti-capitalist politics, in complicity with state and private interests" (Choudry and Kapoor 2013: 2). Although some of the tensions, ambiguities and contradictions are explored, there is a lack of attention to case studies documenting positive interactions and the variables that influence interaction.

The argument in Choudry and Kapoor's (2013) volume is influenced by Marxist and critical political economy approaches to the role of NGOs in contributing to what Stavrianakis (2012) refers to as hegemonic social formations. Stavrianakis (2012: 232) 
suggests that NGOs are embedded in hegemonic social formations because the knowledge they generate and the problems they construct - as well as the responses to them through advocacy and lobbying - demonstrate an exercise of "leadership over other classes and strata by gaining their active consent." Drawing on the global arms trade to support this point, Stavrianakis (2012) states that while NGOs may be critical of multiple aspects of the state apparatus, they effectively work within these structures. In doing so, NGOs engage in hegemonic social formations by reproducing "a hierarchical world military order" in which the South is a site of political intervention (Stavrianakis 2012: 243).

This claim regarding the association between hegemonic social formations and hierarchical relationships between North and South has historically been supported by research in Latin America. Examining the roles of NGOs in Brazil, El Salvador, Bolivia, and Chile, Petras (1997: 16) argues that "NGOs create a political world where the appearance of solidarity and social action cloaks a conservative conformity with the international and national structure of power", ultimately fostering new relationships of dependency and colonialism. According to Petras (1997: 25), once we 'remove the veil', NGOs essentially facilitate neoliberal regimes by linking "foreign funders with local labor (self-help micro-enterprises)."

More recent case studies by Choudry (2013), Kapoor (2013), and Africa (2013) support the claim that NGOs engage in hegemonic social formations. Choudry (2013) critiques the approach of the Royal Forest and Bird Protection Society (RFBPS), a conservationist NGO from New Zealand, in regards to its stance on property rights as they relate to commodifying native flora and fauna on the island. In the context of an 
encroaching WTO TRIP ${ }^{8}$ regime that sought to commercialize and profit off shared natural resources, RFBPS viewed themselves and their government as the rightful owners of New Zealand's biodiversity, effectively siding with the interests of the state as opposed to Maori-led NGOs and resistance movements arguing that such a move would violate existing treaty claims (Choudry 2013). In this instance, Choudry (2013) is able to distinguish between different types of NGOs, and discuss how RFBPS engages in hegemonic social formations, but does not go into detail to explain how Maori-led NGOs and the resistance movement may pose a challenge to the NGOization thesis.

Similar to Choudry (2013), Kapoor (2013) describes NGOs in rural India as "contributory agents of state-corporate capital penetration and as being complicit in processes of rural displacement and dispossession" as a result of mining operations. Antimining movement activists with Lok Adhikar Manch (LAM) accuse NGOs of: (1) spying and gathering information for corporations through workshops on industrialization (2) dividing communities by convincing some to accept mining projects and (3) "failing to act on their promises of solidarity", disappearing from the scene when direct action occurs and protests turn violent (Kapoor 2013: 54).

Examining the NGOization in the Philippines, Africa (2013:118) writes, "the general tendency has been for NGOs to operate in accordance with prevailing political and economic arrangements rather than in sustained opposition to these." To support this

\footnotetext{
${ }^{8}$ The World Trade Organization's (WTO) agreement on Trade-Related aspects of Intellectual Property Rights (TRIPS) is representative of commercial interest in profiting from traditional Indigenous knowledge and biodiversity by buying and therefore owning what are viewed by many Indigenous people as common knowledge that is "inextricably linked to culture, spirituality, identity, and place, and is created communally over time" (Choudry 2013: 27).
} 
claim, Africa (2013: 132) discusses President Aquino’s recent anti-poverty program, involving "hundreds of accredited NGOs... participating in a multi-year... USD 7.1 billion” World Bank supported “conditional cash transfer (CCT) scheme.” By supporting the CCT, NGOs in the Philippines are seen to be naturalizing hegemonic social formations instead of targeting the economic policies that lead to poverty.

\subsubsection{Shifting Accountability \& Changing Movement Agendas}

A second theme found within the literature focuses on the effects of hegemonic social formations. Two effects are largely prevalent: an accountability shift from below to above (away from the grassroots and towards donors) and the corresponding shift from political projects of social transformation to agendas complacent with, and sympathetic to, ruling relations.

In an overview of the effects of funding on mobilization, Jalali (2013) finds that resource dependency (fear of losing funds, professionalization), domestic laws, and the free-rider problem operate as mechanisms that decrease the likelihood of grassroots mobilization. Particularly relevant for my study is Jalali's (2013: 61) finding that professionalization undermines mobilization efforts because NGOs shift their focus away from the grassroots towards their funders, "concentrating on activities such as grantwriting, fundraising, record-keeping and annual reports.” Highly institutionalized and professionalized NGOs that rely on international financial assistance (even if from other NGOs) can transform "conflict movements into consensus movements that follow the institutional, resource-dependent, project based, non-conflictual strategy" (Jalali 2013: 68). In sum, Jalali (2013) links high levels of institutionalization and professionalization 
marked by upward (donor) accountability to an increasingly depoliticized movement strategy.

Choudry and Shragge (2011) share Jalali’s (2013) larger analysis on accountability, but provide a different approach that seeks to explain the role of knowledge in NGOized relationships. Discussing knowledge construction, the authors claim that professionalization and the "obsession with technicism" devalues knowledge from below and displaces activists and community members that act and/or speak for themselves. Instead, the expert NGO professional - because of greater training and a commitment to legal as opposed to traditional knowledge frameworks - speaks on behalf of beneficiaries. At issue with this is that it "tends to lead to formal rules for practice with common forms of governance and similar expectations for formal accountability upwards to funders" (Choudry and Shragge 2011: 508). In the process, local forms of (traditional) knowledge, governance and power are abandoned. According to Choudry and Shragge (2011), this form of professionalization - by deciding which form and practice of knowledge matters according to donor demands - divides NGOs and community organizations from social movements that have a "non-professional leadership and are based on experiential/struggle knowledge/traditions and radical ideologies" (Choudry and Shragge 2011: 508). The consequence of valuing legal vs. traditional forms of knowledge, governance and power is the disciplining of dissent, characterized by a commitment to the ideology of pragmatism - an ideology marked by a commitment to polite reform and limited gains within existing structures that are often disconnected from popular mobilizations (Choudry and Shragge 2011). 
In Nicaragua, amid increasing social problems, citizen engagement in historically and remarkably active grassroots organizations is decreasing while foreign-funded NGOs are increasing (Chahim and Prakash 2014). In their interviews with staff from seventeen different NGOs, Chahim and Prakash (2014: 501) find that "foreign-funded NGOs in Nicaragua exhibit strong upward accountability to donors and weak downward accountability to their beneficiaries." As in Choudry and Shragge's (2011) article, NGOs in Nicaragua are structured to provide the "expert opinions of their staff, donor politics, and Northern development ideologies rather than consistently aggregating and representing the diverse interests and concerns of their beneficiaries", a phenomenon associated with a belief in the intellectual superiority of NGO staff and expressed by a conviction that they alone bear true knowledge about particular issues. As a result of donor control over projects, NGOs cannot mobilize marginalized and poor Nicaraguans because of a lack of downward accountability, instead basing advocacy on mild policy reform according to donor interests. In the process, the agenda for social change shifts from mobilizing the poor to lobbying in their interests. Consequently, social change becomes sanitized and orchestrated by an "NGO elite of middle-class, mestizo, and urban professionals enmeshed in international development discourse..." who lack a "sense of urgency and even the rage and need for change that in the past provided the force behind social transformation and collective action" (Chahim and Prakash 2014: 494-495). The construction of NGOs as elite actors is not uncommon, but shared by others writing in this field (Brown 2014; Gill 1997; Hammami 2000; Kuttab 2008; Mueller-Hirth 2009). The Nicaraguan case, in addition to the work of Choudry and Shragge (2011) and Jalali 
(2013), demonstrates that upward accountability results in less politicized or depoliticized agendas.

Similarities can be drawn between Chahim and Prakash's (2014) illustration of the state of Nicaraguan social movement dynamics and Jad's (2007) account of the Palestinian women's movement. Jad (2007) traces the shift in political position and composition of the movement following the second intifada: from a national agenda struggling for self-determination and the right to independence to one based on a project logic of peace building and conflict resolution, the latter of which is led not by the activists of previous mass-mobilization efforts, but women in NGOs whose work focuses on scaling up to the international level to appease donor demands. Although stressing that it is an oversimplification to view NGOs simply as passive recipients - noting that NGOs and donors negotiate the terms of their relationship - Jad (2007: 628) argues that "women's NGOs and the new discourse that they brought to the public sphere... have acted to disempower, delegitimize, and fragment civil-society secular actors and their movements in Palestine." NGOization in Palestine exhibits a change in power relations from “"power to' women at the grassroots to 'power over' them by the new elite" (Jad 2007: 624), a process echoed by Hammami (2000) and Kuttab (2008).

\subsubsection{Institutionalization and its Discontents: Apolitical Service Delivery}

As explained in the first and second themes related to NGOization, the rise and spread of neoliberal policies is assumed to change the terrain of contentious politics, with once progressive (if not radical) and popular movements increasingly institutionalizing their work, signifying their co-optation into hegemonic social formations through institutional forms of advocacy. The implications of engaging in hegemonic social 
formations, we are told, are related to the direction of accountability and the type of agenda to be advanced by movement actors. Associated with this process is a shift from social transformation to apolitical service delivery. The case studies below provide compelling examples of this effect, ranging from Bolivia to Bangladesh.

Writing in 1997, Gill describes this process in Bolivia's civil society from the early 1980 s to early 1995 . As neoliberal policies became the flavor of many governments in Latin America in the context of an economic crisis, Northern NGOs flooded to the region (Gill 1997). Gill (1997) asserts that at first this created tension between the Bolivian Left (including the progressive wing of the Church) and the newly arrived NGOs. However, Gill (1997) finds that over the years the Bolivian Left began to adopt the strategies of neoliberal NGOs to combat the effects of the neoliberal economic policies on the poor. Gill (1997: 151) writes that the NGOs associated with the Bolivian Left began to focus their energies on providing services, micro-enterprise development and income-generating schemes, and often "signed agreements with the state to shoulder the burden of service provision in particular areas of the country." In conjunction with a shift to service provision was a shift to professionalism, as NGOs began to better train staff to develop stronger technical and administrative skills. In describing this process, one NGO director stated, "formerly concepts like efficiency and competitiveness were sins to us, but now they are very important here" (Gill 1997: 151-152). To be efficient, competitive and attractive to foreign funders, these once radical NGOs had to adapt to their environment by marketing themselves as apolitical, "situating themselves above the raucous, partisan activities of the parties" and the Bolivian Left (Gill 1997: 152). As the cases of South Africa, the Philippines, Bangladesh and India below seemingly 
demonstrate, the NGOization of the Bolivian Left as a result of increasing institutionalization is not a blip in the history of NGO-grassroots dynamics.

Since the end of the apartheid regime in 1994, the South African women's movement, and the movement to end violence against women in particular, has been experiencing NGOization vis-à-vis increasing levels of institutionalization (Britton 2006). The increasing level of institutionalization, marked by partnerships with government agencies, is downloading service provision (self-sufficiency training, violence prevention, counseling) onto NGOs (Britton 2006). Britton (2006: 163) argues that while this action has distributed resources "to people when and where they need it the most," it has resulted in depoliticization by tempering the ability of NGOs to articulate radical agendas and engage in militant resistance. Also speaking to the issue of service delivery as a signifier of institutionalization (and facilitating depoliticization), Africa (2013: 118) argues that NGOs in the Philippines, as a whole, have "consciously or inadvertently... aligned with the conservative political program of the established State rather than with that of progressive social movements challenging inequitable structures." The commitment to short-term service delivery detracts from "real and sustained political engagement" over the long term (Africa 2013: 138). As Africa (2013) argues, the focus on short-term parochial concerns and a chronic lack of funding for service delivery risks relying on a conservative government for funding, ultimately diffusing dissent by altering and constraining the political agenda of NGOs in the Philippines.

In a similar manner, Rahman (2006) notes that the NGO sector in Bangladesh is depoliticized because of its shift away from mobilizing the masses and promoting accountable government to service delivery. However, the Bangladeshi context augments 
the dominant approach to explaining depoliticization. Rahman (2006: 459) suggests that depoliticization is not only a product of conservative donor agendas or the Western model of development discourse, but is also directly related to two local causes: (1) a weak institutional government that "undermine[s] the viability of social mobilization" and (2) a distrust of politically motivated development policy among elites.

Describing the shift from demanding to delivering development in Rajasthan, India, Gupta (2014) provides a grounded case study of the effects of institutionalization and professionalization on the grassroots. By examining the history of Gram Vikas Manch (GVM), an NGO heavily invested in natural resource development interventions, Gupta (2014: 139) finds that the trend towards development delivery and professionalization has increased institutionalization, not only shifting the focus away from villagers to donors and writing reports but also depoliticizing GVM's work by distancing the NGO from activist organizations in "direct confrontation with the state." As this study suggests, the institutionalization and professionalization of social change also affects politicization.

\subsection{NGOization Reconsidered}

In the context of a literature that disproportionately discusses NGOs as engaging in hegemonic social formations, an upward form of accountability with negative implications on movement agendas and providing depoliticized developmental services, it is no wonder that seemingly nuanced analyses such as those in the Choudry and Kapoor (2013) volume fall short of adequately engaging with the complexity, contradictions, and the larger structural contexts (state policies or funding constraints) that influence social movement dynamics and the changing organizational ecologies of 
movement actors. Despite the recognition of the complexity, contradictions, and tensions involved in social movements, they are not sufficiently explored, but mainly operate as side notes to an overarching argument carrying a traditional NGOization thesis. Studies on NGOization need to articulate the instances in which NGOs and grassroots groups interact in social movement webs in order to better understand the patterns of interaction alongside critical examinations of said interactions. In light of the absence of the literature describing the NGOization thesis to demonstrate and engage in such a research agenda, there is a sustained effort by scholars seeking to address the complexity of social movement dynamics (NGO-grassroots relationships) as a subject of inquiry (Bebbington, Hickey and Mitlin 2008; Herzog 2008; Jamal, 2015; Lang 2013; Laurie, Andolina, and Radcliffe 2005; Markowitz and Tice 2002; Nazneen and Sultan 2009; Pithouse 2013; Tsikata 2009). Below are a few examples of some of the different ways in which scholars attempt to shift from outright critique to a nuanced examination of the process of NGOization.

Sonia Alvarez's (2009) oft-cited article - Beyond NGOization? Reflections from Latin America - represents a critical engagement with the NGOization thesis, one that departs from her previous work on the topic. In her more recent piece, and in the context of Latin American feminist movements, Alvarez (2009: 176) contends that the depiction of NGOs "as handmaidens of neoliberal planetary patriarchy" not only fails to capture the "variation in and among NGOs", but it "does not do justice to the dual or hybrid identity of feminist NGOs, their two facets, as technical-professional organizations that are at once integral parts of feminist movements." Instead, Alvarez (2009: 177) suggests that the NGOization thesis overlooks the reality of the NGO boom: that many NGOs actually 
played a critical role in articulating heterogeneous feminist discursive fields of action ${ }^{9}$ in the 1990s and 2000s, remaining "true to their feminist roots." This characterization of NGOs as central actors engaging in movement work - by producing knowledge, disseminating feminist discourses, and providing educational and conscientizacion products and activities to non-feminist social movements and organizations (including unions) - adds a layer of nuance to the NGOization thesis, interrogating the complexity of the internal dynamics of social movements. In locating the important role of NGOs in the production of "effervescent movement currents", Alvarez (2009: 182) suggests, "there is, in short, no $21^{\text {st }}$ century Iron Law of NGOization."

The Iron Law of NGOization continues to be challenged. In their examination of civil society in Mexico City and Sao Paulo, Lavalle and Bueno (2011) argue that the NGOization thesis is an empirically and conceptually flawed depiction of the trends within the civil societies of the two large cities. The authors suggest that it is misleading to assume, as the NGOization thesis does, a linear and substitutive change in the composition of civil society actors from popular movements to NGOs. Instead of viewing change in these metropolises as the "depoliticization and neoliberalization of civil society", attention is shifted to: the modernization of civil society (organizational fields are enlarged to include new ${ }^{10}$ and newest ${ }^{11}$ actors alongside traditional actors); the

${ }^{9}$ Alvarez (2009: 177) coins the term discursive fields of action to refer to the role of NGOs in the diffusion of feminist knowledge, discourses, and "serving as nodal points in the multiple political-communicative webs and networks that link diverse and dispersed feminist actors" - webs and networks that extend vertically into various arenas of governance and horizontally into ethnically, racially and socio-economically diverse communities and cultural spaces, "including parallel social movement publics."

${ }^{10}$ According to Lavalle and Bueno (2011), new actors include NGOs, popular movements and coordinating bodies. Popular movements are regarded as new because 
functional diversification of civil society (all actors coexist in both cities, engaging in all type of work, including service delivery and policy advocacy); and the specialization of labour, with each actor engaging in a different form of labour depending on their own human resources (Lavalle and Bueno 2011: 417-418). Together, Lavalle and Bueno's (2011) findings challenge the substitutive and depoliticized trend implied in the NGOization thesis, asserting instead that NGOs in both cities are highly central actors with ties to NGOs and organizations with strong roots in grassroots communities.

As both Alvarez (2009) and Lavalle and Bueno (2011) indicate, the focus on NGOization may operate to obscure as much as it reveals. In other cases, scholars observe NGOization as a phenomenon that is occurring but recognize that it can also have positive impacts. According to Tsikata (2009), the women's movement in Ghana has been facing NGOization as a key challenge since the 1990s. Nevertheless, Tsikata (2009) documents how women's organizing has experienced growth, as evidenced by the creation of the Network for Women's Rights in Ghana (NETRIGHT), the Coalition on the Women's Manifesto for Ghana (WMC) and the National Coalition on Domestic Violence Legislation (DV Coalition) - all of which, despite different goals, have

they have a bridging function, linking labour with "less privileged actors with little access to the state" beginning in the 1970s and 1980s (Lavalle and Bueno 2011: 421). On the other hand, coordinating bodies articulate and coordinate the actions of NGOs, "leveraging their capacity to aggregate interest and performing as their representative before the state and other social actors" (Lavalle and Bueno 2011: 422). Coordinating bodies, in both cities, are commonly labeled as NGOs.

${ }^{11}$ Of the two newest actors, fora "work as thematic spaces for coordinating agendas and consensus building between issue-oriented actors - HIV-AIDS, basic health, [etc.]..." Pastorals are also issue-oriented actors, but they are different from fora because they are church inspired (Lavalle and Bueno 2011: 423). 
expanded the political and institutional space to openly discuss and challenge the government on issues affecting women.

Similar to Tsikata (2009), Nazneen and Sultan (2009) find that NGOization is occurring in the women's movement in Bangladesh. Nazneen and Sultan (2009), like Tsikata (2009), argue for an analysis of the impacts of NGOization that moves away from outright critique to nuancing evaluations to consider how actors navigate the NGOization

process. By using three nationally active organizations with strong institutional influence as their case studies - the Bangladesh Mahila Parishad (BMP), Women for Women (WFW) and Naripokkho (NP) - Nazneen and Sultan (2009) find that NGOs work within their constraints to control their agenda (which itself is set by its members) and to ensure that they are able to maintain their autonomy by: (1) ensuring that donor demands run parallel to organizational constitutions, objectives, and goals prior to receiving funds and (2) ensuring that core activities to the organization are not funded. The three NGOs maintain downward accountability by involving members in setting organizational agendas, and provide alternative spaces to work on issues of concern to women, but at the expense of having to dilute movement messaging (Nazneen and Sultan 2009). Evidently, NGOization has both positive and negative effects, and the analysis of social movement dynamics needs to take this into consideration.

\subsection{Social Movement Theory}

Although the study of social movements and collective action can be traced to the work of classical sociologists such as Weber, Marx and Durkheim, the first theorists explicitly engaging in this new sub-field within sociology did not emerge onto the scene until collective behaviour theory was formed, stressing social movements as abnormal 
features of society (Della Porta and Diani 2006; Buechler 2011; Edelman 2001; Tarrow 2011). With the advent of the long 1960s - a period of large-scale social change and protest in America from the 1950s to 1970s - previously dominant approaches to social movements began to recede to the background as resource mobilization and political process theories came to the fore (Buechler 2011). Since then, new approaches to the sociological study of collective action have emerged, ranging from the framing perspective, new social movement theories (Edelman 2001; Tarrow 2011), contentious politics/dynamics and passionate politics (Buechler 2011; Della Porta and Diani 2006).

The purpose of the following section is to focus on the key concepts and theories that are evident in the narratives of the movement participants interviewed - these narratives often echo the concepts explained below, indicating threads that bind social movement webs together, including the occasional knots that shape them. The theoretical and conceptual toolkit offered by social movement theory is useful in describing and understanding the complexity of social movement dynamics - that is, the interorganizationally negotiated and situated forms of collective or organizational action, strategic decision-making, and decisive preference for particular tactics. Social movement theory is useful in this regard because it focuses on the interdependence of movement actors (Della Porta and Diani 2006; Tarrow 2011), offering concepts and frameworks that highlight this interaction. Even before I look at resource mobilization and framing theory to make a case for the inclusion of concepts derived from the social movement literature, the usefulness of social movement theory can be traced to how social movements are operationalized. For example, in describing what a social 
movement is and is not, Diani (2003: 1) describes the relational and networked character of movements when he states:

It is difficult to grasp the nature of social movements. They cannot be reduced to specific insurrections or revolts, but rather resemble strings of more or less connected events, scattered across time and space; they cannot be identified with any specific organization either, rather, they consist of groups and organizations, with various levels of formalization, linked in patterns of interaction which run from the fairly centralized to the totally decentralized, from the cooperative to the explicitly hostile. Persons promoting and/or supporting their actions do so not as atomized individuals, possibly with similar values or social traits, but as actors linked to each other through complex webs of exchanges, either direct or mediated. Social movements are in other words, complex and highly heterogeneous network structures. (Emphasis added.)

Beyond identifying the relational character of collective action, this definition of social movements incorporates formal organizations such as NGOs within the boundaries of social movements. Importantly, this definition stresses the complex webs of interactions that structure movements as networks comprised of direct ties between organizational forms. When adopting this definition - which is shared by della Porta and Diani (2006) and Tarrow (2011) - it becomes clear that much of the literature on NGOization fails to capture this crucial element, systematically excluding NGOs from social movements. By ignoring these details, theories and empirical investigations of NGOization obscure the fact that movements are composed of "multiple instances of collaboration on campaigns of different intensity and scope" and are marked by direct ties between organizations; ties that include "most prominently the exchange of information [cultural resources] and the pooling of mobilization resources... [and] shared personnel [human resources]" (Diani 2003: 10). As this suggests, social movements take place when organizations and individuals exchange resources to achieve common short 
or long-term goals (della Porta and Diani 2006). When I employ the concept social movement, I do so with this understanding.

Another term that frequently appears in this thesis, often in conjunction with social movements, is contentious politics. Contentious politics occur when people collectively confront opponents, elites or authorities using the repertoires of contention (tactics) familiar to that society: be it strikes, direct action occupations, marches, or other forms of disruption (Tarrow 2011). Contentious politics precede social movements, taking the form of a movement when they become sustained and feature the characteristics described by Diani (2003) above - structure networks and shared collective action frames (Tarrow 2011). Challenges to Canadian resource extractivism are both a practice of contentious politics and a thriving social movement web.

\subsubsection{Resource Mobilization}

Emerging during the long 60s, resource mobilization gained theoretical currency, challenging the "accepted wisdom about collective behavior," becoming the "first paradigm in the history of the discipline to place social movements at the center of the analysis" (Buechler 2011: 111). In doing so, resource mobilization set the agenda for social movement studies by suggesting that core areas of research should investigate the "dynamics and tactics of social movement growth, decline, and change" (McCarthy and Zald 1977: 1213). This entails that resource mobilization emphasize the twin process of:

...societal support and constraint of social movement phenomena. It examines the variety of resources that must be mobilized, the linkages of social movements to other groups, and the dependence of movements upon external support for success, and the tactics used by authorities to control or incorporate movements (McCarthy and Zald 1977: 1213). 
In explaining the focus of resource mobilization more specifically, McCarthy and Zald (1977: 1216) emphasize that it is critical to study the accumulation of resources since they are necessary "for engagement in social conflict." By extension, it is important to study social movement organizations (SMO) $)^{12}$ because they transmit resources. In chapters five, six, and seven of this thesis, I incorporate these elements into a discussion of the threads that bind NGO-grassroots collaboration in social movements as well as the knots that result from (resource) tensions. Necessary to understanding the efficacy of resource mobilization theory for my thesis is an appreciation of the differing forms that resources take.

Resource mobilization theory did not specify in detail the concept of resources as well as the different types of resources that become available to movement actors until the 1990s (Edwards and McCarthy 2004; McCarthy and Zald 2002). Both Cress and Snow (1996) and Edwards and McCarthy (2004) provide a typology of resources, some of which include: cultural (informational), human, and material resources.

As described by Edwards and McCarthy (2004: 126), cultural resources - referred to by Cress and Snow (1996) as informational resources - include artifacts "such as conceptual tools and specialized knowledge that have become widely, though not necessarily universally, known." Cultural resources include the know-how of writing press releases, holding news conferences, planning protests, forming an organization, etc. In addition to these tacit forms of knowledge, cultural resources include the production of

\footnotetext{
${ }^{12}$ A SMO is a formal organization "which identifies its goals with the preferences of a social movement or a countermovement and attempts to implement those goals" (McCarthy and Zald 1977: 1218). Although most SMOs are NGOs, not every NGO is or may be considered a SMO (Jalali 2013). Social movements may contain both SMOs and NGOs.
} 
music, magazines, research reports, films and video that help with recruitment and socializing new adherents (Edwards and McCarthy 2004). Human resources include the tangible resources "like labor, experience, skills, and expertise" and individuals have control over them (Edwards and McCarthy 2004: 127). In participating in a social movement or social movement organization, individuals make their human resources available to others and the movement at large. Material resources include financial (money) and physical (office space, equipment, etc.) capital, and are perhaps the most important resource as it is a necessity for collective action. In focusing on the accumulation and flow of cultural, human (informational) and material resources, resource mobilization theory offers the relevant theoretical and conceptual tools that participants explain as the threads that bind them in webs of interaction.

\subsubsection{Framing Contention}

The framing perspective represents one element of the cultural turn in studying social movements. It is a departure from the rational and instrumental depictions of human and organizational actions in resource mobilization theory and its successors. Framing theory is rooted in the principle of social constructionism and symbolic interaction, the idea "that meanings do not automatically or naturally attach themselves to the objects, events, [existing ideologies ${ }^{13}$ ] or experiences we encounter, but often arise,

\footnotetext{
${ }^{13}$ There has been some dispute in the literature on the difference between frames and ideology (Benford and Snow 2000; Oliver and Johnston 2005; Snow 2004; Snow and Benford 2005). Oliver and Johnston (2005: 193) suggest, "framing points to process, while ideology points to content." Process is explained above through the three core tasks of framing. Ideology is often understood as the durable and coherent sets of ideas and values that produce the content of the belief systems that may affect one's orientation to politics and everyday life (Benford and Snow 2000; Oliver and Johnston 2005; Snow 2004).
} 
instead, through interactively based interpretive processes" (Snow 2004: 384). In suggesting that reality is socially constructed, scholars working within this tradition adopt the verb framing to focus on how movement participants construct meaning or engage in signifying work. Framing posits "an active, processual phenomenon that implies agency and contention at the level of reality construction" (Benford and Snow 2000: 614). When social movement actors engage in this process, they are actively engaging in articulating dynamic and constantly evolving collective action frames ${ }^{14}$. According to Benford and Snow (2000: 615-617), as agents in the contentious process of reality construction, social movement actors are said to engage in three core tasks:

(1) Diagnostic framing: identifying and negotiating a shared understanding of a problematic condition, which leads to attributing blame

(2) Prognostic framing: identifying possible solutions and the strategies that will assist in materializing stated solutions

(3) Motivational framing: providing a rationale for participation in collective action, often as a result of socially constructed vocabularies (severity or urgency, for example).

Together, these three core tasks allow movement adherents to negotiate a shared meaning to understand the phenomenon that is in need of change; who or what is the subject of blame; and articulate alternatives, urging others to engage in social action (Benford and Snow 2000). The grassroots groups and NGO staff included in this study adopt similar values and share an environmental justice framework. This framework informs a collective understanding of the problem of Canadian resource extraction, the solutions and strategies needed to challenge the industry, and a rationale urging people to challenge the industry and the state.

${ }^{14}$ Collective action frames are the sets of actionable meanings and beliefs informing the activities of social movements (Benford and Snow 2000). 


\subsection{Conclusion: Identifying Limitations, Gaps \& Bridging Theories}

The literature describing the empirical effects of NGO-grassroots dynamics typically takes the form of two separate strands of research. The first strand of inquiry is historically more dominant, condemning the role of NGOs by employing the NGOization thesis. The second strand of inquiry nuances, complicates, and situates studies evaluating NGO-grassroots dynamics. My concern with the former is that the complexity involved in evaluating NGOs is recognized, but not always adequately explored as a serious area of inquiry (Choudry and Kapoor, 2013; Choudry 2013; Kapoor 2013; Africa 2013; Sinwell 2013). This may be a consequence of the position that it is more important to criticize rather than take for granted NGO involvement in contentious politics, or to avoid betraying the movements scholars may work with. Whatever the argument may be, the very important research problematizing NGOs has become one of the dominant strands within the scholarship. I find that this approach is not always helpful to movements dealing with the reality of organizations existing in the 'here and now', and it does little to theoretically explain threads that bind, and the knots that constrain, interaction in social movement webs.

On the other hand, the work that nuances the subject largely examines the role of NGOs: in the public sphere (Lang 2013), engaging in movement work (Alvarez 2009), highlighting the paradoxical - and occasionally positive - effects associated with institutionalization and professionalization (Markowitz and Tice 2002; Tsikata 2009), or challenging the depoliticization thesis (Ghosh 2009; Herzog, 2008; Lavalle and Bueno 2011). Very few of these studies focus on collaboration between NGOs and grassroots 
groups, often excluding NGOs as actors within social movements ${ }^{15}$. One notable exception includes a volume entitled Can NGOs Make a Difference? The Challenge of Development Alternatives, the authors of which argue for the potential of NGOs to be alternative by experimenting with their activities and - more importantly - "by avoiding complacency and being willing to challenge development conventions and outcomes" (Bebbington, Hickey and Mitlin 2008: 26). In providing concrete examples, it is shown that NGOs can build relationships with people's movements and grassroots groups, offering strategic action at multiple scales and in a variety of settings.

However, despite the strength of the Bebbington, Hickey and Mitlin (2008) text, there are several limitations and gaps in the literature. First, none of the texts examined engage in a systematic study of the specific variables that facilitate, if not bind, NGO and grassroots groups together. Second, the literature and associated case studies on NGOization (or NGO-grassroots dynamics) are typically contained within the confines of a particular state in the Global South - interrogation of NGOization in transnational solidarity movements in the North is largely absent. Third, very little has been written on NGOization in Canada (or involving Canadian NGOs), with the exception of the following: the detrimental role of Canadian development NGOs in Haiti (Barry-Shaw and Oja Jay 2012); the reliance of food movement actors on corporate funds (Kneen 2013) ${ }^{16}$;

\footnotetext{
${ }^{15}$ The inclusion of NGOs as active participants in social movements/contentious politics is implied by Alvarez (2009). In addition to Alvarez (2009), Bebbington, Hickey and Mitlin (2008) take this position.

${ }^{16}$ The pressures for accepting corporate funds described in this chapter are more related to the corporatization of the food movement and not necessarily a shift in structure marked by NGOization proper. Kneen (2013: 213) asserts that it might be more accurate to describe this phenomenon as "NGOization by proxy," and I concede that this is a more adequate means of explaining what is occurring.
} 
and the ironies that resulted from the NGOization of Canadian Churches (the United Church) into faith-based NGOs (Brouwer 2014). The purpose of this thesis is to augment and fill the gap in the literature by providing a study of a Canada-based solidarity movement against resource extractivism.

This study seeks to augment the literature by using the conceptual and theoretical tools offered by social movement theory to more effectively describe, as opposed to obscure, NGO-grassroots relationships in the context of NGOization. It is my belief that if studies on NGOization were to integrate some of the insights of social movement theory, then the predominant NGOization thesis would likely have to be re-evaluated, if not receive more contextualization than the literature tends to afford. By making use of social movement theory concepts in the design and analysis of studies on NGOization, it is possible to produce a meso-level understanding of inter-movement interactions and examine in more detail (as well as scrutinize) instances in which relationships of collaboration do occur, why, and under what conditions they are successful. Despite its limitations (Bevington and Dixon, 2005), social movement theory is well positioned (in combination with the literature on NGOization from the fields of development studies and political science and a focus on the lived experiences of movement activists and the meanings and importance they attach to collaboration) to provide an explanatory and analytical intervention in examining NGOization processes, making visible the threads that bind interaction, the knots that create tensions, ambivalence and conflict, and the generally messy character of engaging in social movements and contentious politics. 


\section{Chapter: Methodology}

In an effort to answer my research questions, I employ a qualitative methodology rooted in a social constructivist framework. A social constructivist framework takes as its unit of analysis the subjective and multiple meanings individuals attach to objects or things (Creswell 2013). As Creswell (2013) asserts, adopting a social constructivist framework requires that the research pay attention to the complexity of meanings and views rather than explicating them in narrow categories - in the context of this study, the threads and knots that comprise movement webs. A methodological approach that is well positioned to grasp at the thick descriptions of the lived experiences of participants is a hermeneutic phenomenology that is reflexive and based on a creative interview process. As an approach, hermeneutic phenomenology requires that the researcher interpret the lived experiences of participants, focusing on the complexity of meanings attributed to experience through themes or meaning units (Sloan and Bowe 2014).

This methodological approach and the associated phenomenological attitude of reflexivity (Finlay 2014) are explained in the first section. Following from this, I describe the rationale for selecting the participants and organizations included in this study. In the third section, I describe the methods selected, and engage in a discussion of interview styles and how I navigated my insider-outsider status (as a space between these two). In the fourth section, I describe how I analyzed my data to generate meaningful threads (meaning units) that are "woven into a rich description of the phenomenon as a whole" (Finlay 2014: 122). Finally, I explore the limitations of this study, as well as the retrospective reflections that would have strengthened and thickened the threads and/or the knots that hold this constellation of actors together. 


\subsection{Methodology: Hermeneutic Phenomenology}

This research project utilizes a hermeneutic phenomenological approach. In its most broad definition, phenomenology advocates studying individual lived experiences, asserting that human behavior is not purely determined by an objective and physical reality external to the individual, but includes subjective experience (Creswell 2013; Sloan and Bowe 2014; van Manen 2014). van Manen (2014: 26) captures the crux of hermeneutic phenomenology, with its focus on interpretation, when he describes it as a method of "reflection on the basic structures of the lived experience of human existence" with the aim of using "discursive language and sensitive interpretive devices that make phenomenological analysis, explication, and description possible and intelligible." In the context of this study, participants reflect on their experience and the meanings they attribute to the phenomenon of NGO-grassroots relationships, and I - as the researcher and the vessel through which this knowledge is (co)constructed - engage in the exercise of interpretation.

When adopting phenomenology as a methodology, one needs to affirm according to Finlay (2014) - a phenomenological attitude. This attitude is informed by a reflexive approach to qualitative research and is shaped by a desire to "push beyond what we already know from experience or through established knowledge" by bracketing (putting aside) and holding in abeyance our own biographies, which are informed by particular epistemological and ontological assumptions (Finlay 2014: 122). It is important to engage in a reflexive and phenomenological approach to qualitative research because both promote the recognition that our experiences, although meaningful, are only a partial reading of socio-cultural processes. This does not insinuate that we must bracket our 
knowledge and experience out of existence to completely understand the phenomenon under study. Instead, the suggestion is that we carefully engage in the dialectical task of managing subjectivity so that we may access a holistic approach to life by carefully straddling "subjectivity and objectivity, intimacy and distance, being inside and outside, being a part of and apart from, bracketing the self and being self-aware, and so on" (Finlay 2014: 124). In order to adopt a phenomenological attitude, it is first necessary for me to be reflexive (critically self aware) of how my own experiences represent particular assumptions that I not only hold, but that I brought to the interviews and the analysis of the experiences of my participants.

\subsubsection{Reflexivity: Situating the Research}

My motivation for conducting this study is largely informed by personal experience in the resistance movements that seek to challenge an extractivist model of development predicated on neo-colonial modalities, capitalist expansion and ecological degradation. As a result of this, I think it is important to situate this study in my biography, because as Mauthner and Doucet (2003) suggest, as the researcher, I am engaging in the challenge of interpretation, bringing my own ontological and epistemological assumptions into the research and data analysis process. These assumptions are shaped by the experiences outlined below.

In May of 2012, I attended the Resisting Extractivism: Lessons and Inspiration from Front-Line Communities and Fellow Activists conference, organized by a Torontobased grassroots group working in solidarity with mining-affected communities around the world. The conference was well attended by academics, activists in Canada working on this issue (including NGOs) and most importantly, it included impacted community 
members from Colombia, Tanzania, Papua New Guinea, El Salvador as well as from Canada. Throughout the day, I was exposed to the struggles of actors on the ground, the role of the Canadian state apparatus in promoting and exporting this model of development, and the organizations and groups they work with internationally as a result of this transnational phenomenon. As a white man from a middle-class background, I found myself in a space populated by people of colour and Indigenous men and women from Canada and the Global South. This did not surprise me, as I had known that environmental justice issues originated in the grievances and community organizing of Black communities in the United States, and that global environmental injustices disproportionately affect people of colour, peasant, and/or working class communities. This pause and moment of reflection facilitated the awareness of my own location in the multiple social hierarchies that structure our world. As a settler living on stolen Indigenous lands - and upon listening to similar stories of displacement articulated by Indigenous and union leaders from the Global South - I decided that the best thing I could do at this point in time was to shift from a position of complacency to one of active solidarity, working to amplify the voices from below. Following the conference, I emailed the organizers and attended a new members' meeting a week or two later.

From 2012 to 2013 (and prior to moving to Ottawa to complete this MA), I was an active member of the grassroots group Mining Injustice Solidarity Network, fully immersed in the Toronto activist scene with a focus on environmental and mining justice issues. With my fellow comrades, we organized various public events and protests, including an environmental justice contingent in the 2013 May Day march, featuring banners that read "Water is more valuable than gold" and "Global Resistance to Canadian 
Mining" amongst more traditional class-based flags and banners. During this year I was able to become intimately familiar with the dynamic character of resistance to resource extractivism as a model of development and the networks and coalitions that inform this type of work. I noticed that small and even large NGOs frequently collaborated with grassroots environmental justice groups by planning events or speaking tours together, working in coalitions, and occasionally, the former spoke at (and participated in) the protests organized by grassroots groups. As I explain in the next section, this experience, and the meanings I associated with the phenomenon of NGO-grassroots relationships, shaped my research project.

The experience of organizing with this group and being involved in the activist community in Toronto not only shaped my project, but also my anti-capitalist worldview while consequently helping me to articulate a vision of an environmentally and economically just world that centers the lived experiences and often brutal realities of people of colour, peasant, Indigenous and/or working poor communities outside of urban centers and G7 nations; communities that disproportionately face the violence imposed by imperial logics and who are at the forefront of a transnational movement challenging resource extractivism in general and its Canadian manifestation in particular.

\subsubsection{Asking Phenomenological Questions}

Once I began my MA, I found myself - in the winter of 2014 - pondering potential projects in the Logic of the Research Process seminar. Then, one night, at a book launch at the 250ne Community space in Ottawa, my project started to come together. The launch was for Choudry and Kapoor's (2013) NGOization: Complicity, Contradictions and Prospects. I purchased the text, eagerly reading through the 
provocative and critical evaluations of NGO-grassroots relationships across a myriad of contexts and histories. But I was not satisfied. I found the analysis, which seeks to explore the complex nature of social movement dynamics, limited: not one chapter explored the instances in which social movements might include heightened levels of interaction between NGOs and grassroots groups in spite of existing tensions and/or experiencing NGOization. I began to ask myself phenomenological questions such as: "How does my experience relate to these accounts of NGO-grassroots relationships? How do activists, including NGOs, experience this phenomenon? What meanings do they attach to this process?", all demonstrating that this project was sparked by a sense of wonder typical of a phenomenological approach.

According to van Manen (2014: 31), phenomenological questions arise when "we have had a certain experience that brings us to pause and reflect." Phenomenological questions - and certainly the ones I was asking - are guided by existentials (common themes and experiences that people share). The existential that guides my inquiry is, in van Manen's (2014: 302) own words, "lived relations (relationality)," which focuses on explaining and reflecting on how the self and other are experienced with respect to NGOgrassroots relationships. This form of relationality asks, "How are people or things connected?" I could not keep myself from wondering about my own experience and the crucial element of relationality that I found to be written out of the Choudry and Kapoor (2013) text. I decided to fashion my project in response to and in light of this literature on NGOization by extending this wondering to how other activists make sense of this process. I pitched the idea, along with my (rudimentary) research questions, to a few grassroots activists involved in environmental justice organizing - at large fundraising 
parties or over small, more intimate dinners - and they received it positively. The next question I asked myself was: with whom do I choose to study relationality in the context of this movement?

\subsection{Rationale for Selected Participants/Organizations}

In an effort to engage in a preliminary analysis of the internal and relational dynamics of the movement challenging Canadian resource extractivism, I decided to conduct a phenomenologically inspired study by interviewing two self-identified grassroots groups and two self-identified NGOs, ${ }^{17}$ using secondary data (organizational websites) to look at campaigns, instances of inter-organizational collaboration, etc. to provide context to the substance of the interviews. These organizations have been selected according to purposive sampling, a common qualitative sampling strategy in which the researcher purposefully selects participants because of their unique role in understanding the phenomenon under study (Creswell 2013). I decided to choose the samples included in this study because they involve some of the main actors within this organizational field. I based this decision on my own involvement in the movement as well as the role of each organization in the public sphere: all are actively engaged in contentious politics and appear frequently in mainstream (CBC, for example) and alternative (Rabble, for example) news sources on issues related to Canadian extractivism at home and abroad. What is unique about this movement is that it is interconnected with other movements broadly situated in solidarity initiatives that bring to the fore the role of the Global North in the Global South.

${ }^{17}$ A more detailed description of each NGO and grassroots group is captured in Appendix A. 
As a result of this, only one NGO and one grassroots group dedicates its work to resource extraction exclusively. The other two work on resource extraction in addition to other issues that are embedded in the social, economic and political relationships that shape ties between the Global North and South. Despite some NGOs and grassroots groups not dedicating all of their resources to resource extractivism, they all - to different degrees - engage in (collaborative) campaigns questioning Canadian extractive operations at home and abroad. In an effort to protect the anonymity of my participants, and because I am studying inter-organizational relationships - which may be imbued with micro-conflicts in addition to instances of collaboration -I decided to redact organizational names and individual identities ${ }^{18}$. I chose to do this because I want to minimize any potential harms that may result from this study, including harming the movement by potentially causing internal divisions. As an activist-academic attempting to write with as opposed to about movements, I feel a deep sense of accountability and want to ensure, as much as possible, that I do not negatively affect inter-organizational relationships as a result of this research project.

In addition to selecting NGOs and grassroots groups purposefully, I also adopted this sampling method for my participants. I chose participants based on two criteria. First, I considered their location in the NGO structure or their role in the grassroots group (some were founding members no longer with the group, others recent but very active members). I selected these participants because I felt that they were well positioned in their own organizations and inter-organizational coalitions to speak to NGO-grassroots

\footnotetext{
${ }^{18}$ The pseudonyms I employ are gender ambiguous, and I use "they" and "their" as personal pronouns because I do not want to assume the gender identity of my participants.
} 
dynamics, instances and reasons for collaboration, and to share insight into the elements comprising NGOization. Second, I chose participants - particularly those involved in grassroots groups - based on my own involvement in the movement. The year I was involved in a grassroots group was enough time for me to establish friendships with actors involved in the broader environmental justice community. As an insider - someone who is part of the phenomenon they are studying (Dwyer and Buckle 2009) - I acquired a familiarity with the actors operating in this field. This allowed me to locate key actors who would be able to provide valuable insight for this study.

Originally, I wanted to conduct between twelve and sixteen interviews, to be divided evenly amongst the four cases. This number was selected primarily because these organizations are small, and either do not have many staff available for interviews (in the case of the NGOs) or do not retain enough volunteers over a long period of time who would be able to adequately answer questions regarding interactions with NGOs (as is the case for the grassroots groups). However, by the time I started to e-mail NGOs and grassroots group actors (in November, 2014), this number seemed too ambitious: some prospective participants were out of the country visiting impacted communities; others did not respond to my repeated requests for an interview. I ended up interviewing nine participants: one from NGO 1, three from NGO 2, three from Group A and two from Group B. This number worked out well in the end, particularly because research employing a phenomenological approach typically involves smaller sample sizes due to its focus on in-depth interviews to solicit the experiences and meanings participants attach to a particular phenomenon (Creswell 2013). 


\subsection{Methods: The Interview Process and the Space Between}

I started to interview participants in the last week of December 2014 with the final set of interviews completed by the end of January 2015, including all transcripts. The interviews were in-depth and semi-structured, ${ }^{19}$ with the average interview lasting two hours. The interviews were divided into five different sections, with some sections garnering more attention than others, dependent on the flow of conversation between the participant and myself. The location of the interview varied, but was always chosen by the participant: I met Alex from NGO 1 at Future's Bistro, with the interview taking place over breakfast; I met members of NGO 2 in their offices; and the interviews with grassroots groups were conducted at cafés, their own place of residence, or at a pub. Elwood and Martin (2000: 650) suggest that interview sites are important because they "provide a material space for the enactment and constitution of power relations," with what they term the "microgeographies of the interview [reflecting] the relationships of the researcher with the interview participant, the participant with the site, and the site within a broader sociocultural context that affects both researcher and participant." Beyond ethical reasons, I asked participants to set a location as a strategy to disrupt the disparities in power (but not erasing them) between myself as the researcher and the activist/NGO staff member as the participant. I found that, specifically for the NGO representatives (many of whom I had known of but never formally met), regardless of the site, participants were able to speak openly about potentially contentious questions those dealing with conflicts between their group/organization and another group/organization.

\footnotetext{
${ }^{19}$ See Appendix B for the interview guide used for the thesis.
} 
Semi-structured interviews were selected as the style of interviewing for a few reasons: (1) semi-structured interviews allow for flexibility in the ordering of questions according to the flow of conversation; (2) semi-structured interviews allow freedom when it comes to probing research participants "for more information on particular points"; (3) semi-structured interviews allow me as the researcher "to explore topics that may emerge that were not included in the interview schedule"; and finally (4) semistructured interviews can imply a co-construction of knowledge in which researchers can work through ideas with participants (Gibson and Brown 2009: 88-89). Adding to point number four, Fontana and Frey (2008) suggest that all interviews involve an active process of collaboration that gives the interview its meaning and substance. It is based on this characterization of the interview that I pursued a creative interview strategy. The creative interviewing style is consistent with the benefits of semi-structured interviews listed above as well as the notion that interviews are spaces in which knowledge is coconstructed. Holstein and Gubrium (1995) describe this concept as entailing the production of "a climate of mutual disclosure between interviewee and interviewer by allowing the latter to have a deep involvement in the conversational development" (as cited in Gibson and Brown 2009: 89, emphasis added).

In an effort to follow this method, I always disclosed my previous affiliation with one of the several grassroots groups active in this movement nationally. I did this partly because I wanted to position myself as an insider, but to also avoid deceiving the participant (particularly NGO members who I had never met) that my interest in this topic is disconnected from personal experience. I also engaged in the practice of disclosure for another reason: to indicate to participants with whom I have established 
friendships that I am also an outsider - someone who is, at this point in time, no longer active in the movement. For all participants, disclosure would occur before the interview began. I am paraphrasing now, but I would say something similar to:

As you may (or may not) know, I was an active member of the Mining Injustice Solidarity Network. I carry some insight into inter-organizational relations, including tensions and conflicts. As I mentioned in the consent form, whatever information you divulge about particular individuals or organizations will not be shared with any group. If it appears in the final version of the thesis, or potential publications, you can rest assured that organization and individual names will be redacted, and presented in an abstract way.

For grassroots group members in particular, I would complement this by stating the following, usually in between the first and second series of questions:

Some of the questions in this section may appear obvious, and you may think to yourself "come on Max, you should know this!" Although I was involved in similar work, my experience in a grassroots group is likely to be different than yours. Please try to keep this in mind as you answer questions and as we progress through the interview.

In stating this, I hoped that participants would avoid making the assumption that we share the same experiences, and therefore "fail to explain their individual experience fully" (Dwyer and Buckle 2009: 58), impacting my understanding of the meanings they attach to their organizing work and their relationships with other activists and groups. I also stated this because I wanted to engage in the hermeneutic and phenomenological practice of reflexivity and bracketing. I created a (reflexive) space to discuss my own biography "not as an exercise in solipsistic self-indulgence but as a way of gaining further insight into our mutual, embodied intersubjective world" (Finlay 2014: 130). In doing so, I hoped to gain a deeper understanding of the phenomenon through this form of relationality. On the other hand, bracketing involves more than situating the researcher, and includes first discussing and reflecting on personal experiences - indicating an 
awareness of personal perspectives - and then "partly set[ting] them aside so that the research can focus on the experiences of the participants in the study" (Creswell 2013: 78). By adopting this technique typical of a creative interview, as well as a reflexive and phenomenological approach to research, I was open and honest with my participants while simultaneously displaying an interest in learning, understanding, and (eventually) accurately representing their experiences.

To sum up, I entered the research as both an insider and an outsider, occupying a space in between these two statuses. Occupying this position requires a dialectical approach that appreciates the "fluidity and multilayered complexity of human experience": although I held membership in a group, I do not have the same experiences as other grassroots groups; yet, as a non-member I am not necessarily completely different from the group (Dwyer and Buckle 2009: 60). In this space-between, such similarities and differences are preserved and originate in Fay's (1996) understanding that "there is no self-understanding without other-understanding" (as cited in Dwyer and Buckle 2009: 60). This creative interview process was a good practice because I found that - in combination with allowing participants to choose the interview site and while engaging in a reflexive approach to the research - it helped bypass potential barriers that would hinder the progress of the interview, particularly interviews with participants I was meeting for the first time. Instead, I found that the creative interview process built bridges based on mutual engagement in conversational development: I shared my experiences working on similar campaigns with NGO actors I had met for the first time and I reflected on protests with grassroots group participants as we attempted to recall specific details. 


\subsection{Data Analysis}

Initially, I printed all nine transcripts (40-60 pages each). My intention was to go through all of them in detail - paragraph by paragraph - to establish "narrow unit[s] of analysis" such as significant statements or broader meaning units/themes, which would assist me in writing a detailed description of the phenomenon as it is commonly experienced by participants (Creswell 2013: 79). However, after doing this for half of one interview, I realized that this method of coding (or generating meaning units/themes) was extremely messy as I found it difficult to keep track of the different themes generated. Another reason I decided not to do this was because I would not be able to - after going through every interview - extract each theme into one document since the themes fall across nine different piles of paper.

I decided to download NVivo and, using the software to organize my themes, was then able to generate nineteen broad parent nodes (for example, "collaboration") and forty-one child nodes (which included, for example, "shared resources" and "common values" under "collaboration"). Of course, I did not utilize all of these nodes, but selected the nodes that were most frequently experienced and given meaning by participants. Once I printed a select number of the nodes, I engaged in a second round of coding: one that was committed to refining and expanding on the themes already constructed. After this process, I was able develop the themes into five threads that bind NGOs and grassroots groups together, which include within them the knots that strain relationships.

As part of my data analysis, I also created the following nodes: "strengthening relationships" and "movement-building". These nodes contain reflections from the interviews on how relationships could - if they should at all - be strengthened, and what 
participants believe needs to occur for the movement to gain greater momentum. These questions were not necessarily related to my thesis. Nonetheless, in an effort to have my research transcend the confines of the Ivory Tower - and to make it more "movement relevant" (Bevington and Dixon 2005) - I decided to use the information gathered within these nodes to generate a report for my participants once my analysis has been completed and my thesis defended. This report will not only describe the two items listed above, but it will hopefully provide insight into NGO-grassroots relationships: how NGO participants feel about grassroots groups, how grassroots groups feel about NGOs, and magnify some of the shared understandings actors have about the state of the movement what has worked, what has not, and what needs to change.

\subsection{Limitations and Retrospective Reflections}

Although this research is unique because it engages in understanding NGOization in the context of a Canadian solidarity movement challenging resource extractivism, it is not without its limitations. First, this study only examines NGO-grassroots relationships and NGOization in the context of the Global North. Due to time constraints and the fact that this is an MA thesis (a study naturally smaller in scale and scope), I do not include the voices of NGOs or grassroots groups in the Global South. If I included the experiences of NGOs and grassroots groups in the Global South, elements of NGOization and more severe tensions might have been more evident. In light of this limitation, it is important to remember that this study takes somewhat of a novel approach: as opposed to examining NGO-grassroots relationships and NGOization in the context of foreignfunded NGOs entering a “developing” country (North-South relationships), I examine this dynamic in the context of a solidarity movement, and the relationship between actors 
in the North in relation to the South. Thus, the unit of analysis is quite distinct because it contains its own field of actors subject to similar concerns (tensions, feelings of ambivalence, and contradictions) as the movements in the Global South.

Second, while I examine the movement challenging Canadian resource extractivism, most of the participants in this study challenge a particular form of resource extraction: mining. This limits the claims I am able to make about NGOization as a process evident in this movement since most of the participants I interviewed focus on a small aspect of this larger phenomenon. This begs the question: why frame it as a movement challenging Canadian resource extractivism? I did this for a variety of reasons, but the two most important are that: (1) activists and organizations included occasionally lend critical support to, or organize to bring awareness of, other resource extraction related struggles (oil sands development in Canada; hydro-electric dam projects in Honduras) and (2) several actors frame the issue as a problem with resource extractivism as a model of development, irrespective of its particular manifestations. Given the complexity of involvement and the scale of the issue of natural resource extraction, I decided to adopt 'Canadian resource extractivism' as it is more general and represents the complexity more accurately - despite its apparent abstraction.

A third limitation stems from the second: for a study that looks at Canadian extractivism, it is questionable whether two NGOs and two grassroots groups can adequately represent "the movement" challenging Canadian extractivism. This is ultimately a question of validity. In response to this apparent limitation, I turn to phenomenology: I am not seeking to describe "the factual empirical but the existential empirical meaning structures" of NGO-grassroots relationships (van Manen 2014: 348). 
My study focuses on how my participants experience this phenomenon, and the meanings they attach to it. For such a project, a large sample size and triangulation of methods are not required, for the real concern stems from the "originality of insights and the soundness of interpretive processes" (van Manen 2014: 348). Given the data analysis strategy described above, successive analyses of the interviews led to the development of thick themes that complicate dominant understandings of NGOization.

Having now completed this thesis, I have come to realize that this project would have been stronger had it included focus groups comprised of participants from the same group or NGO. By including focus groups in addition to interviews, I would have been able to gain insight into changes in the meanings attached to collaboration, complicating the threads that bind. Similarly, focus groups could have offered the NGO or group the time to collectively reflect on additional movement knots. An additional benefit of focus groups would have likely included the development of thicker descriptions of the meaning units - threads - generated from the lived experiences of participants as well as the knots that periodically strain relationships. Unfortunately, I could not engage in focus groups because of the time constraints of a Master's program.

Another means by which to have proceeded differently with this project would have been to incorporate the vast literature on transnational social movements, theories of solidarity, and the literature on space and place to further complicate the NGOization thesis. Drawing on the substances of the interviews I have conducted, I believe that place, and the spatial distance between Northern actors and the movements and communities they work in solidarity with, have significant implications for the threads that bind Northern groups and NGOs together. I am unable to fully appreciate the implications of 
place, space, and the transnationalization of solidarity movements within this thesis because it would have resulted in following up with participants with additional questions, which would have required more time, not to mention that it might constitute an entirely separate research project. However, I feel, as Hunter from group B did when we discussed solidarity, identity and place that "there's something there...there's just something there that we really need to be thinking about".

\subsection{Conclusion}

Hermeneutic phenomenology is well suited for a research project that asks why NGO and grassroots group relationships in this social movement experience a heightened level of collaboration, if elements of NGOization are evident, and how they affect strategies for social change. This is largely because phenomenology in general requires strict and disciplined attention to the lived experiences and the meanings attached to a particular phenomenon shared by participants - movement activists in this case - which can be discerned through in-depth and semi-structured interviews. In practicing a phenomenological attitude, I adopt a reflexive approach to the phenomenon and my participants, not only situating my own ontological and epistemological assumptions about NGO-grassroots relationships, but also actively bracketing these experiences to ensure that I am able to capture what Finlay (2014) refers to as the 'is-ness' of the phenomenon - in other words, the essence derived from meaning units and my interpretation of them. The is-ness or essence of the phenomenon takes the form of five threads and their corresponding knots, two of which we turn to in the next chapter. 


\section{Chapter: Shared Values and Frames of Contention}

My findings indicate that five main determinants serve as mutually binding threads facilitating collaboration and mutual support. In this chapter, I will be describing the first, which is composed of two related meaning units: shared values and frames of contention. The first section will include a detailed account of the importance of selfdetermination and corporate and state accountability to movement actors. Although I will stress the importance of these values alongside the narratives and meanings attached to them, I will also draw attention to the praxis knot that creates tensions and ambivalence with attempts to put the value of accountability into practice. The second section explores the framing of contention, with a focus on how participants come to understand the nature and scope of the problem as an environmental justice issue, proposing solutions described by Alex from NGO 1 as the "bare minimum" in addressing the harms associated with the resource extraction industry.

\subsection{Shared Values: Self-determination and Accountability}

Common or overlapping values in the movement supporting communities impacted, or potentially impacted, by resource extraction projects shape collaboration and contribute to the creation of a collective action frame rooted in a multi-faceted notion of justice. The most common values expressed by participants include self-determination (community agency) and accountability (preventing or claiming responsibility for harms produced by resource extraction). These values not only influence collaboration but also contribute to the articulation of an environmental justice framework. 


\subsubsection{Self-determination, Community Agency and Free, Prior and Informed}

\section{Consent}

Of all the values mentioned, self-determination - or more broadly, community agency - is the most frequently cited amongst actors in both the NGOs and grassroots groups included in this study. As Dakota notes, "being really pro self-determination and Indigenous sovereignty... is common between all the groups." More than being common, Skylar suggests that self-determination is one of the most important motivations influencing their NGO's decision to collaborate with any NGO or grassroots group. On the importance of self-determination, Skylar comments:

But I think more important than all that - more important than anything... is that people respect communities and respect community... agency as the sort of starting block. Those are our most trusted allies - people that use that as a guiding principle in their work, [including] self-determination... Indigenous rights and also collective rights of non-Indigenous communities... Without that it's kind of hard to do any of the other work, or it presents challenges in coalition work [when it comes to] making decisions.

The value of self-determination resides ultimately in the notion it evokes of a world free from oppression, and is a term often associated with decolonization in which Indigenous and non-Indigenous peoples demand "determination of and proprietary over the title to the territory they inhabit" (Castellino 2014: 41), effectively placing development - economic, social, cultural - into the hands of communities themselves. This becomes clear when Brook reflects on what development entails in the context of self-determination and community agency:

Hmm. I guess that development is a collective project rather than an economic process and that it may involve external support, funding, more investment... but ... it needs to do that on the terms determined by the community itself based on its own need and desires - not [by] one external actor including local elites who are insulated and actually don't have the same interest in the outcome. 
Phoenix, also working for this NGO, supports this collective (but always community driven) approach to development, claiming:

...Those are really important things for us - that we're community driven, that we're responsive to what we're being asked to do, and that means that if a community actually wants a mine and they're looking for help for how to make sure that happens in the best possible way, we also respond to those requests.

For NGO 2, respecting community agency means supporting all communities, including those that do wish to see the fruition of resource extraction projects - a function that is unique to this NGO and not found in the mandate of the other NGOs or groups interviewed for this study. Skylar expands on this support for community agency, indicating that it is "front and center in terms of community consent before any mining activity on their land and at all stages of where there are projects that have gotten underway and that they would have meaningful participation where there are projects already established and such.”

In discussing self-determination, participants mention the importance of internationally recognized legal principles such as Free, Prior and Informed Consent $(\text { FPIC })^{20}$. As a member of a grassroots group, Casey situates the importance of FPIC as a mechanism of self-determination and a principle value that determines collaboration:

I think free, prior and informed consent is a definite must - ideas around, you know, respecting the consultations that really happen. I think as [group B], we have personal experiences of what mining brings to communities. A lot of times it's the disintegration of relationships and I think that's our basic understanding obviously if a community wanted that to happen, and every community around them that would be affected wanted it to happen - well we can't really say much about that, you know what I mean? And [if] everyone felt like things were being

\footnotetext{
${ }^{20}$ The acronym FPIC is commonly used amongst both NGOs (Forest Peoples Programme, First Peoples Worldwide, Amnesty International Canada, and KAIROS) and researchers writing on the policy (Coumans 2012; Laplante and Nolin: 2014; Minter et al: 2012).
} 
treated fairly, who are we to say that that's not right for communities? It's communities that we are concerned about that don't want it, don't have a choice, and are violently forced to accept the companies in their communities - accept, I don't know if that's the word - but the idea is, you know, to be a support, to be with the direction of the community.

Despite having mentioned this, the interviewees in both grassroots groups did not indicate that FPIC was a mechanism of self-determination that they actively advocate through institutional avenues. This makes sense, as engagement in issues concerning FPIC assume engagement with state actors and international law at multiple scales - an insider strategy with which grassroots groups do not typically engage. However, the NGO personnel interviewed made reference to their efforts in securing FPIC as an activity that companies engage in prior to the approval of a resource extraction project. Both NGOs indicated that FPIC is a principle that they actively work to secure as a standard at the provincial, national, and international arena.

\subsubsection{Accountability}

In the movement challenging Canadian resource extraction, accountability is often understood as NGOs and grassroots groups organizing to hold the Canadian state and corporations responsible for the conduct of companies prior to, during, and following the life of a project. The avenues for change can sometimes vary - from insider to outsider strategies - but the predominant mechanism for addressing the issue of corporate and state accountability is one based on an insider strategy that seeks to reform the Canadian political-legal system. These attempts at reform demand that: (1) the Canadian state take

a regulatory approach to the sector to avoid harms and/or to ensure that remedy is secured when harms are incurred and (2) corporate actors be accountable to the communities affected by their operations, encouraging FPIC during resource exploitation and 
providing remedy when harms are produced. All of the participants expressed accountability as a value their respective NGO or group holds to be important in diagnosing problems associated with this sector and one that is intimately tied to a vision for social change. The problem, as discussed below, is a lack of corporate and state responsibility in the North.

The notion that resource extraction abroad is a symptom of problems in Canada is well established amongst the participants in this study. This understanding is a critical element for collaboration between Northern actors, as expressed by Alex:

If there is a group in Canada or the US working on human rights violations in Honduras or Guatemala and the group in the North - their only vision is to hold the [Honduran or Guatemalan] governments accountable - I'd be like "No, I don't want to work with you on that" because if we're in the North, we should be holding ourselves responsible for our role. These groups in Honduras and Guatemala are already trying to hold their governments accountable.

In the interview, Alex goes on to suggest that NGOs or grassroots groups that focus solely on changing the laws of host nations ultimately share a different diagnostic frame. If organizations (small or large NGOs) and/or grassroots groups (in Canada or in host nations) share a different diagnostic frame, then this impedes interaction, as it often results in "bumping heads" (Alex). Assisting communities in strengthening their legal system is good, "but only up to a certain point, because our main role is to change our country, our corporate responsibility, our pension fund reform, [and] our free trade agreements." (Alex)

Accountability is an important value that shapes the objectives of NGO 2. In discussing accountability and its relationship to coalition building, Skylar remarks: ...corporations and states should be held to account for the constant abuses, violations and impacts that this very destructive industry is having on a daily basis and has for a very long time. One of the things - and I think this has also been true 
in terms of [our] view of a mine - is that the time it's in operation is actually a very small part of the project... it's the tens and dozens and hundreds of years after that have a long-term impact. And that goes to accountability- both the state and the corporate actors involved - here at home and internationally. So we're working on that in different provinces with different coalitions and communities in Canada and we're also working on that in terms of the abuses of Canadian mining companies abroad. And they have different implications and terms of the sorts of changes you're looking for.

Expanding on the details of what it means for states and corporations to be accountable, and introducing the notion of responsibility as harm prevention, reduction as well as access to justice, Phoenix explains that the overarching purpose of NGO 2 is:

...to create better legislation and policies to hold the industry accountable so that the industry has to live up to certain standards wherever it operates in the world and if it doesn't, [that] there's actual sanctions and that the industry has to remedy harm it causes and be held responsible for [the] harm that it causes. That means right through closure. So preventing harm through regulation and policies and legislation and then remedying harm when it is caused... but through mechanisms that have teeth, that are regulatory in nature. As part of the remedy part, we are trying to work on getting better access to justice for people that have been harmed either through non-judicial or judicial mechanisms that are effective.

In an effort to eliminate, prevent and/or remedy harm by making Canadian state and corporate actors responsible for their operations, both the grassroots groups and NGOs build and/or participate in coalitions that seek to push accountability using various tactics. A recent and highly publicized example of the coordinated effort to bring accountability to this sector includes the three pending lawsuits against HudBay Minerals Inc. The three lawsuits were filed by Indigenous Mayan Q'eqchi' plaintiffs from El Estor, Guatemala "over the brutal killing of Adolfo Ich, the gang-rape of 11 women from Lote Ocho, and the shooting and paralyzing of German Chub" by HudBay security personnel (Choc v. Hudbay, n.d.). It was decided that HudBay can be tried for the human rights abuses of its security personnel, and the three lawsuits will proceed to trial. In describing 
the coordinated effort to achieve this precedent setting ruling driven by the value of accountability, Alex comments:

...groups across Canada are increasingly involved in their local activism, going after their MPs, the Canadian government, the headquarters of Hudbay, letter writing, pressure - whatever - before you even get to Group A- that street stuff. And into this fairly positive mix comes a lawsuit - what other struggle has that? So thanks to the lawyers - they're not leading the struggle, they're not the stars of the show, but that just took a solid struggle to a new level because it goes right to the power structure in Canada.

Institutional and public advocacy regarding HudBay's responsibility to the survivors of El Estor has put pressure, in Alex's words, on Canada's "power structure”, including HudBay, exposing "that the emperor is wearing no clothes on all the other mechanisms ${ }^{21}$ ", (Alex). In general, the pressure placed on the Canadian state from above and below is punitive, as Phoenix explains:

$\ldots$ it needs to hurt to do the wrong thing. If it doesn't hurt to do the wrong thing, you're going to keep doing the wrong thing. So you need to be taken to court, you need to have to pay to fix things, you need to put huge bonds up for your closure so that that mine gets closed properly - that'll change how they act. That's our thing. So we're all about the stick and that's what we get accused of: "oh, you're just one big fat stick". Yeah, we're one big fat stick because there are a lot of carrots out there being thrown at you guys. You need a couple of sticks (both laugh)."

Both grassroots groups and NGOs utilize the figurative stick described by

Phoenix. The conceptualization of this figurative stick, or what Alex refers to as the "bare minimum $^{22}$ ethical position we should all be taking" varies. This variance, as well as the

${ }^{21}$ The other mechanisms include private member Bill C-300, entitled "An Act respecting Corporate Accountability for the Activities of Mining, Oil or Gas in Developing Countries" and Bill C-323, entitled "An Act to amend the Federal Courts Act (international promotion and protection of human rights)."

${ }^{22}$ Alex expressed the bare minimum position as having the legal structures in place to facilitate community access to court systems in Canada in holding corporations accountable. It's a bare minimum position because, according to Alex "poor people get 
implications of engaging in institutional advocacy, is a source of tension and ambivalence across and between organizational forms and which I refer to as the praxis knot.

Interestingly, both grassroots groups and NGOs point to the limitations of such a focus on a bare minimum, although for different reasons. Grassroots groups typically suggested that they struggle with institutional mechanisms for change because of the political compromise that this entails. As Micah notes,

Like how much of our energy do we put campaigning towards a particular bill that like maybe is a small step towards things being slightly better but really doesn't address the core issues: really doesn't honour the huge harm and violence and doesn't address accountability or justice in any real way - like how much are we compromising our values...

This type of reflection is not uncommon, as several grassroots actors reflected on the difficulty of navigating spaces in which institutional advocacy and private members bills are cherished at the expense of a more comprehensive approach that, for instance, provides an analysis of the underlying capitalist structures that shape corporate and state practices abroad which violate Indigenous self-determination. However, this reflective critique of the politics of acceptability is not reserved only for grassroots actors, as some of the NGOs that they collaborate with also express such concerns. Speaking for NGO 1, Alex elaborates on their tensions with NGOs engaging in historical and contemporary forms of institutional advocacy within the mining sector. In describing the tensions and critiques associated with the praxis knot, Alex states that ...The roundtables ${ }^{23}$ were fatally flawed to begin with. And that led to some

screwed over by the rule of law anyway." Members of NGO 2, group A and group B also find that a strong legal framework is necessary, but not necessarily the end goal. ${ }^{23}$ The Government of Canada initiated the National Roundtables on Corporate Social Responsibility and the Canadian Extractive Sector in Developing Countries in 2005 in response to a report tabled by the Parliamentary Standing Committee on Foreign Affairs 
tensions, but I didn't get fully involved. I didn't go to the roundtables. I had tensions with [NGO 2]. I know them all more or less. There have clearly been some tensions around Bill C- $300^{24}$ and the roundtables because I didn't think the roundtables - (pauses) - looking back, they contributed to where we are at now. Both the roundtables and Bill C-300 contributed to the increasing awareness in Canada. But the roundtable mechanism - that was like the government saying "we have a serious problem, let's talk it to death"... But it happened. Bill C-300 - bad law. But it contributed to more awareness....

In Alex's evaluation of the roundtables and the subsequent Bill C-300, this type of institutional advocacy has not proven to be an effective means of ensuring corporate or state accountability, and NGO 1's public critique of this approach has resulted in interorganizational tensions. These tensions appear from competing understandings of what a bare minimum is: for NGO 2 (and to some extent, groups A and B) it is the legal principles introduced in Bill-300 and for NGO 1, binding law. This latter approach fuels NGO 1's lack of interest in current attempts to reform the Ombudsperson office. As Alex of NGO 1 confidently asserts,

...I'm not in favour of it. Until we have binding law - when Canadians say "I pride myself living by the rule of law" - that means something. At a bare minimum, it has to mean something, and it means that anyone can have their day in court if and when their rights are harmed or anyone can be pursued criminally if they engaged in criminal behaviour. It's a bare minimum - poor people get screwed over by the rule of law anyway, so that's why I say law is not even - it's not going to solve all the problems. But at the bare minimum you need a minimal standard that applies to everyone. The Ombudsperson office - if there is not a bare minimum law for all people, then it's weak law over here saying "we don't need laws because we have this". So I don't like the effort. And the new effort is rehashing the effort that went on a few years ago to set up this office with Marketa

and International Trade (SCFAIT). The SCFAIT report recommended to the Government that it adopt a more regulatory approach to corporate accountability as well as initiating a series of roundtables to determine the standards companies are to meet in their activities abroad. The Government ignored most of the substantive regulations in the report, only committing to the roundtable process.

${ }^{24}$ Bill C-300 (An Act respecting Corporate Accountability for the Activities of Mining, Oil or Gas in Developing Countries) was a private members bill introduced by Liberal MP John McKay in 2009 and defeated in 2010 by six votes. 
Evans - it was BS.

Since the efforts to change the Ombudsperson Office is a recent iteration of previous demands that NGO 1 has disagreed with, Alex is firm in their lack of interest in engaging in this mode of advocacy. However, Alex moves beyond explaining this as a source of tension to recognizing their own ambivalence towards these insider strategies. This occurs in an earlier passage when Alex recognized that institutional advocacy has increased awareness of issues associated with resource extraction, which is a goal of this NGO (to be elaborated in Chapter 6). Evidently, both NGOs and grassroots groups experience tension and ambivalence in regards to praxis, particularly when institutional advocacy is the preferred approach. As mentioned previously, Micah (group A) recognizes that Bill C-300 does not seriously address the harms associated with the industry, with Alex (NGO 1) echoing this concern. The difference is that group A supports Bill C-300 while NGO 1 refuses to accept it as a "bare minimum", complicating the presumed association prescribing institutional advocacy to NGOs and public forms of advocacy to grassroots groups. The NGOs and groups in this study blur seemingly fixed spheres of action, either by supporting institutional advocacy in the case of grassroots groups or refusing to do so in the case of NGO 1. However, in providing support for particular bills, Group A struggles to reconcile its critical politics and values in a coalition space wherein institutional strategies are favoured to more public forms of advocacy, which may include National Days of Action against a particular type of resource extraction. In discussing this tension between NGOs and grassroots groups, Micah states:

...I was trying to push towards a national day of action... Like that as being something else that we do in addition to the MP visits that they're (NGOs) really 
into. I mean, no one was really against it but I was like "it would be really cool if it lined up with the Intercontinental Day of Action and everyone was like "oh everyone's on holiday in July... we wouldn't have staff" (both laugh). I'm glad they're honest - they probably won't have any capacity - but I also think "typical. You need to do a special NGO day of action because you can't line up with the global one."

Group A would like coalition spaces to value advocacy in multiple forms, suggesting that coalitions incorporate public advocacy alongside the traditional institutional forms of advocacy. While the NGO actors do not disagree with this on principle, professionalization operates as a barrier for coalitions to engage in public forms of action, as some staff may take vacations in the Spring and Summer months. This operates as a barrier for public mobilization and action since a significant number of activities are planned in this period of time. This works to create tension across organizational forms in a context of mutual collaboration.

Despite the criticism leveled by Alex against NGO 2 for engaging in a weak form of institutional advocacy, actors within NGO 2 are aware of the potentially compromising nature of insider strategies. Skylar expresses this position by describing corporate accountability, for example, as too narrow an approach. In our interview, Skylar reflected on the value of accountability when confronting the goliath that is Canadian resource extraction:

Skylar: ... I think there's maybe different ways of looking at things going on in Canada and different things that need to be considered. But in terms of responding to the massive problem that we're creating abroad, I think we've been too narrowly focused and I don't think... I think there's a lot more to do.

Max: Too narrowly focused on what's happening abroad and not necessarily in Canada? Or do you mean -

Skylar: No, too narrowly focused in terms of the scope of the problem. Not making the links to the whole issue. Demanding corporate accountability is a piece of it, but seeing it more holistically... seeing Canadian imperialism at work 
through the Embassy, seeing how the whole free trade agenda and the globalization framework locks in these regulatory changes, seeing what scope of territory is under threat in all of these countries - 20-30-40 percent of national territories - seeing the numbers of people being criminalized, killed or threatened. And seeing how much wanton and blatant and arrogant work is being done as much by corporate agents as by state agents on a daily basis in these countries. And so I think at the end of the day, if it takes us another five years to get an effective complaints mechanism in Canada and we haven't done anything to say "actually, there's a real structural problem: we need to stop promoting Canadian mining overseas and we need to build a much more visible, vigorous movement against this in Canada" then I don't know where we're going to be at. I think we'll be nowhere in terms of what we could maybe do from Canada or at least channel more resources to the community resistance processes that are underway. I think it's too narrowly focused and we need to be demanding that this stuff stop before it starts, not that we just deal with things after people have already been killed or taken advantage of.

Evidently, NGO 2 - like NGO 1 and group A - finds accountability to be too narrow of an approach and/or politically compromising. What is required is a strategy that addresses in a more comprehensive and holistic manner the ills associated with what Veltmeyer (2012) refers to as "extractivist imperialism." As this is an on-going process in the movement, it is beyond the scope of this thesis to investigate what strategies are to be formed. However, I can shed insight into the (current and constantly changing) frames adopted by actors within this organizational field.

\subsection{Framing Contention}

The values described in the previous section contribute to an environmental justice collective action frame that is articulated and shared by both grassroots groups and NGOs included in this study. As discussed in Chapter 2, framing - the process of constructing and reproducing collective action frames - is an important activity in which social movements engage (Walker 2009). Framing is a cultural phenomenon that is deeply informed by what Benford and Snow (2000: 613) refer to as "meaning work- the struggle over the production of mobilizing and counter-mobilizing ideas and meanings" 
and involves three core tasks: diagnostic, prognostic and motivational framing. Collective action frames, and in particular the environmental justice framework, are flexible, dynamic, and subject to reconstruction and recontextualization (Stanley 2009; Walker 2009; Schlosberg 2013).

\subsubsection{The Environmental Justice Movement and Framework}

Finding that the dominant approach to environmental issues was rather onedimensional, activists in the US convened at the First National People of Colour Environmental Leadership Summit in 1991 to "begin to build a national and international movement of all peoples of color to fight the destruction and taking of our lands and communities" (Principles of EJ 1991). This summit was a convergence of six formerly independent movements: (1) "the civil rights movement" focusing on environmental racism; (2) "the occupational health and safety movement" working with labour and undocumented workers; (3) "the Indigenous lands movement" seeking land reclamation; (4) "the environmental health movement" focusing on wilderness preservation, clean air and water, and sustainability; (5) "community-based movements for social and economic justice" that have now adopted an environmental justice framework, and finally (6) "the human rights, peace, and solidarity movements" that stress connecting issues at home to struggles in other parts of the world (Faber 2005: 44).

Summit participants from these various social movements set the agenda for a rich and changing environmental justice movement (EJM) and framework that seeks to focus on the relationship between race, the environment, economic, and social inequality (Faber 2005). This environmental justice frame also deals with issues related to the distribution of environmental risks and hazards, finding that they are frequently 
disproportionately burdening racialized communities (Haluza-DeLay and Fernhout 2011). The environmental justice framework has not been static as its conceptual boundaries are under a constant process of expansion and construction. On this point, the frame has shifted from an analysis purely rooted in distributional justice to include issues of procedural or participatory justice that focus "on the process by which decisions are made - in government, organizations, etc. - and who is or is not included in the decisions" (Haluza-DeLay and Fernhout 2011: 729). It continues to shift away from a position purely rooted in identity politics by building cross-class and racial alliances (Faber 2005) that recognize, for instance, the fact that white working class communities are also burdened by environmental hazards. Not only has the environmental justice frame evolved from a singular politics of identity, but according to Schlosberg (2013) it has also experienced a horizontal expansion (application of the discourse in a variety of countries) as well as a vertical expansion (the adoption of the discourse by multiple transnational movements). Further expanding the spatial barriers of the framework, Schlosberg (2013) suggests that the level of environmental justice includes not only individual but also community justice, favouring communitarian as opposed to purely liberal individualist approaches to justice. Since the 1991 summit, academics and activists have been refining and expanding the boundaries of environmental justice as a framework, moving from purely distributive justice and environmental racism to participatory and community justice that is multi-scalar in scope.

\subsubsection{Environmental Justice \& Resource Extraction in Canada}

The literature on environmental justice in Canada has largely suggested that there is no environmental justice movement in the country (Haluza-Delay \& Fernhout: 2011) 
or that it is unclear if a movement exists in particular localities such as Toronto (Keil, Ollevier, and Tsang: 2009). What has been confirmed is that various environmental groups, NGOs or community organizations adopt an environmental justice frame. Although an environmental justice movement similar to the scale (local-national) and scope (from community to policy supported grievances) of the U.S. is not a present reality in Canada, my findings indicate that social movement actors challenging Canadian resource extraction utilize the environmental justice frame, and embody these frames in the movement (some use mining justice ${ }^{25}$, for example). The shared frames allow for collaboration, as all actors share an overlapping - if not the same - diagnostic, prognostic and motivational frame. Speaking to the frame adopted by one NGO, Phoenix comments:

But we do very much work from a perspective of solidarity. We consider ourselves part of a social movement, a social justice organization. Our focus is more on the human side - impacts of the industry on - so we're not environmentalists per se, although we certainly are very concerned about the environmental impacts because they have such huge human impacts. We're not conservationists, we're not environmentalists in the narrow sense, but we're concerned with the huge environmental impact of the industry because of the social consequences on local people, who are often extremely marginalized and need the environment in a much different way than we do just to survive. So social justice, human rights, Indigenous rights are major concerns for us and the way we work is also important for us in that it has to be community driven.

This quote is interesting on two levels: (1) its ideas are expressed in similar ways by almost all of the other participants and more importantly, (2) it seems to adopt the social justice frame, but then describes the ways in which the environment is a precondition for justice. Speaking to these two points, Skylar supports Phoenix's framing:

\footnotetext{
${ }^{25}$ I could not find any scholarship that interrogates the use of resource-specific environmental justice frameworks. In the Canadian context, several groups challenging resource extraction projects frame their work as mining justice, often employing the principles of environmental justice within the context of mineral extraction.
} 
Community agency is probably front and center in terms of community consent before any mining activity on their land and at all stages of where there are projects that have gotten underway and that they would have meaningful participation [and] where there are projects already established and such. But then you have complimentary goals which go towards protection of water bodies, protection of important ecologically and culturally sensitive areas - those again determined based on where the communities are coming from, so it always kind of parts from there - and health.

Hunter speaks to the framework adopted by group B, which - like NGO 2 - frames the issue as one of social justice but intimately bound to environmental justice:

I think that ultimately the work that we're trying to do is justice based. We are trying to create spaces where communities can speak out about the injustices that they're seeing... Putting pressure on the Canadian government to respond to some of the human rights abuses that are occurring... whether that's related to ongoing violence against women or sexualized violence... or issues related to the extractive industry which also include environmental justice issues. And I think that a large part of what drives group B is educating Canadians about what is going on and Canada's role in much of that.

The sentiments expressed by Phoenix, Skylar and Hunter are seemingly rooted in human and community based concerns, but in the substance of the interviews and the work described by participants it becomes quite clear that their work is representative of the new iterations of the environmental justice framework. According to Schlosberg (2013: 45-46), this conceptual shift understands that "a working environment is necessary for justice, and that justice entails creating human practices and material flows that do not undermine environmental processes and systems." This means that the environment and nature, as Phoenix mentioned, create the conditions for justice. Not only are the environment and nature mentioned in interviews, but also the importance of community level justice for environmental justice proper. Due to the fact that self-determination (community agency) and accountability as values maintain significant currency in terms 
of establishing action plans and collaboration between groups/NGOs, it appears that these actors embody environmental justice frameworks, effectively:

(1) Understanding the problem as a lack of Canadian accountability in honouring harms committed by the sector, including the consequential hazards (distributive justice) resulting from industry processes (diagnostic framing)

(2) Pressuring state and corporate actors to regulate the industry, including respecting the desires and decision-making (procedural justice) of impacted or potentially impacted communities (prognostic framing) and

(3) Rationalizing action by adopting a justice (including environmental, social, health, gender) vocabulary to mobilize participants (motivational framing).

The Canadian movement challenging resource extraction is one rooted in environmental justice principles and these principles are embodied in the everyday practices and discourses of movement participants.

It is interesting to note that despite operating according to this reconceptualized environmental justice framework, some participants express a conscious understanding that this framework is evolving and needs to continue to evolve. Brook, working for an NGO, shares their thoughts on this when stating that:

I think we're starting to get more people to an understanding of what the real environmental and human costs are of resource extraction... and I think there is still a gap between the environmental justice movement and the climate justice movement. There's been a confluence, but it's not quite happened yet. And I think there's a lot left to do to actually change the structures, so our economic dependency is still massive, we're still all very much dependent on the extractive industries - not just in terms of our daily lives, but in terms of our future - our pension fund and everything all deeply dependent on speculative extractive investment. And that's my next project (laughs). 
The recognition of the lack of confluence between the environmental and climate justice movements ${ }^{26}$ described above is insightful because it re-affirms the need for the movement to "become more embedded in an understanding of the way that environmental conditions provide for individual and community needs and functioning" (Schlosberg 2013: 48). This necessarily entails that the movement - in particular, the NGO actors involved in resource extraction issues beyond those interviewed here - make more of an effort to adopt a critical evaluation of the power structures that guide, influence and value resource extraction processes as opposed to socio-ecological sustainability. This requires that movement actors shift away from what Lesley refers to as a "decontextualized environmentalism". In place of a decontextualized environmentalism predicated on a moral aesthetic in which environmental protection is the ultimate goal, frameworks have to - as Lesley suggests - become more comprehensive. This entails a shift away from the individual approach cited by Schlosberg (2013) to one that takes seriously a humanistic perspective that appreciates the "collective and interdependent nature of things" (Lesley). According to Lesley, this collective approach to environmental justice is necessarily anti-colonial and anticapitalist. As group A practices it, this environmental justice framework:

...Is motivated by a deep love for all of humanity. We recognize that we need the earth - perhaps more than the earth needs us - but, we are in the here and now thinking about the violence and urgency faced by communities we are in solidarity with. Often, these communities have structured their economies in ways

\footnotetext{
${ }^{26}$ The crux of the climate justice movement and framework rests in its attempt to conceptualize the interrelationships between, and address the root causes of, social injustice, ecological destruction, and economic domination perpetrated by the underlying logics of capitalism that has seen industrialized countries reap the benefits of fossil fuel intensive development (Routledge 2011: 385).
} 
that honour and sustain this interdependence with nature and these economies are threatened by the false promises of capitalism and so-called development. We can learn from them, not just because the earth needs better, but also, because we all need to work through decolonization to save one another. And of course, the dichotomy I have just constructed here doesn't really matter - nature/humans - but when you care more about an endangered seal than an Indigenous woman opposing a mine, I am forced to recognize the fragmentation in the environmental movement and be strategic about how I approach the issues affecting us (Lesley).

This passage suggests that the framing of contention matters if it is to be a thread that binds groups and NGOs together. In particular, NGOs (and large environmental NGOs focused on protection/conservation specifically) incapable of articulating issues in a larger framework that considers socio-ecological relationships as central to ecological concerns may not make for adequate allies. As Lesley suggests in this passage above, it is believed that an environmental justice frame should be guided by a project of decolonization that interrogates the power structures (be they economic, political and/or social) that inform the lived realities of impacted communities. Therefore, in order for the environmental justice framework and movement to have strength, it must work not only to challenge the Canadian resource extraction industry, but also engage in a comprehensive critique of capitalism and colonialism as driving forces perpetuating the destruction of environmental conditions - the same conditions necessary for the manifestation of justice in its multiplicity. The shared environmental justice framework of the participants in this study facilitates collaboration as NGOs and grassroots groups engage in similar reflections regarding the need to astutely critique the dominant power structures that shape resource extraction processes. For the framework and the movement to continue to evolve, a space needs to be created for political dialogue and debate in which the contours of justice and strategic action are sharpened. 


\subsection{Conclusion:}

This chapter explored the first thread that binds collaboration: shared values and frames. By adopting self-determination and accountability as primary values, social movement actors operating within this organizational field are able to establish a basis for co-operation. This occurs in spite of a praxis knot that creates ambivalence or tension between and across organizational forms. Tensions arises when values are put into practice, and in the context of this chapter, when institutional forms of advocacy - for example engaging in roundtables or lobbying in support of Bill C-300 - are preferred over public forms of protest or stronger legal regimes. Despite these different strategies in praxis, groups and NGOs critical of these approaches either participate in them or find them to be useful. This suggests that (1) grassroots groups find utility in engaging in institutional advocacy, carefully navigating these strategies to avoid political compromise and (2) studies on NGOization must recognize that NGO structures are not homogenous but heterogeneous, and the pull to institutional advocacy - characteristic of NGOization is not guaranteed but subject to a complex consideration of contextual factors. In terms of framing contention, my findings indicate an overlapping environmental justice framework that is constantly shifting and in flux, but contextualized in the "here and now" (Lesley) concerns of impacted communities and activists for socio-ecological sustainability. The participants in this study believe that socio-ecological sustainability entails that a decolonial environmental justice framework be adopted by actors (in particular by NGOs outside this study). There is a shared belief that this framework centers on the recognition of the destructive role of capitalist and colonial power structures in which resource extraction processes are embedded. Should civil society 
actors at large adopt such a comprehensive framework, it may function to increase collaboration between and across organizational forms. 


\section{Chapter: Strengthening Threads \& Navigating Knots: Resources,}

\section{Goals \& Complimentary Forms of Advocacy}

Three additional threads that bind NGOs and grassroots groups together include sharing or pooling scarce resources, overlapping long-term goals and engaging in complimentary forms of advocacy marked by a diversity of tactics and a division of labour. Although these threads have strengthened collaboration, tensions have also become visible in the form of a capacity knot. The capacity knot identified by participants largely deals with a lack of resources to expand the scope of work and to engage in more coalition work. Another series of knots identified include the institutionalization knot found in the literature (Choudry and Kapoor 2013; Kuttab 2008; Rahman 2006), and the depoliticization knot that is concerned with a lack of activist voices and representations in coalition and institutional spaces. These knots act as a source of tension, but more often than not are minor, without a significant effect on the threads that bind. This chapter explores the three threads that bind and the knots that entangle this movement web.

\subsection{Resources}

Resources have always played an important role in any given social movement industry $^{27}$, and constitute one explanatory variable describing mobilizing capabilities and outcomes. Beyond this, resource flows indicate the patterns of interaction between

\footnotetext{
${ }^{27}$ Social movement industry is a concept introduced by McCarthy and Zald's (1977) inaugural article explicating the conceptual and theoretical terrain of resource mobilization theory. A social movement industry includes all of the organizations and groups "that have as their goal the attainment of the broadest preferences of a social movement" (McCarthy and Zald 1977: 1219).
} 
organizations and groups working within a particular organizational field ${ }^{28}$. As described in Chapter 2, there are various types of resources. In the context of this study, the types of resources that underpin NGO-grassroots interactions and collaboration include the provision or sharing of material (financial), human (time, energy, labour, skill and expertise), cultural ('how to' knowledge, informational knowledge produced for mobilization or goal attainment) resources. Participants not only confirmed the dependence of collaboration and coalition building on resource availability and/or pooling, but also suggested that resources at all levels - NGO or otherwise - were generally in short supply, resulting in tensions between movement actors.

\subsubsection{Resource Flows}

In the movement challenging Canadian resource extraction, resource flows are situated within a dense web of interaction, bypassing a simplistic vertical or horizontal relationship of supply and demand. Although it is true that a majority of material resources flow from top (NGO) to bottom (grassroots groups in Canada and abroad), this characterization obscures the multiple forms and directional flows of resources operating in this movement web. In general, human, cultural and informational resources are not only in limited supply across organizational types, but flow between and across organizational forms. For instance, both NGOs and grassroots groups rely on NGO 2 for its informational resources. When asked whether or not they believe that NGOs make

${ }^{28}$ An organizational field, as defined by Cress and Snow (1996: 1092), constitutes the overlap in interests between different groups or organizations. Furthermore, there is recognition amongst these actors that the activities of any given group or organization is "relevant to those concerns." 
organizing more difficult, Hunter responds by confirming their importance in

informational politics:

(pause) No. I don't think they make it more difficult. I think that they are very fortunate in the sense that they have much more resources, they have people that are staff members and devoted to policy and analysis which creates a wealth of information for grassroots groups to base their own analyses on.

Micah, a member of grassroots group A, confirms the importance of NGO 2 in providing solid research and analysis:

I think we're super strategic about this stuff; if we want access to information and concerted thinking and concerted connections we do a lot of stuff with NGO 2 because they have the staff and the time to like work on things in a concerted way for years, and to put out reports on things, which is awesome (laughs).

According to the experiences of both Hunter and Micah, NGO 2 is an important actor in the movement: staff at NGO 2 provide access for resource-scarce grassroots groups, providing them with links to other actors in the movement, or with the reports and evidence they need for their own activities and claim-making. Access to informational and human resources facilitates collaboration for both group A and B with NGO 2. Another way in which resources (cultural, in this instance) are dispersed across and between groups occurs when NGOs 1 and 2 and group B rely on group A for planning and executing public protests and creative actions/street theatre (cultural resources) that they may or may not participate in. The following sections describe these resource flows, the logic supporting them as well as the capacity knots resulting from resource acquisition and diffusion.

\subsubsection{Resource Sharing \& Pooling: Strengthening Networks and Coalitions}

In my conversations with participants, it became clear that collaboration across and between organizational forms often results from a desire to access particular 
resources that may be non-existent or in short supply for a particular group or

organization. However, and more importantly, it originates from a desire to share or pool resources to broaden mobilization and strengthen networks and coalitions. As mentioned previously, NGOs not only share or pool resources with grassroots groups, but also between NGOs. This becomes apparent in my conversation with Skylar, a paid staff member of an NGO 2:

Max: You mentioned at the beginning of this question skill and capacity. Are there any other resources that you share with these organizations that you work with frequently?

Skylar: Definitely information. Some people have access to different sort of information and relationships than we do, and at different times.

Max: Does your organization usually provide the information?

Skylar: Hmm, it goes both ways because some people sit in on different sorts of meetings for different reasons and we won't. Sometimes resources like money. I mean, NGO Y, union A and others give us money on an annual basis - union B so that's helpful...there's a few different ones.

NGO 2 is a small NGO, not only providing resources to other groups or organizations, but also receiving and relying on resources from other NGOs. When asked whether they believe their organization has been successful in bringing about change to the way the industry and the Canadian state operates to secure resource extraction projects, Phoenix notes:

...I guess some of the things we're seeing we can attribute to our work but it's also become way more complex because we purposefully went out and tried to build a coalition of NGOs that would help us work on [these issues]. So we're trying to spread [NGO 2] out by marshaling the resources of a whole bunch of other NGOs - that way we could have a bigger clout. And we very, [stresses] very consciously did that - those were discussions we've had right within the first few months of our organization. We looked at each other and went, "this is impossible. We can't do this... We need more people so we're going to have to find them". So when you ask what are the successes of [NGO 2] I would say maybe part of the success of [NGO 2] is to have built those types of coalitions, to get more people involved. 
Since the movement challenging Canadian resource extraction is fairly recent and specific to particular natural resources, the human, monetary and informational resources for all groups involved - be they grassroots or NGO - have been scarce. This scarcity has informed the strategy of this particular organization, in that the effectiveness and strength of advocacy appears to rely on the pooling of human, material, cultural and informational resources.

From the grassroots experience, working with NGOs has its benefits, including access to different types of resources. Micah explains this when stating:

I think we work with other groups because they have different types of resources like sometimes they are bringing people over from impacted communities - like they bought them plane tickets and we're like "ok, we can jump on that and collaborate with that".... Or... They have a different audience in [the city]. Sometimes when we partner with [NGO Z] it's been really cool because it means all of these awesome older folks come to events who don't know about us otherwise. Umm.... Yeah.

As Micah notes, the utility of collaborating with NGOs rests with having the material resources to bring representatives of mining-affected communities to Canada as well as to provide group A with opportunities to mobilize a wider audience. Lesley, also a member of group A, further elaborates on the types of resources made available (monetary, human, informational) across and between organizational forms:

NGO 1 has supported us financially. Group B in terms of - we end up pooling our resources if they're bringing someone... then we can jump on that band wagon, which I think matters a lot. In reality it's not just the economic resources though; why would you bring someone and use up their time and energy when you could have a way bigger - or they could have a tour in all of these cities instead of just the one, right? I think in part too it's the same power dynamic as within group A it's like some of these organizations have direct access to community members and have direct relationships with them, so they're the ones who can report back what's going on on the ground and you know, I've had meetings with like NGO 2 people or group B people who are like "Ok, I was just in Guatemala, this is what the situation is". Um, but it can be mutual - like when I was doing research in 
Guatemala, some woman from group B called me and was like "OK, what's the situation there? Who should I be meeting with? Do you have any ideas?" - that type of thing, right? And I could tell her stuff like, you know, "you can meet with this group, I think it's great, but you're probably not going to have many women tell you about their experience. You can meet with these [other] women - you're not going to hear the most graphic stories - but you're going to get a good account of day-to-day stuff."

Here, Lesley explains that although the transfer or pooling of material resources is important, human resources - time, energy, and networks - should be maximized, and information is shared between (horizontally) and across (vertically) organizational types. This is particularly crucial for a movement that is based on building solidarity and accountability with affected communities. Recognizing that different groups have different contacts and networks - and resources in general - indirectly binds NGOs and grassroots groups together. Moving beyond organizational forms to collaborate through the sharing and pooling of resources is a strategic choice actors make to build effective coalitions and networks. Reflecting on this, Casey comments:

Umm, I think, first of all, it's great - the sharing of information, resources... and it's mostly individuals more than anything - basically three individuals in those organizations that share information, share experiences. And also I think due to the real lack of financial [and] human resources it's amazing to have other people to take things on and to work together and share responsibility of, you know, writing a letter, getting (inaudible) complaint, or reading over the blog - you know, things like that it's invaluable to have that support.

In a movement that suffers from a scarcity of resources, pooling and sharing resources works to strengthen inter-organizational ties through networks and/or coalitions that share responsibilities and report on different community partners. As Skylar claims, "the neat thing about a coalition is that there's different organizations that have different relationships." 


\subsection{Capacity Knots: Understanding Tensions and Strains}

While it is certainly true that resource flows shape collaboration, resources can create knots in movement webs. Participants mentioned two primary components of the resource knot: scope of work and human and monetary resources. In terms of the former, both grassroots groups and NGOs suggested that their respective scope of work is limited because of scare resources. In explaining the scope of the work of NGO 2, Skylar underscores the internal tensions that result from a lack of human resources. Skylar stated that the lack of human resources creates a barrier for taking on work that addresses other types of resource extraction, commenting that:

... There's been concern since [NGO 2] has been founded - a lot from the Board and I think amongst the group - that we're too small to take up much more. I think initially there was a bit of concern that even though there are some similarities, the legal framework is different enough that the amount of capacity we would need to actually do a good job wasn't there.

Because NGO 2 is a small NGO with limited human resources, they are unable to expand the scope of their work, despite often revisiting this debate. Grassroots group A shared similar concerns regarding the scope of their work in relation to human resources: "I think it's a big critique that group A gets - that you know - it's not even a critique but it's just that people are like "Oh, well, you know this stuff is happening in the North too?" And it's like "well there's usually four active people in group A at any given point in time”, right? (Lesley). Since group A is predominantly linked to communities in the Global South, and because they value long term and committed partnerships with specific communities, they are unable to expand the scope of their work because of a lack of human resources. This lack of resources at the grassroots level has led to knots in the form of tensions with NGOs. During our conversation on instances in which relationships 
with NGOs have been strained, Lesley notes:

...Well I'm saying - and it would probably vary from person to person - but if people are very aware of what their limits are - but I think a lot of times - I know when I've been most pissed off at NGOs was when they'd be like "Oh, can you do this?" and it's like "No, I can't, that's a huge thing to ask me to do" and it's probably an innocent question or assumption, you know, but it's - It can be really offensive to have no idea what people's constraints are...

In this instance, Lesley is referring to an offer by NGO 2 to provide group A with more contacts in a Latin American country. Although an innocent question, it is perceived to be offensive, lacking any recognition of the scarce human resources available to grassroots groups.

As demonstrated above, the scarcity of human and monetary resources has caused knots in the movement web comprising different organizational forms. In an effort to avoid knots sparked by political misalignment, group B has to constantly engage in a reflexive exercise in which group members determine whether or not a coalition effort is worth the time in the context of already stretched resources. This is particularly important if the coalition does not completely adopt or share the same politics as group B, which can lead to tension. As Casey questions:

...How much energy do you put into a coalition? It's always a question that we look into. Ok, we're part of [this coalition] - how much time do we put into it? Do we lose a week of our own work to go travel? You know what I mean? We have to evaluate all of the time what percentage... of our time...we're willing to dedicate to these organizations when really our hope, in a lot of ways, is that we can more radicalize a lot of the time organizations that hopefully -

Max: Steer them in the right direction? (Laughs)

Casey: Yeah! Pull them to a different thought process, and you know, that might be kind of difficult. Maybe our efforts are better spent somewhere else.

Attempts at collaboration and building coalitions are a difficult process in which group B 
has to navigate a political terrain that is moderate in nature and marked by demands that are, according to Micah of group A, "watered down" to appear more "politically palatable". Due to a scarcity of human resources, whether or not group A or B can positively influence this political terrain and its subsequent strategies shape both groups' decision to collaborate. If there is political misalignment, it is unlikely that collaboration would occur in an effort to avoid the tensions these knots may create.

As reflected in my interviews, another means by which a lack of human and monetary resources has led to tension is in regards to professionalization and the effect that this has on coalition spaces. Micah from group A describes their experience and ambivalent thoughts on this matter when they state that:

... It's been interesting for me personally to be on all these very NGO-y tables, spaces, and meetings.... And very frequently to be the only person who's not paid to do that work and to sort of.... See how tricky that is. Often these are people that I know very well personally, and in some cases I've lived with some of them - I am very well positioned to feel very comfortable in those spaces but there's definitely some moments - whether it's a meeting time thing which they just see as "oh [Micah] is just not free at these times" and I'm like "No, [Micah] is not free at these times because I'm part of a grassroots organization that's not paying me". This is not a singular [Micah] issue - is this group accessible to that? Does it need to be? I don't know.

Coalition spaces have a high concentration of NGO staff. As a result of professionalization, NGO staff can only set meetings that fall within the work week and within working hours. Since group A is volunteer based, it is difficult for its members to participate when they have other obligations, and this lack of accessibility is a source of tension. On the other hand, the same can be said of NGO staff: they may have other responsibilities (child care, for example) outside of their 9-5 hours and on weekends, operating as a constraint on their own availability. In speaking to their experience, Micah is unsure if this requires that coalitions be more sensitive to these issues. However, 
Lesley - also from group A - believes that “... our work just can't be done without NGOs, especially because we have an international scope. I think that's a really clear no." If a successful and effective movement that challenges the Canadian resource extractive regime is desired, then it appears that both NGOs and grassroots groups have to navigate the knots that may serve to impede collaboration. However, as NGOs do have more power in this respect, they are in a position to reflect on the privileges associated with professionalization and in turn be more sensitive to the constraints of grassroots groups. Such reflection, and the ability to be more accessible to grassroots group, may work to strengthen the movement by offering opportunities for greater collaboration, amplifying the concerns and voices of activists from above and below.

\subsection{Overlapping Long Term Goals}

As with many social movement webs, this one is inspired by grievances that in turn shape the articulation of long term goals. Typically, it is understood in the literature (Petras 1997; Jad 2007) that goal setting fluctuates according to organizational type, with grassroots groups articulating immediate (if not radical) goals (i.e. to shut down the tar sands) while NGOs dilute their demands to ensure organizational survival and popular appeal (i.e. slow down tar sands production while introducing green energy). Interestingly, when asked about the goals of each NGO or grassroots groups, there was significant long-term goal overlap amongst actors. The two primary long-term goals that each group and NGO share are: (1) educating publics, and (2) institutional reform. These overlapping goals motivate movement actors to collaborate on events, protests, campaigns, and coalition work in general. Each will be explained in turn, and the implication of the goals will be examined in section 5.4. 


\subsubsection{Educating Publics: Cultivating a Critical Consciousness}

The first goal that NGOs and grassroots groups share is in educating the Canadian and international public(s) on resource extraction issues. This is often the result of speaking tours with impacted community members, writing reports on specific case studies, or even speaking to the press, be it alternative or mainstream. According to Alex, NGO 1 has established three goals, one of which is education and activism. This pillar involves:

...Focusing all of our attention on how Canada and the USA are often part of the problem. So all the groups we fund [and] all the groups we accompany are involved in community defense struggles that are usually related to North-South issues. Mining is an example; economic issues; political issues; military issues. So the third component is educating North Americans to then hopefully get them involved in the work for change in the North.

As Alex notes, the goal of educating publics is not concerned with simply calling out a particular country or industry, but involves understanding the complex web of interactions between multiple states and issues that constitute resource extraction. Expressing this in a slightly different language, Micah explains this goal of group A as one that seeks

To educate the Canadian public hopefully in a way that raises critical consciousness and helps people understand what's the problem, why there is a fundamental problem, why we're not just talking about bad apples - what fundamentally is at stake. Whether that's helping people just sort of understand "ok, there are some Canadian mining companies who are doing bad things" and hopefully working towards a place of also understanding colonization and bigger issues.

Through protest and public education, group A seeks to transform public understanding of resource extraction practices, a transformation that requires interrupting imaginaries of a benevolent Canadian state. This transformation - vis-à-vis the cultivation of a critical consciousness - exposes and accentuates the structural processes and imperial logics that 
drive resource extraction. This includes framing resource extraction - mining in this instance - as an inherently colonial process. Mining as colonization necessarily entails appreciating "what fundamentally is at stake", including the livelihoods, land, natural resources, and economic and political formations of impacted or potentially impacted communities. In an effort to address the problem of Canadian resource extraction, the actors operating in this organizational field seek institutional reform.

\subsubsection{Institutional Reform}

Along with education and activism, all actors have cited institutional reform as a long-term goal. This goal is largely informed by the shared value of accountability. This goal can be achieved by pressuring the Canadian state to create

...better legislation and policies to hold the industry accountable so that the industry has to live up to certain standards wherever it operates in the world and if it doesn't there's actual sanctions and that the industry has to remedy harm it causes and be held responsible for harm that it causes. That means right through closure. So preventing harm through regulation and policies and legislation and then remedying harm when it is caused, but through mechanisms that have teeth, that are regulatory in nature. As part of the remedy part, we are trying to work on getting better access to justice for people that have been harmed either through non-judicial or judicial mechanisms that are effective (Phoenix).

Corporate, and more importantly, state policy must be regulatory in nature and

demonstrate that it has "teeth". Without a strong commitment by the state to monitor and regulate the practices of corporate actors abroad, the harms associated with the industry are bound to continue. Recognizing this, both NGOs and grassroots groups pursue institutional reform that will allow communities harmed by the industry to seek justice, albeit justice confined to the constraints of a liberal capitalist system. Reflecting on the goal of institutional advocacy outlined by group A, Micah sees it as an experiment, ... [as] us dabbling in trying to change...some of the top-down powers, whether that's working to influence the creation of laws, whether that's supporting change 
through the courts - but that would be a grassroots support of - I mean this is the way I see it - a grassroots support of fundamentally not grassroots forces.

Institutional reform is necessary, but as mentioned previously, only offers a partial means of addressing the injustices of Canadian extractivist imperialism. In addition to this, institutional reform is not viewed as a traditional grassroots approach to advocacy because, as Dakota explains in relation to civil society's campaigning for non-citizen access to Canadian courts:

...It's [legislated access to courts by impacted communities] one form of justice but it's not all encompassing and it's so hard for communities to do that. We're trying to take away barriers but I can't imagine how emotionally and financially taxing it [the process of removing barriers and engaging in long-term lawsuits] is - so we don't want to present it as "oh this is the solution". And the same with whatever the legal reform will be. It's probably some kind of incremental thing, and I don't fault the other groups for doing that, because if you're working with the government to try and make these changes, that's what you have to do. But I think those of us in the group - I think a lot of us in the group - have a more radical kind of, I don't know, our political views are not really for any of the parties so it's kind of hard for us to get on board.

Engaging in institutional advocacy, as an exercise of political governance, involves making compromises. Due to this requirement, and the ideological distance between group A and political party beliefs, values and interests, it is difficult for grassroots groups to primarily engage in this avenue for change, which leads to the knots and entanglements explored in the final section of this chapter. Recognizing this, the grassroots group activists interviewed expressed support and the will to collaborate on campaigns seeking institutional reform. However, they navigate institutional avenues with caution, as such goals are believed to be, according to Micah, fundamentally a nongrassroots cause and too politically compromising. Of course, this is not to say that all NGOs favour institutional mechanisms for social change. In Chapter 4, I highlighted the historical tensions between NGO 1 and NGO 2 in regards to Bill C-300 and the 
contemporary tension and ambivalent feelings Alex of NGO 1 expresses towards the campaigns to reinvent the Ombudsperson Office. In light of this, and as explained below, NGOs and grassroots actors navigate this complexity by evaluating which approach to change (institutional or public forms of advocacy) to engage in to meet established goals based on perceived strengths that facilitate a division of labour and a diversity of tactics.

\subsection{Complimentary Forms of Advocacy: Diversity of Tactics \& Division of Labour}

As will be demonstrated below, navigating the terrain of contentious politics is marked by complexity. It involves the active and conscious deliberation amongst actors of the particular mode of advocacy with which they wish to engage, and this is often the result of a reflexive evaluation of skills, abilities and strengths as well as the political climate in which advocacy would occur. According to Skylar, this also entails the recognition "that mining issues are complex and have different facets and so communities need different things at different times."

Due to the complexity of resource extraction processes, which involve a multiplicity of actors (state, corporate, community groups, NGOs, etc) operating at multiple scales (provincial, regional, national and international) with various consequences (social, environmental, health, etc.) both NGOs and grassroots groups understand that contentious politics require diverse strategies. Explaining this sentiment, Lesley (who has experience in health care) from group A comments:

...This issue can be attacked from all these different avenues [and it] made me realize how much of it was kind of symbolic of kind of like, you know.... capitalism, or the world order... the way things are... But I think what really kind of attracted me to get involved was that I saw a place for myself in it because a lot of people were talking about health issues, but there weren't any health researchers or advocates, or allies. They were just people who were like "we know we are sick, but we can't prove it", or "we know we are sick, but no one can help us get better". Right? So I thought "Ok, here is a place where I can actually 
use my supposed professional skills to actually help the movement in a constructive way."

Speaking to the complexity of both resource extraction process and the differential effects it produces, as well as "the way things are" in modernity, Lesley recognizes the need for a movement in which various avenues for change are explored based on the skills and resources available to individuals and/or groups. Echoing this line of reasoning, Skylar from NGO 2 believes that,

... there is room for different kinds of actors in a movement like this, which requires a whole range of people, and a whole range of organizations with different skills and abilities. But I think [NGO 2]... dedicated a lot of resources... to try and make itself a credible voice within a really colonial-conservativecapitalist sector that's just very powerful (both laugh). And part of that has been engaging in lots of multi-stakeholder meetings with a certain technical capacity [that] makes us sound a bit more academic and stuff at times...

As both these excerpts demonstrate, participants recognize that advocacy and strategies for social change vary according to individual or organizational/group access to resources. This helps avoid what Dixon (2014: 113) refers to as the fetishization of tactics, a predicament for movements when "activists come to think that any particular tactic or bundle of tactics should be use in any and all situations regardless of the circumstances." The fetishization of tactics removes social action from its context, and results in an excessive focus "on debating the validity of certain tactics" as opposed to considering how tactics fit within particular goals (Dixon 2014: 113). In an effort to avoid this, NGOs and grassroots groups included in this study accept and welcome a diversity of tactics. This diversity of tactics and corresponding division of labour is informed by the accumulation of specific resources and the perceived strengths of a particular group or NGO.

\subsubsection{From Each According to Their Strength, To Each According to Their Need}


Both NGO and grassroots groups are cognizant of their strengths, limitations, and roles in the movement challenging Canadian resource extraction projects. This division of labour is implicitly known and understood in the context of coalition spaces. During my interview with Dakota, we were discussing the different types of strategies and forms of advocacy found within coalition spaces. In one of the coalitions that Group A is part of, there is a desire to build up capacity and political party support of coalition demands in light of the October 2015 Canadian federal. At one point, I interrupted Dakota:

Max: But you mentioned that that wasn't necessarily a priority. Is that something that comes out of the coalition?

Dakota: That's more for the [coalition]; that's where the discussion is happening. Some of the larger organizations within it - like [organization W] - they're a big part of that. We don't work directly... I think that's more of a role for them because they want to do outreach with the leadership of the Liberals and the New Democratic Party to get them to make it part of their platform. It's not something that group A would [do]... It's just not even our strength. It's not that we're necessarily opposed; it's just not... We haven't really been talking about the election, no.

In this section of the interview, Dakota admits that institutional advocacy and lobbying politicians is not a strength of their group, nor is it a role for group A to fill. Despite it not being a strength or a primary means by which the group would want to advocate for change, it is something that they support and are not "necessarily opposed" to. Having identified that this form of advocacy is not the strength of group A, Dakota speaks to the process involved in identifying strengths:

And what group A does - I mean, that's probably why we have our visioning every year - how can we best use our resources to meet our goals? But part of that's always going to be with a mind towards what our resources are and what our strengths are. It's not necessarily that this is the best way of doing something, but it's the best way for us to do it. And maybe other groups have a better way for themselves. I don't know if you can say that one form of political advocacy is more or less effective than street theatre or something. It has a different reach... 
In this instance, Dakota underscores the importance of engaging in a reflexive exercise that evaluates group successes/areas for improvement in terms of developing strategy as well as the resources at hand to achieve stated goals. Realizing that group A's resources cultural, material, human etc. - are not conducive to institutional advocacy, the group prefers to channel their resources into activities that demonstrate their strengths: organizing protests, creative actions ("street theatre"), and public educational events. Dakota admits that engaging in public advocacy is not necessarily nobler than institutional advocacy: it is just the best tactic for group A to reach their goals.

Some of the members of Group B share a similar perspective regarding organizational strengths while framing it in a lexicon of differing roles, or a division of labour. In discussing the nature of solidarity work, Hunter claims:

What we've learned about solidarity work and coalition work is that everyone does their piece - everyone has their role. Group B is - one of the strongest things that we bring to [coalitions]... is the fact that we're in Guatemala. We're connected to people directly. And we have insight that groups like even NGO 2 don't have because they're not there on a long-term basis... And that's the piece that we provide.

Members of NGO 2 share this perspective, both understanding their role in coalition spaces as well as their reliance on both larger NGOs and grassroots groups in contributing their piece. On the reliance of NGO 2 on larger NGOs in helping facilitate their own partner organization's wishes to engage with Canadian politicians, Skylar states:

...I actually don't think that's our best strength in part because when it comes to the government itself we've got such an antagonistic relationship it's not really that helpful (both laugh). And we don't pretend that it is. I mean, that's where you'd want [large NGO X], and that's why we would try to keep the door open with groups like that because they can do things we actually can't do.

Although NGO 2 cannot facilitate access to government officials because of an 
antagonistic relationship, their strength - like group B - is in the direct contact they

have with particular communities:

We've done a lot of the research and we'll bring specific cases - the fact that we have relationships and have followed the case around Excellon, or around Marlin, and have participated in those complaint processes in Papua New Guinea [or] Tanzania - that stuff becomes the arguments for what we need.

Each organization contributes to the movement challenging Canadian resource extraction based on their strength, and relies on the resources and strengths of their coalition partners to fill needs that they themselves cannot meet. In explaining this dynamic, and establishing collaboration with the grassroots, Phoenix, from an NGO perspective, explains:

So we want to at least reach out to them and say, "if you want to join, that will be great" because it would actually be really useful to have the grassroots groups be part of this coalition because they work at a different level and they work in different ways and there is stuff they do that we can't do, that we just don't have time to do.

Max: So more of the public forms of advocacy?

Phoenix: Mhm! Yeah, and being able to just throw up a protest or something, you know? We just don't have the resources in house to do that kind of stuff -

Max: It's like a division of labour.

Phoenix: It's like a division of labour, but the problem is that some of it is paid and some of it is not. And that's really really tough. So we try to find ways to support that either by being there, or writing texts, or financially to the extent that we can. If people need to be brought in, how can we find resources to do that? So we try to see how we can support this without a) taking it over which is not the intention, nor could we do it - we don't have the capacity and b) without exacerbating those tensions around resources.

In this excerpt, it becomes clear that NGOs rely on grassroots groups to fill a void that cannot be filled by any NGO because their strengths and resources and organizational structure inform tactics that are predicated on institutional forms of advocacy. Seeking to 
compliment this advocacy, the NGOs in this study are attempting to reach out to grassroots groups to fulfill the need for public forms of advocacy. Together, NGOs and grassroots groups engage in a diversity of tactics to strengthen the movement.

As described above, both NGOs and grassroots groups are conscious of what their respective strengths and weaknesses are. This awareness influences collaboration, with actors assuming particular roles (an assumed division of labour) that employ diverse tactics. Lesley explains this when stating that

...You need diverse strategies: you need the person trying to get the church to divest and you need the person who is, you know, going to live with the community and take photos for a couple of months, and you need the person who speaks the technical side of things, the person who is going to lobby the government... I guess the problem is so intertwined with how the state of Canada works, you know, that it just doesn't make sense, I think, to... to only champion one strategy, you know?

Once again, Lesley links the necessity for movement actors to assume different tactics to the complexity of existing structural formations; in this case, the state apparatus. It is because the drive for natural resource extraction flows through various state departments (DFATD, Natural Resources Canada, Environment Canada, Export Development Canada) that movements need to attack this destructive industry at multiple sites. When asked whether they thought that working with NGOs is an advantage, Hunter responded:

It's absolutely an advantage. I do not want to spend time, and I don't think group $\mathrm{B}$ has the resources to spend time, on the legal strategies. We can accompany the legal cases in Guatemala, and we can accompany a witness who comes up and gets held in an Immigration Detention Centre when they arrive. You know, we can do things like that because we're here so we can support those processes. But we don't necessarily - that's not our main priority. But we definitely - diversity of tactics is brilliant.

Here, the human resources (expertise) in legal structures (and taking companies to court) 
is a tactic reserved for NGOs, while the grassroots actors can accompany and support human rights defenders, or, as Micah describes, utilize their cultural resources (knowhow) to engage in more militant forms of protest:

I think we fill a particular niche. I don't think any other group in [this city] is doing what we're doing. I think one thing we do is like - we're relatively unpredictable. I think we keep mining companies a bit more on their toes. I don't think our approach is actually better or more important than any other approach. If NGO 2 didn't exist I would say "Oh my god there's a real need for a group that does serious research and really analyzes the situation like a think-tank". But NGO 2 does exist so I'm like ok, "what we need is a group that actually is a group of activists and takes some type of direct action and does things in a less predictable way". I think we would be more effective if we had a bigger capacity, if we were able to respond more often and quicker when many things happen. But I think our model is good - we're limited by scale.

Considering that institutional advocacy is already the strength of NGO 2, group A prefers to engage in public advocacy in an effort to compliment existing strategies. By filling this niche, group A exerts pressure at different sites of the extractive regime.

\subsection{Linking Knots: Depoliticization and Institutionalization}

Although it is true that participants spent most of the interview discussing the multiple ways in which they cooperate across organizational forms, this should not obscure the knots and resulting tensions expressed by both NGOs and grassroots groups. In my interviews, I found that knots exist at two main levels, moving from the manageable to the increasingly dangerous: (1) between small NGOs and grassroots groups or (2) between large NGOs (especially those engaging in public-private partnerships) and small NGOs and grassroots groups. These knots either temporarily strain relationships at best, or at worst, result in a refusal to collaborate. The knots identified by participants are linked, including the institutionalization knot and the depoliticization knot. The institutionalization knot represents a preference for institutional 
forms of advocacy and strategies for enacting social change. The depoliticization knot is associated with a weakening "activist voice" - to borrow Lesley's terminology - and results in NGOs that are understood to be politically compromised by both sets of actors. In explaining the difficulty of collaborating with large NGOs in general, Dakota states: ...I imagine larger NGOs wouldn't have a place for [group A]. [NGO X] gave us money for the film screening in the fall, and they've done work around mining and Indigenous rights, but they're so - with [NGO X] it's such a huge organization that they have to be so - I'm sure every single sentence that is put out has been checked by like ten people. So when they do work with other people it's very regimented - this is our material, you cannot change them in any way, and so it's very - it's hard to collaborate... Whereas with some of these smaller NGOs there's more collaboration because there's less - I don't know. The have more flexibility.

Institutionalization can cause large NGOs to be more regimented and inflexible, creating a knot that impedes the exploration of creative alternatives or approaches to contention. Even if grassroots groups will work with larger NGOs to promote and/or organize joint film screenings, the inflexibility of large NGOs merits minimal collaboration. The inverse is also true: the flexibility of small NGOs like NGO 1 and NGO 2 facilitates collaboration. Due to the heightened level of institutionalization of larger NGOs, a political or activist voice is exchanged for credibility, and this may take multiple forms. One form is in the involvement of opposing groups and companies in public debates. In my discussion exploring depoliticization knots between organizational forms with Dakota, they suggested that group A would not work with "credible" NGOs that have a weak or absent activist voice because it is too politically compromising. As Dakota explains,

It's the way they want to present it. It's always like "let's listen to both sides and we'll weigh them evenly". And it's not fair because the companies already have so much voice and so much power that I don't agree with these debates - I mean, it's going to happen. But we wouldn't work with them in a greater capacity. It's just too potentially compromising - in terms of the way people perceive us, the 
messaging we have.

When large NGOs engage in partnerships with industry representatives, their individual voice becomes muted. This unwillingness to challenge the power of the industry has led group A, group B, NGO 1 and NGO 2 to refrain from collaborating with NGOs that are engaging with industry representatives as it potentially compromises the credibility these groups and organizations have with their constituents and allies. In doing so, the grassroots groups - but more importantly - NGOs in this study avoid the pitfalls associated with NGOization. First, they have a tendency to avoid the total depoliticization (political compromise) associated with larger NGOs by maintaining an activist voice. Second, they manage to maintain downward (community) accountability as opposed to upward (donor driven) accountability, indicating that institutionalization for small NGOs has not resulted in a shift in goals or strategies. On the contrary, engaging in institutional advocacy alongside industry representatives results in weakened demands. In discussing their perspective on these types of partnerships, Skylar from NGO 2 has many insights to make:

I think that just because you can engage in a dialogue, doesn't mean you should when you can anticipate [that] the aim of the government and the state is to weaken your demands... I think there's people that say, if we were ultimately going to get the government to adopt things we would have to at some point enter into a dialogue with the government and the industry to get somewhere. I don't know if that's always the way to do it. But I think if you lose sight of what you're fighting for and you start to weaken things and focus on the weaker demands because that's what you've arrived at a consensus for, then the state and the industry win on some level. So I do [think] there's a lot of jeopardy in engaging in that. And I think you can have inside and outside strategies around some of this stuff sometimes, but you gotta be - I think it's fraught with issues. I find it's in some ways hard to judge because I don't know what it was like earlier in this organization when nobody was talking about mining and you're trying to build credibility and part of how you do that is by being able to engage in different spaces. I mean, one thing [NGO 2] through the years has been clear about [is] not engaging in industry driven spaces - they always have some state involvement 
with the idea that it's about public policy change not about industry voluntarily doing something. But I think there's a lot of jeopardy in those processes and I do think that NGOs [in general] are a bit more inclined because they've got the time and the resources and the inclination to jump on some of those things, thinking - I think naively (laughs) - that they can be an opportunity.

By engaging in spaces in which industry and state representatives are present, NGOs may weaken their demands (Africa 2013; Britton 2006; Gill 1997; Kuttab 2008; Petras and Veltmeyer 2011). This effectively serves to minimize activist voices in an effort to achieve some traction in bringing about changes to industry operations. As noted by Skylar, the effectiveness of this strategy is highly questionable, as it legitimizes and recognizes the power of the industry. This does not mean that NGOs should abandon insider strategies (institutional forms of advocacy), but that they should not weaken their activist voice to appeal to the interests of capital. In order to effectively challenge Canadian resource extraction, the movement actors are convinced that a strategy involving industry representatives tips the scales of power in their favour, adopting an approach from above as opposed to below.

In the current political climate, activist voices are predominantly originating from the grassroots or smaller NGOs that amplify the voices of impacted communities. As expressed above, larger NGOs have been coopted into the dominant neoliberal framework of public-private partnerships. In order to combat depoliticized voices and weakened demands, small NGOs and grassroots groups have to amplify their activist voices. In discussing their organization, Skylar claims

... we have a lot of liberty with what we say. We are not worried about criticizing the government, and we don't limit ourselves very much in terms of taking a strong stand. And taking a strong stand with our partners. That said, one of our 
principles in terms of how we work and the work we try to do is very much from a solidarity framework. And try to ensure that that is front and center in terms of the decisions and priorities we're setting. And how we work and how we really prioritize mining-affected communities and where they're coming from, the risks they're facing, and the demands that they are making to make sure that what we're doing is in line with them.

Amplifying activist voices entails a rooted form of solidarity in which NGOs (in this instance) operate as vessels for community concerns from below. This is often presented in contrast to the lack of activist voice utilized by larger NGOs whose relationships with communities are thought to be weak or non-existent. Despite amplifying activist voices, small NGOs still need to exercise caution. As Phoenix from NGO 2 suggests,

We're comfortable calling out the media; we're comfortable calling out the socalled socially responsible investment industry and all those other groups. A lot of groups are not comfortable doing that "oh it's not polite". It's like no; they need to be called out. And we're also comfortable doing quite hard-hitting press releases and quite hard hitting on the companies. Where there's differences, for example, is that we're really conscious of how we need to do these things. We're very careful to do these things so that we can keep doing them and not get sued, right? And it's so easy to get sued. Most people are amazed we've been here for [over a decade] and - well, we've had a couple of close calls - but we haven't actually had to defend ourselves legally (stresses) yet. So that's where we may have differences [with the grassroots]. We have to be a lot more careful - we can't just put out a press release without someone having read it here. There has to be two eyes on it. And we've talked to enough lawyers that we know how we need to word things, right?

The potential threat of a lawsuit requires that small NGOs take extra caution when amplifying activist voices. Practically, this means that small NGOs have to edit - but not censor - "hard hitting press releases" to ensure that they can continue public criticism of Canadian resource extraction. In spite of this precautionary approach, the activist voice expressed within the constraints of institutionalization does not inhibit collaboration with grassroots groups. Nonetheless, it is understood that this tension vis-à-vis voice positions grassroots actors as desirable and authentic subjects for cultivating activist voices as they 
"are making the connections really well between colonialism at home and Canadian imperialism abroad and provide those spaces for ongoing political and public education, political action... With constraints in terms of how much time and how much people stick around" (Skylar). Grassroots groups in this study also believe that they are well positioned to offer critical perspectives, even suggesting that the lack of representation of activist voices in coalitions can lead to some tensions. During my interview with Micah, they suggested that group A likes to call for what they want, and believe that

... People in general vastly prefer when we can actually have a message that really represents how we feel - one that hasn't been watered down or [made] politically palatable where we can just be like (starts laughing) "This is the fucking problem!" This is the actual issue, we're not going to sugar coat it....

Even though small NGOs contain activist voices, their institutionalization can sometimes preclude a more "authentic" representation of activist voices that recognizes the root of many resource extraction projects: a colonial mode of operation, which Micah was referring to in the quote above. The lack of this authentic form of representation of activist voices can lead to some tension, with grassroots groups cautiously navigating coalition spaces.

\subsection{Conclusion:}

The threads of resources, overlapping goals and complimentary forms of advocacy bind grassroots groups and NGOs together. Both sets of actors included in this study have to navigate the knots often associated with NGOization - institutionalization and depoliticization. As a result of the institutionalization knot, professionalization affects internal coalition dynamics, as NGO personnel have limited availability, not considering the concerns of volunteers within grassroots groups. The negative impacts of institutionalization are made evident when larger NGOs engage in institutional spaces 
with industry representatives, wherein activist voices are muted or non-existent. Larger NGOs employing this strategy create tensions within coalition spaces, and frequently result in both the NGOs and grassroots groups in this study refraining from working with these groups, suggesting that they are too politically compromised, engaging in - as opposed to struggling against - hegemonic power relationships characteristic of NGOized movements (Choudry and Shragge 2011; Stavrianakis 2012). However, because the knots between the small NGOs and grassroots groups I studied are minimal, the elements associated with NGOization are not significant. Consequently, this suggests that studies on NGOization need to pay more attention to the types of NGOs and the heterogeneous nature of NGOs operating in civil society in order to effectively grapple with the essence of NGO-grassroots relationships. As explained in this chapter, both small NGOs and grassroots groups cautiously navigate coalitions and networks to ensure that activist voices are echoed from below. The next chapter explores this commitment to a rooted and grounded form of solidarity. 


\section{Chapter: Rooted and Grounded Solidarity}

The final thread that binds grassroots groups and small NGOs in webs of mutual collaboration is a rooted and grounded form of solidarity. A rooted solidarity is embodied and practiced when it is predicated on a participatory methodology and meets two requirements: it is engaged in community driven advocacy and premised on establishing long-term relationships with communities. In practicing this form of solidarity, groups and NGOs are able to establish trust with one another and the communities they represent, facilitating collaboration at both levels. As will be discussed in the final section, significant tensions are not a concern between small NGOs and grassroots groups. However, tensions are evident between large NGOs and small NGOs and grassroots groups, often because of a rootlessness knot wherein the former is perceived to have weak or non-existent roots to mining-affected communities.

\subsection{Rooted Solidarity: Bridging the Local and the Global}

In order for the movement challenging Canadian resource extraction projects to be effective, it is crucial for activists and NGO advocates in the Global North to amplify the voices, experiences, and concerns expressed by communities confronted by this extractivist model of development. This requires that movement actors establish and expand durable relationships with impacted communities, which can also function as a means of connecting groups to struggles they are not rooted in. Although the nature of the relationships is different ${ }^{29}$, all of the NGOs and grassroots groups in this study have

${ }^{29}$ One NGO has a funding relationship, in which they provide direct community support through the provision of financial resources. Another NGO provides financial as well as technical resources. The grassroots groups provide some financial resources, but mostly assist in planning protests, creative actions, and accompaniment. 
strong and durable relationships with the communities with which they engage ${ }^{30}$. Intergroup collaboration in Canada occurs either if groups have established the same relationships with communities, or by facilitating the access of other groups to communities through dense networks or coalition spaces. Solidarity work has been described by participants as engaging in participatory (community driven) methodologies predicated on long-term relationships in which strategy formation is a collaborative process. The value placed on long-term and committed community relationships is a prerequisite for North-North collaboration, often resulting in coalition building to either gain access to community relationships and grounded information regarding current resistance struggles or to strengthen overlapping community ties. As will be discussed below, running through all the interviews is a commitment to what Brook refers to as a participatory methodology. Speaking about their organization in particular, Brook comments:

If we're committed to participatory methodology - to really going back to community voices on any issue, making that into a real concrete part of our work - then that also has to be part of other projects that we're involved in. So we're not getting dragged off to sort of... third party discussions that don't reflect, or can wander away from, the actual needs and demands and mandate from people that are living with the situation.

In this context, in order to do solidarity properly, one must always be rooted to particular communities. This rootedness ensures that there is a direct link between community concerns and demands and consequently, the type of advocacy engaged in by movement

\footnotetext{
${ }^{30}$ The frequency of dialogue between northern groups and NGOs and communities affected by resource extraction projects (including local groups and NGOs resisting projects alongside community members) varies. NGO 1, NGO 2 and grassroots group B maintain constant contact with its partners in Latin America. Grassroots group A maintains contact sporadically, with active communication reserved for periods of heightened protest activity.
} 
actors in the North. Otherwise, as Brook notes, NGOs can engage in "third party discussions" that are detached from community concerns. As mentioned in the previous chapter, this form of advocacy is characteristic of the large NGOs that engage with industry representatives and the state in public-private partnerships, which are fundamentally top-down in nature. For NGOs or grassroots groups to engage in a participatory methodology that seeks change from below, they must be community driven and embedded in long-term and committed relationships.

\subsubsection{Requirement 1: Community Driven Advocacy}

Effective solidarity work requires establishing strong and durable community relationships. Effective solidarity work also necessitates that communities are able to voice their concerns themselves in the national and international arena, or transmit their voices through the work of grassroots groups or NGOs who have visited and witnessed the harms produced by extractivist imperialism. Phoenix, from one of the small NGOs, explains this when they state that:

...We do work on the ground with individual communities and then we do the policy, regulatory work and the international work which is working with international bodies like the World Bank, the UN - anyone who seems like they might have some leverage, or some clout, we try to work at those levels. We work nationally and internationally, but what we do is we - we're first of all grounded in the on-the-ground research, the on-the-ground work we do with communities - the support and solidarity work - but then that allows us to have an authoritative voice in those other realms so that when we speak at the national level, the regulatory level, or internationally, that we can bring those stories and those realities that we've personally experienced. As much as possible, and as much as resources allow, we bring people from the communities we work with to those other levels. So we're always trying to get people here so that we can put them in front of MPs, in front of civil servants, get them to do media work, really rub Canadians and the Canadian government's face in to the realities by the people speaking for themselves. There's no voice as effective as the voice of a person that's directly affected. We couldn't write scripts that are as effective as what people say.

As a member of an NGO, Phoenix and their colleagues adopt an activist voice to either 
retell their encounters with the harms associated with the sector to international bodies or, if resources allow, bring affected communities to Canada so that they can provide powerful and authoritative testimonials. In a similar manner, Micah tells of their group's close personal connections to communities and the subsequent importance of being rooted (or to adopt Phoenix and Micah's language - grounded) in an effort to more authentically represent the voices of members of affected community:

I think we focus on where we have personal connections, so it's very fluid and depends on who's in the group. I also think that's one of our strengths - we generally will do work around a particular mine or particular company because we have specific close relationships with people who are impacted, which means we are grounded in that. And it means that we don't say we're speaking on behalf of Chileans, but that we are speaking on behalf of this community because we spoke this month with this particular person.

This sense of strong ties with a particular community ${ }^{31}$ shapes the messaging of both institutional and public forms of advocacy. Speaking to group A's protests at Annual General Meetings (AGM), Dakota states that:

...Certainly, for AGM season, we only go to AGMs of companies where we have had contact with communities that are opposing the companies. Or where a similar group in another country has asked us to attend it and so we try to get in touch with those communities for the AGM to find out what kind of message they want sent, where they're at - and a lot of it depends on people's personal connections. Micah has strong ties to some of the communities in Guatemala... so [they] have a lot of messages and interviews from them.

Both small NGOs and grassroots groups believe that effective solidarity requires a community driven approach in which the voices of impacted communities are brought to Canadian publics, institutions, and political actors. As a result of this participatory

${ }^{31}$ It is not uncommon for communities to be divided on the question of whether or not to allow (if given the chance to) a resource extraction project to commence. The grassroots groups interviewed in this study appear to have ties with those communities whose majority has voted no to a particular project. 
methodology, priorities are not pre-set, but - as Skylar explains - are "set in tandem with whatever the demands and the lead we're getting from folks on the ground in different places." If organizations or groups do not adopt a participatory methodology, it makes it difficult for the participants in this study to collaborate in coalitions or on specific campaigns. Speaking for group B, Hunter explains that this lack of rootedness "makes us wonder how they make their decisions, whose voices they're representing, what kind of collaborative approach came into the construction of their strategy." As will be discussed in the final section of this chapter, a lack of rooted solidarity results not in tensions between small NGOs and grassroots groups, but between large NGOs and the small NGOs and grassroots groups included in this study.

\subsubsection{Requirement 2: Establishing Long-Term Relationships}

A grounded or rooted solidarity must not only ensure that contentious politics are community driven, but it must also stem from the establishment of long-term and committed relationships with particular communities. While reflecting on what constitutes good solidarity in practice, Skylar notes, “...you can't do solidarity unless you have good relationships, and you've got to have a commitment over the long term." All of the participants spoke to the importance of long-term relationships in challenging the resource extraction sector as well as in building North-North collaboration. In our discussion on solidarity, Casey comments:

Group B has been working in Guatemala for [many years] and the relationships we started, we still have. That's been a huge asset - or something to be really proud of. It's not an organization that's like "oh we met you yesterday, we're friends and we want to learn about mining and then tomorrow something else is interesting so we're going to go over there" you know? So those relationships with different men and women and organizations have really stood through the test of time... 
Long-term relationships are important for various reasons. One reason, which Casey identifies indirectly, is that it begins to build trust between impacted communities and the grassroots group or organization from the North. If communities are to divert their energy from local resistance movements by scaling up contention, they must learn to trust that Northern groups or NGOs are seriously committed to a particular struggle. In describing the issues of trust, Casey recalls her entry into a particular community in Guatemala. Casey was new to the group, and an inactive member of group B provided Casey with community contacts surrounding the Marlin Mine. Casey describes this experience below:

Some of those contacts in the Marlin mine were lost because to develop trust in Guatemala, and I think a lot of places I'm sure, but at least the context I know in Guatemala, it's really hard. First of all, a lot of people come in, are interested for a moment, and then leave and you never hear from them again. Also, you never know... [speaking of herself] this young white woman - maybe she could work for the mine? Why would I trust her? You need to take time to build those relationships and usually you need a good foot in the door - somebody to introduce you - and some of that has been lost. That's what I've been thinking about a lot lately - how do you maintain those relationships even if it's not the same actual person doing it? Because it's all about trust. It's all about trust and respect... and also consistency.

As Casey claims, trust, consistency, and respect are important for establishing long-term relationships with impacted communities. Establishing and cultivating long term relationships with mining-affected communities requires that both grassroots groups and NGOs carefully select partnerships with communities based on an evaluation of the human resources they have available in an effort to maintain support and commitment. Although this may result in fewer relationships in the case of grassroots groups in particular, it allows them to strategize with impacted communities across time and space. 


\subsubsection{Collaborating with Communities: Engaging in Strategy Formation}

In a previous section I had mentioned that grounded solidarity requires

community driven advocacy. Despite this being the case for this movement, local

communities often involve NGOs and grassroots groups in deciding on a particular

strategy at the local and international level. Alex expands on this process:

Everything is just one on-going process. My understanding is that they're not local issues that they are suffering from. So part of the trick is to go, "What is the part of the local issue - what's happened on the ground in that mining affected community?" Whatever it is, they decide what they should do about it and what they can do about it. Because we're friends we always brainstorm, but they decide what they do there. But they don't decide what I do in Canada because that's my part of the problem. I don't ask them for permission to go with group A and protest in front of the shareholders meeting because that's my responsibility that's a Canadian responsibility. They don't have to give the lead on that. They're the leaders in local and national issues in Guatemala because that's where they are, that's who they are and they work with local groups and national groups. I know these people - we all sit around like this and chat - so we all know we're on the same page. But in terms of taking the lead, I don't take the lead from them on what I might do in Canada or the United States because that's my responsibility.

As a result of its long-term relationship with particular communities and their organizations and groups, Alex is able to brainstorm strategies that will assist in bringing forward some semblance of justice at the local or national level. In this excerpt, Alex suggests that they do not take the lead - or require permission - from communities for the work they do in the North, including participating or helping plan a protest. However, when discussing the lawsuits against HudBay, the inverse seems to be true:

But technically, the folks in Guatemala had no clue this was remotely an option and it hasn't been in Canada for all the wrong reasons - so we come to the table with an option and then the relationship built very slowly. So that's how that happened.

In this case, Alex - alongside other actors - proposed a legal strategy to challenge HudBay in Canadian courts, with the community accepting this proposal. Based on this 
experience, NGO 1 does (to some extent) take the lead from impacted communities, which involves sharing informational resources gathered, in this case, from lawyers in Canada. Group B recognizes this form of collaboration, in which information is shared, strategies are formed, and decisions regarding at which scale (national, international) strategies will be implemented are deliberated. This becomes evident in my conversation with Hunter:

We try to make all of our decisions based on what Guatemalan groups are asking for. I think, though, that because we've also been working with these groups for such a long time we've also developed a relationship with them that we're able to share information about what's going on in Canada and the context here that can help inform those decisions. So we do not take this -

Max: It's not a one-way thing?

Hunter: We don't make an assumption that Guatemalans know everything about their situation and they're just going to guide our actions because there's a transnational component about this that you can't ignore. And there is a responsibility to share what we know here about how that world is with the decision makers in Guatemala. And then it's up to them to decide and we respect their decision based on that.

The movement critical of Canadian extractivism is transnational, linking actors to communities in different places. This relation to place provides an opportunity for grassroots groups and small NGOs to assist impacted communities in shaping strategy by sharing their experiences and informational resources. As Skylar remarks, the purpose of this is "to come up with different strategies... in ways of building solidarity." Building and engaging in solidarity occurs not only in North-South alliances, but also in instances of North-North collaboration.

\subsubsection{Threads that bind North-North Collaboration}

Movement actors understand that effective solidarity begins when grievances are rooted in the lived experiences of communities. Consequently, connection to specific 
communities shapes the decision to collaborate. As Skylar reflects on collaboration with both Northern and Southern groups or organizations: "I think in terms of when I judge what networks I try to build solidarity with in different countries, I try to look for ones that have working relationships or who are leaders of the directly affected communities." For Alex, collaboration occurs from a similar diagnostic frame as well as when groups or organizations work in the same communities:

This is what I understand the work to be: we need to change the North. So that's our message - we get it out, over and over. And as years go by, you realize "oh, so and so agrees with me. Oh, they happen to be working in Guatemala and Honduras. Let's see if there's room for collaboration". So you're looking for a likeminded understanding of the issue, and then an overlap on specific struggles. When you come across NGO 2 - they work on mining companies around the world, but there's a little bit of overlap in Guatemala and Honduras.

Micah, a member of grassroots group A, expands on the rationale for collaborating with small NGOs, indicating not only that smaller NGOs are typically more accountable to communities, but also highlights the strategic motivation to work with them:

Umm.... I think if we want to be part of a bigger national impact then it makes sense to work with other groups, especially with other groups who have a larger capacity or a larger membership or national influence or have access to MPs or have access to press releases that people will read (laughs)... And I think sometimes we realize that we are working with the exact same people in impacted communities. That was our thing with [large NGO Z], actually - just to realize that we are both supporting and have personal relationships with the same people so we should obviously be working together to be better accountable to them.

By collaborating, NGOs and grassroots groups can increase the capacity and influence of the movement domestically. In addition, working with NGOs allows the movement in the North to be more accountable to their partner organizations, groups, or communities in the South. However, underlying both domestic influence and accountability is a commitment of a particular group or NGO to remain grounded in the lived realities and experience of the communities they are seeking to represent: 
... It's hard for us to commit to collaborating with groups who don't have that sort of long term relationship and whose representation of a specific struggle is not grounded - and I use grounded in a very non-grounded way because even after 13 years or how ever many years I have been working on Guatemala, [some] of which have been spent living in Guatemala - I do not have a grounded understanding of resistance there. It is (stresses) so complicated and dynamic that what I thought I knew four years ago is not the case anymore; it's shifted, it's changed. When I participate in group B advocacy calls I often say "I will refer to you guys on this one because you're living there right now and you're meeting with people and you're able to communicate about stuff that you can't share with us on the phone right now in terms of security issues." And so because we are just really committed to that, it's hard for us to work with groups who aren't as committed to that or who don't have the resources to do that. (Hunter)

In order to collaborate, group B expects that NGOs or other grassroots groups will have a grounded engagement with specific struggles. This grounded engagement, as Hunter notes, can only be achieved when actors are aware of the complex dynamics of resistance in the present. This means that solidarity must not be the product of a past relationship, but one in which connections are cultivated and maintained over time, and involve constant and active awareness on the part of Northern actors of what is happening on the ground.

What of collaboration if relationships are not grounded? The participants in this study suggest that collaboration also occurs when relationships between a particular organization or group and an impacted community cannot be forged because of how large the industry is, the difficulty of accessing remote communities as well as the scarce availability of resources. Dakota attests to this when stating:

Um... I think... I can't imagine an issue where people wouldn't work with other groups. I'm sure it makes sense with mining because of - the companies are operating in so many places that you can't... It's difficult to have contact and maintain relationships with people in all these different countries with different languages....

As a result of the international reach of Canadian resource extraction companies, it is not 
possible for group A to maintain ties to all places wherein extractivist imperialism is operating. However, this is not only the case for grassroots groups. The impossibility of having grounded and rooted relationships with all impacted communities is recognized by NGOs. Skylar speaks to the benefits of engaging in coalition work to address this issue:

...Actually the neat thing about a coalition is that there's different organizations that have different relationships. So some organizations are doing more in $\mathrm{La}$ Puya where they are on the ground and can do that. We, with [our network partners and grassroots groups] have been more on the ground in San Rafael around Tahoe's project in the last year and a half, two years. And [an environmental law group] have really been nurturing the next steps around Marlin which went through a bit of a lull.

The benefit of coalitions is that they bring together a diverse group of organizations and grassroots groups with access to specific human and informational resources that facilitate the establishment of relationships with particular communities. As Dakota notes, the main benefit of working with different organizations in coalitions "would be their connections... their connections in Latin America and other places, and the knowledge they build up around... what communities are doing." By appreciating that collaboration results from a desire to access informational resources regarding particular anti-extractivist struggles, coalitions and collaboration more generally will not occur unless groups or organizations can trust one another. Trust is especially important for both NGOs and grassroots groups, and is mentioned by seven of nine participants included in this study. In summarizing the importance of trust, Brook comments:

...If we can't find or build a relationship, and often it's not directly - we go to people that we know and trust that work in an area and go "how are things working here? Who do we talk to? Who's trust worthy?" Both in terms of reliable information but also political understanding of community dynamics and the regional dynamics - what are the sensitivities? 
In a coalition space, being able to trust partners and the validity and reliability of their sources is crucial for collaboration, as well as providing access to communities. Because solidarity requires a grounded and rooted connection to particular contexts, and because navigating community dynamics is a sensitive endeavour, movement actors rely on relationships of trust to ensure that they engage with impacted communities in a respectful, accountable, and informed manner.

\section{2 "These organizations are dangerous, man!”: Examining Rootlessness}

The small NGOs and grassroots groups included in this study collaborate because both embody a rooted and a grounded type of solidarity. As a result of this practice, and in addition to the threads described in previous chapters, they rarely experience significant knots in coalition or network spaces. The knots identified are minor, involving miscommunication, a preference for one type of advocacy over another, or a lack of recognition of the scarcity of human resources on the part of the grassroots. The rootlessness knot that participants did identify is predominantly oriented towards larger NGOs: the NGOs described in the previous chapter that participate in multi-stakeholder meetings and public-private partnerships with industry representatives. NGO X - a large human rights $\mathrm{NGO}$ - is depicted by multiple participants as dangerous because of the influence it exerts in the local, national, and international arena. This level of influence is perceived as dangerous because it involves large NGOs engaging in advocacy without any grounded connection to impacted communities.

\subsubsection{NGO X in Latin America}

One example mentioned by several participants includes a specific campaign in and Latin American county and a report released by NGO X. During our interview, 
Casey describes NGO X's approach to advocacy as disconnected from grassroots groups

and the communities they produce informational resources about:

...So an organization that gets tons of money, which everyone knows, easily can say "Ok, I want to write a report about royalties, and how communities feel about royalties". We already know how they feel about royalties. We know that. But what we don't know is X, Y or Z. So if we could have a discussion about that, maybe that money that we don't have, and will never have access to could be used to check out this and this and this because the person - even sometimes they hire people who don't even know anything about it. And it's like "OK, give me the money and I'll go do it" (laughs)... When you read it, you think "that could have been way different" and that kind of happened with [NGO X] - And, you know, people were really mad about that report. Not in the sense that things were wrong - I guess some things were wrong - but things that weren't included, that they didn't focus on this and that and the other thing and so that becomes a real... I don't know, that's when it's challenging.

As Casey mentions, NGO X is a large NGO with substantial resources, and despite these resources, it is seen as failing to engage directly with community members. Instead, my research participants reported that NGO X hires staff disconnected from the community, creating a situation wherein informational resources are produced without integrating local concerns. This creates tension between small NGOs and grassroots groups in Canada and large international NGOs like NGO X. More importantly, it creates tensions between large NGOs and the communities impacted by Canadian extractivism. Micah reiterates the problems associated with large and highly institutionalized and professionalized NGOs when stating angrily:

[NGO X] just released a report on mining in [a Latin American country] that they were supposed to release for forever, and it's fine but I'm like "come on! You have so much capacity and so many people and so many resources and access to everything and people will talk to you and THIS is what you've done? " Wafucking-hoo. I can't even believe it. (Micah and Max laugh). I really think everything we've done, as ridiculous as it is, is way more useful. And I think that's how impacted communities in this case felt. They're like "why is this report a thing?"

By adopting a top-down approach to the production of knowledge, large NGOs open 
themselves up to criticism from all angles: by impacted communities themselves and the small NGOs and grassroots groups in the North that work directly with communities. By not practicing a participatory methodology that is rooted and grounded, activist and scholarly critiques of NGOs are reinforced. For Power, Maury and Maury (2002: 274), a lack of participatory engagement signifies that the NGO under consideration is exhibiting "alien-hand syndrome", a type of "organizational learning disorder" characterized by a complete disconnect between a given NGO's "intentions and actions." For an NGO to correct this disconnect, it must practice a bottom-up form of learning, wherein "an organization makes a moral choice to draw insights and feedback from people at the low end of a socially constructed hierarchy" (Power, Maury and Maury 2002: 275). More importantly, practicing bottom-up learning entails that NGOs reconfigure their internal structure and culture "to the complex and evolving struggles of those in poverty, including even the choice not to be 'developed"' (Power, Maury and Maury 2002: 275).

The strength of this approach - as practiced by the NGOs in this study - is that it is grounded in the lived experiences of impacted communities, whose interests, concerns and voices "are not only heard, but can exercise a discrete and overriding influence not only on the actions of INGOs [international NGOs] on the ground, but in their internal operations as well” (Power, Maury and Maury 2002: 276). As indicated above, participants believe that NGO X does not engage in bottom-up learning, consequently creating tensions between large NGOs and small NGOs, grassroots groups and impacted communities. The participants in my study felt that the failure of NGO X to engage in a participatory methodology that includes bottom-up learning is largely a consequence of an institutional failure to engage in and practice a rooted form of solidarity. However, as 
Skylar explains,

It's also not black and white. You make strategic decisions sometimes. I mean, I've been disappointed at times. I will not break the relationship entirely but there have been moments where we've had tensions with [NGO X] over the campaign because some of the stuff they've put out - the direction and strategy wasn't aligned with what organizations in [that Latin American country] were trying to drive at. And they're big enough that when they come in and say things it can weaken what you're saying because people listen more to them than they do to you (laughs) or your partners. So it's not all bad and I definitely work with - I think they still have things to offer but with the bigger organizations and stuff you have to watch and manage and deal with.

In not embracing a rooted form of solidarity, NGO X depoliticizes demands and sets the agenda for the informational resources that are read and the demands that are heard. Although NGO X lacks a rooted form of solidarity, this does not entail a refusal on the part of grassroots groups or small NGOs to cut all organizational threads. Instead, it requires that grassroots groups and NGOs make strategic decisions that balance the opportunities and costs involved in collaborating with larger NGOs.

\subsection{Conclusion}

In this chapter, the key thread of a rooted and grounded solidarity was highlighted. This thread is marked by a participatory methodology that requires community driven advocacy and long-term relationships with communities. Both the small NGOs and grassroots groups included in this study expressed the necessity of the other for a successful and effective movement in Canada. The knots identified are often minor and thus manageable, including issues in communication or a preference for a certain type of advocacy. The most significant knots participants identified are those that result from the apparent rootlessness of large NGOs: they are perceived to lack a grounded and rooted solidarity, producing informational resources that are disconnected from local movements and activist voices. In addition to this, large NGOs that partner 
with industry and state representatives - securing hegemonic interests and solidifying existing power structures - render invisible the voices and epistemologies from below (Choudry 2010). As this chapter has suggested, participants believe that large NGOs often embody the ills associated with NGOization. In the view of my participants, large NGOs appear to have a tendency to engage with (as opposed to contest) hegemonic forces, depoliticize claims as a result of the institutionalization and professionalization of action, and seem to lack a grounded and rooted solidarity that informs organizational plans of action. 


\section{Chapter: Conclusion}

The neoliberal restructuring of Canadian aid, development and foreign policy regimes to promote historically embedded nation-building practices has consequently placed under state surveillance the webs that challenge Canadian extractivism. From the collapsing of CIDA into the DFATD, the adoption of voluntary CSR codes as opposed to strong regulatory regimes, the use of Canadian embassies to further extractivist imperialism, and the auditing of environmental NGOs critical of the Canadian government by the CRA, alongside the criminalization of activist dissent, the current configuration of the Canadian state is marked by a lack of political opportunities and an abundance of threats. Despite this context, the solidarity movement challenging resource extractivism continues to grow, pressuring the Canadian state and corporate actors from above and below, as well as inside and outside the halls of power. This occurrence itself belies the theoretical and empirical literature on NGOization, with the predominant NGOization thesis overlooking the relational elements that comprise social movement webs.

In seeking to understand the meanings and lived experiences of some of the activists involved in this movement, this study adopted a hermeneutic phenomenological approach to investigate the relationality of collective action. In order to explicate and interpret the phenomenon of NGO-grassroots interaction, I asked the following questions: (1) What factors explain the relatively high level of collaboration between NGOs and grassroots groups working to challenge Canadian resource extraction projects? (2) Are there elements of NGOization occurring within the movement that is critical of Canadian 
extractive operations? (3) What effect does this have on the movement's capacity to enact change in this sector?

In conducting nine in-depth and semi-structured interviews with participants from two NGOs and two grassroots groups that work on social and environmental justice issues within the resource extraction sector, preliminary answers to the first and third research questions can be found in the five threads that bind grassroots groups together in webs of interaction and collaboration. The second question concerning elements of NGOization becomes evident in the tensions and feelings of ambivalence that take the forms of five knots that strain, but give shape to, the movement web. Prior to expanding on the findings of this research project, it is important to situate the research in the wider literature that attempts to discern and capture the essence of NGO-grassroots relationships, as well as the methodological approaches adopted to answer these questions.

\subsection{Theoretical and Methodological Foundations}

As described in this thesis, and borrowing from Lang (2013), NGOization marks a shift from loosely structured grassroots groups to institutionalized, professionalized, and bureaucratized NGOs. The institutionalization, professionalization, and bureaucratization of social action is contextually situated and dependent on the degrees to which the elements of NGOization are evident. This means that we can speak of less NGOized or more NGOized movement webs. More importantly, NGOization as a process is always occurring given the current state of civil society globally, which has experienced an NGO boom since the 1980s (Macdonald 1995; Lang 2013). The global (Lang 2013) as well as regional (for Latin America, see Macdonald 1995) NGO boom has consequences on the 
organization of civil society and the relationships between movement actors. The NGO boom has piqued the interest of scholars since the early 1990s, and appears in two distinct strands of research.

The first strand, dubbed the NGOization thesis, includes normative theories and empirical accounts of the ills associated with this process. The literature within this strand, although providing insightful critiques, conceals not only the instances in which NGOs and grassroots groups maintain working relationships in spite of NGOization, but also the heterogeneity of NGO models in accounts of social movement dynamics. NGOization needs to consider the complexity of social movement webs, including external funding constraints as well as the character of the state, in order to provide a comprehensive understanding of the phenomenon. I suggest in Chapter 2 that the conceptual and theoretical tools offered by social movement theory, including resource mobilization theory and framing theory, be adopted in order for studies on NGOgrassroots dynamics to better explicate the relational character of movement webs.

The second strand of research attempts to complicate, nuance and occasionally highlight the relational aspect of social movements (Alvarez 2009; Nazneen and Sultan 2009; Pithouse 2013; Tsikata 2009). This body of literature more explicitly explores the patterns of interaction that characterize NGO-grassroots relationships. The general benefit of this strand of research is that it not only critiques NGOs, but also provides a more nuanced, and therefore more comprehensive, account of the complexity involved in social movement webs. This project, as chapters four, five and six illustrate, falls within this second strand of research by speaking to the complexity of NGO-grassroots dynamics. It examines the opportunities and costs associated with collaboration with 
NGOs, and points to the multiple models NGOs embody which requires that actors carefully navigate different organizational ecologies. In his observation of South African civil society, Pithouse (2013: 256) remarks that movements "will require certain forms of NGO support for the forseeable future." I tend to agree with this observation, especially given the scarcity of resources found within the movement challenging Canadian extractivism. A research agenda for NGO-grassroots dynamics should shift from outright critique to theorizing the lessons to be "drawn from both the successes and failures," of NGO-grassroots dynamics, with the hopes of sparking "open and constructive discussion about praxis... that is necessary for making progress" (Pithouse 2013: 256-257) - an observation and hope reflected in the interviews conducted for this research.

In order for this study to reflect the second strand of the research agenda, I decided to integrate social movement theory into an examination of NGOization. This is because social movement theories offer a sustained look at the relational character of social movement dynamics, with resource mobilization and framing theories providing a conceptual toolkit for addressing threads that bind, and the knots that shape social movement webs. I also employed a social constructivist framework that analyzed the subjective and multiple meanings individuals attach to a particular phenomenon, necessitating that close attention be paid to complexity (Creswell 2013) - for this study, this occurred through the articulation of meaning units that include both knots that strain and the threads that bind actors together. The particular social constructivist methodology that I adopted is hermeneutic phenomenology. This methodology moves beyond a mere description of the lived experiences and meanings participants attach to a phenomenon by engaging in the practice of interpretation (Sloan and Bowe 2014; van Manen 2014). 
In practicing the phenomenological attitude of reflexivity (Finlay 2014), I situated the research within my own experience in the movement, and the meanings I attach to the phenomenon. In doing so, I was able to reflect on and contemplate inter-organizational relationships with some participants to access the essence of the phenomenon.

Undertaking a hermeneutic phenomenological approach, marked by a reflexive attitude, is important because I give voice to the experiences of participants. Theoretically, this implies a shift from attempting to ascertain a universalizing theory of NGOization to a situated, contextual, relational and collective account of the meanings attached to the phenomenon.

\subsection{Research Findings: NGOization and the Complexity of Movement Webs}

My research into the phenomenon of NGO-grassroots relationships finds that the movement web is comprised of many organizational forms, including unions, small NGOs, large NGOs and grassroots groups spread out - the last of which are slowly multiplying - across the country. Both sets of actors in this study are less likely to engage with large NGOs as a result of the knots that may entangle the web, and refuse to work with NGOs that engage in public-private partnerships. This is indicative of the need for NGOization theory in general to pay attention to the size and different types of NGOs, as both these variables play a role in connecting - or disconnecting - actors within a movement web. In spite of the elements of NGOization that are occurring in the form of the five knots examined in this project, there appear to be five key threads that have more significant implications for NGO-grassroots relationships, often binding them into dense networks and coalitions. This challenges the notion that NGOs are disconnected from the grassroots, and argues for the inclusion of NGOs in movement webs. Each of the threads 
and knots shed light on the heightened level of interaction between NGOs and grassroots groups, with some clarifying the effects of NGOization on social change.

\subsubsection{Five Key Threads that Bind}

To answer the first research question, this study found five key threads that explain the relatively high level of collaboration between NGOs and grassroots groups working to challenge Canadian resource extractivism. The five threads include (1) shared values and frames (2) pooling or sharing of diverse resources (3) overlapping long term goals (4) complimentary forms of advocacy based on a division of labour and a diversity of tactics and finally, (5) commitment to a rooted and grounded form of solidarity activism. Chapter 4 described the first thread: the values and frames that bind groups and NGOs together. All of the participants in this study place significant meaning in the value of self-determination as a principle that unites diverse actors in this movement web. This value is important because it determines, for both NGOs and grassroots groups, suitable candidates for collaboration. The second value that binds actors together includes accountability. In order to bring about state and corporate accountability, NGOs and grassroots groups engage in diverse tactics, ranging from bringing Hudbay Minerals Inc. to Canadian courts to engaging in street protests outside of AGMs.

The other half of the first thread that facilitates interaction is sharing an environmental justice frame, with movement actors diagnosing the problem as a lack of accountability, pressuring the state to regulate industry, and pressuring corporations to respect the right to self-determination and free, prior and informed consent of impacted or potentially impacted communities. Participants also expressed the importance of the environment in creating the conditions for social and community-based justice. 
Interestingly, both NGOs and grassroots groups expressed the need to move beyond (for large NGOs especially) the current environmental justice framework to one that links individual resource extraction industries to a comprehensive critique of capitalism and colonialism as driving forces that perpetuate the destruction of environmental conditions - the same conditions necessary for the manifestation of justice in its multiplicity. The NGOization thesis posits that NGOs lose critical public voice, becoming depoliticized. However, it appears that some NGOs are, in tandem with the grassroots, thinking through issues more deeply, creating a real potential for radicalization in thought and action. It remains to be seen if and how this will occur in light of the current Canadian political landscape.

In Chapter 5, I explored threads two, three and four. The second thread - sharing and pooling resources - includes the types of resources that bind grassroots groups together and the directional flows of material, human and cultural resources. I find that the availability of the aforementioned resources determine whether or not collaboration will occur and more importantly, that resources flow between and across organizational forms according to a desire to increase mobilization and/or to strengthen networks and coalitions. The third thread that binds actors together is overlapping long-term goals, which include educating publics and institutional reform. The commitment to institutional reform by both sets of actors, although occasionally mired by uncertainty (especially on the part of grassroots actors), complicates a literature that suggests that NGOs change movement agendas. In this movement, institutional change is on the agenda, albeit subject to a cautious approach in lieu of fears of its potential to politically compromise grassroots group demands and politics. Since these goals are shared, and 
because resources are scarce, there is an incentive to collaborate on campaigns or in coalition spaces.

The fourth thread that binds includes complimentary forms of advocacy based on a division of labour and a diversity of tactics. In the interviews, participants expressed the need for one another in the movement, explaining that a diversity of tactics approach (ranging from protests and creative street theatre to participation in multi-stakeholder meetings) is valued given the complexity as well as the size of the industry. This leads to a division of labour in the movement based on the strengths of each organizational type. An important finding made evident in this thread is that although there may be tensions with the adoption of particular tactics, the grassroots groups shift away from a "holier than thou" (Lesley and Micah) politics, adopting a more pragmatic view that institutional advocacy is required alongside more confrontational approaches. An interesting finding that complicates the NGOization thesis is that both NGOs and grassroots groups engage in both public and institutional advocacy as well as reflexively question the usefulness of the latter. The critiques associated with insider approaches have resulted in, for instance, NGO 1 experiencing tensions with NGO 2, refusing to support the 2005 roundtable process. This finding suggests that both NGOs and grassroots groups recognize the limitations of particular forms of institutional advocacy, preferring to take multiple avenues to achieve change in the sector. In Chapter 6, the final and fifth thread that binds grassroots groups and NGOs together in this organizational field was established, and includes a commitment to a rooted and grounded form of solidarity. In practicing this type of solidarity, movement actors stress the importance of a participatory methodology 
(characterized by community driven advocacy and long-term relationships with communities) in binding groups together in collaboration.

\subsubsection{Five Knots that Strain Relationships \& the Capacity to Enact Change}

In addition to five threads that bind, this study found that there are also knots that may strain relationships and create entanglements in the movement web. The knots represent the tensions and feelings of ambivalence experienced by both sets of actors, and include the: capacity knot, praxis knot, institutionalization knot, depoliticization knot, and the rootlessness knot. The knots limit the capacity for substantive change because of: the scarcity of resources; a lack of sustained and mass public mobilization, in part due to the institutionalization of advocacy in a context in which political opportunities are disappearing; and the apparent depoliticization of large NGOs who are the recipients of a significant amount of resources. Although the capacity knot is important for understanding the ability to enact change in the industry, it only creates minor strains in relationships. The capacity knot has two components, both of which are resource tensions: scale of work and the lack of human resources to engage in coalitions. In regards to the first component, movement actors suggest that a lack of resources prevents them from expanding their mandate (for NGOs) or organizing (for grassroots) to include challenging multiple forms of extractivism, suggesting a tendency to focus on a particular sector. The second component speaks to the lack of time and energy to participate in coalitions. While the capacity knot has significant implications for changing the industry, this does not appear to be a result of the processes associated with NGOization.

The praxis knot represents the tensions and feelings of ambivalence both NGOs and grassroots groups experience when institutional forms of advocacy are preferred. In 
the case of the grassroots in particular, participants explain that they have to engage in a reflexive exercise to determine if the approach is a serious compromise to their political values and beliefs. In some cases, they will refrain from participation and in other instances they will participate, but do so cautiously. For NGO 1, some forms of institutional advocacy are avoided, while staff from NGO 2 are beginning to think of alternative means to address accountability, calling attention to the need for a space to do so. For instance, Skylar from NGO 2 believes that a more comprehensive approach that highlights the imperial tendency of extractive projects needs to be developed, in addition to a shift to building a mass movement in Canada. These examples support my suggestion that studies of NGOization appreciate more explicitly the heterogeneity of NGO forms, the fact that NGOs can amplify activist voices, and that the pull to institutional advocacy characteristic of NGOization is not always guaranteed and subject to a consideration of contextual factors.

The most potentially damaging and significant knots include an institutionalization knot and a depoliticization knot, both of which typically occur as a tension between small NGOs and grassroots groups and large NGOs. This tension is particularly present in relation to large NGOs that engage in public-private partnerships with industry representatives. The institutionalization knot takes the form of a belief shared by grassroots groups that large NGOs are inflexible when it comes to adopting different strategies for social change. The more toxic depoliticization knot is a result of heightened levels of institutionalization evident in larger NGOs, and the belief that this results in a loss of activist voice in exchange for legitimacy and credibility, which ultimately serves to weakening demands. This critique is similar to that of the 
NGOization thesis. However, it is different because it derives from both NGOs and grassroots groups involved in this study, complicating the NGOization thesis, suggesting that NGOs can maintain activist voices in institutional spaces.

A final knot that often results in a disconnect between large NGOs and smaller NGOs and grassroots groups is the rootlessness knot. Both the smaller NGOs and the grassroots groups in this study believe that some large NGOs, such as NGO X, may refrain from community driven work or lack long-term relationships. NGOs that do not engage in this participatory methodology are viewed with suspicion, and are not likely to make for strong allies. As Hunter from group B comments, it makes them wonder how the NGO makes its decisions and "whose voices they're representing," hinting at the issue of accountability - are they accountable to communities or to donors? The rootlessness knot captures the perceived lack of grassroots accountability of large NGOs

that is typical of the NGOization thesis. However, it does not always mean that grassroots groups or smaller NGOs will not engage with large NGOs. On the other hand, it requires that they strategically calculate the opportunities and costs associated in collaborating with NGOized (larger and more institutionalized) organizations.

\subsection{Implications and Future Areas of Inquiry}

This study makes a contribution to the literature nuancing research on NGOization by magnifying the relational aspect of a solidarity movement web in Canada challenging an extractivist model of development. The implications of this study rest on multiple levels. First, this study confirms that theories and empirical studies demonstrating the NGOization thesis can provide a more holistic analysis of the phenomenon of NGO-grassroots dynamics by discerning the threads that bind these 
actors into networks of mutual support and collaboration while critically highlighting the knots that create entanglements in movement webs. Second, this study suggests that the literature needs to appreciate and pay more attention to the various types of NGOs (development, advocacy, etc.) and their corresponding models (sources of funding, organizational structure, etc.) - in essence, the heterogeneity of NGOs needs to be considered in critical evaluations of NGO-grassroots relationships. Third, this study implies that the institutionalization of advocacy is not without its complexities, and that NGOs - in addition to grassroots groups - engage in a reflexive exercise to navigate the opportunities as well as the costs associated with this avenue for change. Following from this, the fourth implication is that not all NGOs are depoliticized actors, and some do believe in the need for a mass movement in Canada to effectively challenge the extractivist model of development.

Future research on this topic would benefit from casting a wider net to examine the threads and knots that comprise this movement web. This includes first expanding the amount of Canadian grassroots groups and NGOs as well as the resistance movements with whom they purport to act in solidarity. By expanding the scale and scope of the project, future studies on NGOization in the solidarity movement challenging Canadian extractivism would be better positioned to make more general claims in addition to providing the perspective of affected communities themselves. 


\section{Appendices}

\section{Appendix A Grassroots Group, NGO and Union Profiles}

This appendix provides a brief description of the NGOs, unions, and grassroots groups mentioned throughout the thesis. All descriptions provided are brief and general in an effort to maintain anonymity.

\section{A.1 Grassroots Group A}

This group is a small collective of volunteers mobilizing on issues concerning the mining sector in particular. They frequently work directly with impacted community members in countries in South America, Africa and Oceania. Group A primarily engages in public advocacy, but will support institutional advocacy in coalition spaces. Group A also supports struggles in Canada against the development of the tar sands. Group A does not receive funding from governments or corporations, often relying on its own funding drives. Group A occasionally receives donations from small NGOs.

Members interviewed: Lesley, Micah and Dakota.

\section{A.2 Grassroots Group B}

This is a predominantly volunteer-run grassroots group with few staff members. Natural resource extraction comprises a component of the work of this group, but not its entirety. The focus is on establishing long-term solidarity relationships with communities in Latin America. Group B engages in both public and institutional forms of advocacy, and receives its funding from individual donations as well as a sister charity.

Members interviewed: Hunter and Casey.

\section{A.3 NGO 1}

This is a small NGO that works in the Global North (USA and Canada) in solidarity with communities in Latin America impacted by resource extraction projects (including mining, oil development, and hydro-electric dams). The activities of NGO 1 vary from providing direct funds to communities to engaging in movement building that connects actors from the North and the South. NGO 1 engages in both institutional and public forms of advocacy, and receives its funding from individual donations, unions and various funds.

Staff interviewed: Alex 


\section{A.4 NGO 2}

The second small NGO aims to ensure that resource extraction occurs according to sustainable development principles and with the participation of host communities. NGO 2 primarily engages in institutional advocacy to ensure state and corporate accountability. NGO 2 often builds coalitions at the local, regional, provincial, national, and international level. This NGO relies on unions, organizations, and co-operatives for donations. NGO 2 does not receive government funding.

Staff interviewed: Brook, Skylar and Phoenix.

\section{A.5 NGO X}

This is a large international human rights NGO operating in country offices around the world. This NGO works to hold actors accountable for human rights violations in accordance with internationally recognized human rights principles. They primarily engage in institutional advocacy at the national and international level (lobbying foreign governments and international institutions) to strengthen human rights and influence legislation. NGO X does not accept funding from governments.

\section{A.6 NGO Y}

NGO Y is a medium-sized NGO that works with activists and organizations throughout the world to advance social and economic justice. NGO Y works in solidarity with its counterparts by raising funds, engaging in institutional advocacy to implement policy changes, educating the Canadian public on issues of importance to the organization, and by bringing activists to Canada to exchange their stories. NGO Y receives donations from the government of Canada.

\section{A.7 NGO Z}

This organization is based in Canada and has dozens of chapters across the country that work on issues related to green energy and natural resource protection, amongst others. This NGO works to empower people in Canada to hold their governments and corporations to account. NGO Z has staff, but also relies on volunteers. NGO Z does not accept donations from governments or corporations.

\section{A.8 Union A}

This is a large North American private union whose membership works in every sector of the economy, including the natural resource sector. Union A funds some of the work of NGOs working to challenge the Canadian mining industry, often supporting the regulatory demands of these NGOs. 


\section{A.9 Union B}

This is a large union representing Canadian public sector workers only. Union B works on issues related to environmental sustainability and natural resource management as well as global justice. It also funds some NGOs working to challenge the Canadian resource extraction regime. 


\section{Appendix B Draft Interview Guide}

All of the in-depth interviews in this study followed this semi-structured guide.

Each interview was divided into the six sections detailed below.

\section{B.1 Involvement in Resource Extraction Advocacy}

1. Can you name and explain an experience that first led you to get involved with resource extraction issues?

2. How did this first encounter with the Canadian resource extraction industry affect your view of Canada and its role in the world?

3. What type of advocacy did you get involved in after this point in time?

4. What organizations have you worked with - either as a volunteer or as staff - that address the resource extraction industry?

(IF APPLICABLE):

5. For each NGO or grassroots group that you have worked with in the past:

a. How did you first get involved?

b. What was your role in the group or organization? Did it change at all during your time with them?

c. Is there a reason, or set of reasons, that explain why you moved on to a different NGO or group?

\section{B.2 Understanding NGOs, Grassroots Groups \& Advocacy}

6. Having just described previous affiliations, why did you decide to join the current organization (or group) that you are working with?

7. How would you classify your organization (or group)? For example, would you classify it as an NGO, grassroots group, solidarity group, etc?

8. What distinguishing features make your organization (or group) fall under that category?

9. Do you focus on a particular sector of the natural resource industry, or perhaps a particular company? If so, why?

10. What type of advocacy (direct actions, lobbying, etc.) does your organization primarily engage in?

11. Following from this, what are some recent examples, and what was the goal of this endeavour?

12. In your work, do you look to impacted communities to guide your activities?

13. How often do you consult with the communities you advocate on behalf of?

14. Do you think your organization's (or group's) approach is effective in bringing change to how resource extraction is approached by the industry? Why or why not?

\section{B.3 Relationship with other Organizations: Collaboration}

15. Does your organization (or group) work with other NGOs or grassroots groups?

16. If yes, which NGOs and/or groups do you work with? 
17. How often do you work with those organizations?

18. If you could list the top three that you work with most often, which would they be?

19. Can you briefly describe the general work of these organizations (or groups)?

20 . What motivates you to work with these particular groups?

If they do not adequately answer this question, I ask:

a. Do you work with them because they engage in the same type of advocacy?

b. Is it because of common political beliefs? Can you describe what they are?

c. Do you work with them to share resources? Do you provide resources, use resources offered to your organization, or do you pool resources?

d. Do you work with them because you are interested in initiatives in solidarity with impacted communities?

e. Does it have anything to do with the context of your work (the Canadian resource extraction industry)? How so?

21. Can you describe some of the recent campaigns, events or actions that you have worked on with these groups or organizations?

22. Are these campaigns, events or actions initiated by impacted communities?

23. Did you find working with these organizations or groups advantageous?

24 . Will you continue working with these organizations or groups?

25. Are you involved in any coalitions or networks with these organizations or groups?

26. If yes, can you identify them and briefly describe the work involved in this coalition?

\section{B.4 Relationship with other Organizations: Strains}

27. Are there any organizations or groups that you refuse to work with?

28. If yes, which NGOs and/or groups are these?

a. What factors made this relationship unproductive?

29. If no, are there groups or organizations you perhaps try to avoid working with? If yes:

b. Which organizations or groups are these?

c. Can you describe why you do not collaborate as much with this organization or group?

30. Can you identify and describe instances in which relationships with NGOs or grassroots groups you collaborate with were strained?

d. What caused this strain?

e. How has it impacted your working relationship?

f. Did it result in less frequent forms of collaboration?

31. If they identify as an NGO-type group:

g. Do you think grassroots groups make organizing around issues related to Canadian resource extraction more difficult?

h. If yes, how so? Can you provide an example?

32. If they identify as a grassroots organization:

i. Do you think NGOs make organizing around issues related to Canadian resource extraction more difficult?

j. If yes, how so? Can you provide examples? 


\section{B.5 Achieving Social Change}

33. Would you consider the movement challenging Canadian resource extraction projects successful?

34. What are some of the successes that have been achieved?

35. What types of actions, campaigns, form of advocacy, etc. does your organization or group believe to be most effective in bringing about change?

36. Are you looking to build more coalitions across organizations and groups that are working on resource-related issues?

37. How do you think the movement can be improved?

\section{B.6 Concluding Questions}

38. Are there any topics that I haven't covered, but that you think are relevant for this project?

39. Do you have thoughts or hopes for what benefits might come out of a project like this? 


\section{References}

Africa, Sonny. 2013. "Philippine NGOs: Defusing Dissent, Spurring Change." Pp. 118143 in NGOization: Complicity, Contradictions and Prospects, edited by A. Choudry and D. Kapoor. New York, NY: Zed Books.

Alvarez, Sonia. 2009. "Beyond NGOization? Reflections from Latin America." Development 52, 175-184.

Alvarez, Sonia. 1999. "Advocating Feminism: The Latin American Feminist NGO 'Boom”" International Feminist Journal of Politics 1(2), 181-209.

Alvarez, Sonia. 1997. "Reweaving the Fabric of Collective Action: Social Movements and Challenges to "Actually Existing Democracy" in Brazil." Pp. 83-117 in Between Resistance and Revolution: Cultural Politics and Social Protest, edited by R.G. Fox and O. Starn. New Brunswick, NJ: Rutgers.

Annis, Rogers. 2012. "A Movement Against Tar Sands Oil, Pipelines and Tankers is on the Rise in Canada." Retrieved July $3^{\text {rd }} 2015$ (http://www.socialistproject.ca/bullet/720.php).

Barry-Shaw, Nikolas and Dru Oja Jay. 2012. Paved with good intentions: Canada's development $N G O s$ on the road from idealism to imperialism. Winnipeg, MB: Fernwood Publishing.

Bebbington, Anthony J., Samuael Hickey and Diana C. Mitlin, eds. 2008. Can NGOs Make a Difference? The Challenge of Development Alternatives. New York, NY: Zed Books.

Benford, Robert and David Snow. 2000. "Framing Processes and Social Movements: An Overview and Assessment." Annual Review of Sociology 26, 611-639.

Bevington, Douglas and Chris Dixon. 2005. "Movement-relevant Theory - Rethinking Social Movement Scholarship and Activism." Social Movement Studies, 4(3), 185-208.

Blackwood, Elizabeth and Veronika Stewart. 2012. "CIDA and the Mining Sector: Extractive Industries as an Overseas Development Strategy" Pp. 217-245 in Struggling for effectiveness: CIDA and Canadian foreign aid, edited by S. Brown. Kingston, ON: McGill-Queen's University Press.

Bowness, Evan and Mark Hudson. 2014. "Sand in the cogs? Power and public participation in the Alberta tar sands" Environmental Politics 23(1), 59-76.

Britton, Hannah. 2006. "Organising against Gender Violence in South Africa." Journal of Southern African Studies 32(1), 145-163. 
Brouwer, Ruth. 2014. "When Missions Became Development: Ironies of "NGOization" in Mainstream Canadian Churches in the 1960s." Pp. 229-243 in Modern Canada: 1945 to Present edited by C. Briggs. Don Mills, ON: Oxford University Press.

Brown, Trent. 2014. "Negotiating the NGO/Social Movement Dichotomy: Evidence from Punjab, India." Voluntas 25, 46-66.

Buechler, Steven. 2011. Understanding Social Movements: Theories from the Classical Era to the Present. Boulder, CO: Paradigm Publishers.

Castellino, Joshua. 2014. "Self-Determination and Secession in International Law: Peoples, Minorities and Indigenous Peoples." Pp. 28-46 in Self-Determination and Secession in International Law edited by C. Walter, A. von Ungern-Sternberg and K. Abushov. Oxford, UK: Oxford University Press.

Chahim, Dean and Aseem Prakash. 2014. "NGOization, Foreign Funding, and the Nicaraguan Civil Society.” Voluntas 25, 487-513.

Choc v. Hudbay. N.d. Retrieved April 22 ${ }^{\text {nd }}, 2015$ (http://www.chocversushudbay.com/)

Choudry, Aziz. 2014. "Examining the Disconnect Between Mass Mobilization and International Trade Union/NGO Networks in Struggles over Bilateral Free Trade and Investment Agreements." Globalizations 11(1), 107-117.

Choudry, Aziz. 2013. "Saving biodiversity, for Whom and for What? Conservation NGOs, Complicity, Colonialism and Conquest in an Era of Capitalist Globalization." Pp. 24-44 in NGOization: Complicity, Contradictions and Prospects, edited by A. Choudry and D. Kapoor. New York, NY: Zed Books.

Choudry, Aziz. \& Dip Kapoor. 2013. "Introduction.” Pp. 1-23 in NGOization: Complicity, Contradictions and Prospects, edited by A. Choudry and D. Kapoor. New York, NY: Zed Books.

Choudry, Aziz and Eric Shragge. 2011. "Disciplining Dissent: GNOs and Community Organizations." Globalizations 8(4), 503-517.

Choudry, Aziz. 2010. "Global Justice? Contesting NGOization: Knowledge Politics and Containment in Antiglobalization Networks." Pp. 17-34 in Learning from the Ground Up: Global Perspectives on Social Movement and Knowledge Production, edited by A. Choudry and D. Kapoor. New York, NY: Palgrave Macmillan.

Claps, Muis Manuel, Catherine Coumans, Ximena Cuadra, Ariel Fornari, Natalie Lowrey, Marie-Eve Marleau, Isabel Orellana, Sakura Saunders and Francheza 
Serrano. 2013. Debunking Barrick. Retrieved July $2^{\text {nd }}, 2015$

(http://protestbarrick.net/downloads/DebunkBarrick-Report_fnl_web_single.pdf).

Coumans, Catherine. 2012. "Mining human rights and the socially responsible investment industry: considering community opposition to shareholder resolutions and implications of collaboration." Journal of Sustainable Finance \& Invest 2(1), 44-63.

Cress, Daniel and David Snow. 1996. "Mobilization at the Margins: Resource, Benefactors, and the Viability of Homeless Social Movement Organizations." American Sociological Review 61(6), 1089-1109.

Creswell, John W. 2013. Qualitative inquiry and research design: Choosing among five approaches. Los Angeles, CA: SAGE Publications.

Dagnino, Evelina. 2008. "Challenges to Participation, Citizenship and Democracy: Perverse Confluence and Displacement of Meanings." Pp. 55-70 in Can NGOs Make a Difference? The Challenge of Development Alternatives, edited by A.J. Bebbington, S. Hickey, and D.C. Mitlin. New York, NY: Zed Books.

Della Porta, Donatella and Mario Diani. 2006. Social Movements: An Introduction (2nd Ed.). Malden, MA: Blackwell Publishing.

Diani, Mario. 2003. 'Introduction: Social Movements, Contentious Action, and Social Networks: 'From Metaphor to Substance?'” Pp. 1-20 in Social Movement and Networks: Relational Approaches to Collective Action, edited by M. Diani and D. McAdam. Oxford, UK: Oxford University Press.

Dixon, Chris. 2014. Another Politics: Talking Across Today's Transformative Movements. Oakland, CA: University of California Press.

Dwyer, Corin and Jennifer Buckle. 2009. "The Space Between: On Being an InsiderOutsider in Qualitative Research." International Journal of Qualitative Methods 8(1), 54-63.

Edelman, Marc. 2001. "Social Movements: Changing Paradigms and Forms of Politics." Annual Review of Anthropology 30, 285-317.

Edwards, Bob and John McCarthy. (2004). "Resources and Social Movement Mobilization.” Pp. 116-152 in The Blackwell Companion to Social Movements edited by D.A. Snow, S.A. Soule, and H. Kriesi. Malden, MA: Blackwell Publishing.

Elwood, Sarah and Deborah Martin. 2000. "'Placing' Interviews: Location and Scales of Power in Qualitative Research.” Professional Geographer 52(4), 649-657. 
Faber, Daniel. 2005. "Building a Transnational Environmental Justice Movement: Obstacles and Opportunities in the Age of Globalization." Pp. 43-70 in Coalitions Across Borders: Transnational Protest and the Neoliberal Order, edited by J. Bandy and J. Smith. Lanham, MD: Rowman and Littlefield Publishers.

Finlay, Linda. 2014. "Engaging Phenomenological Analysis.” Qualitative Research in Psychology 11, 121-141.

Fogarty, Edward. 2011. "Nothing Succeeds Like Access? NGO Strategies Towards Multilateral Institutions.” Journal of Civil Society 7(2), 207-227.

Fontana, Andrea and James Frey. 2008. "The Interview: From Neutral Stance to Political Involvement." Pp. 115-160 in Collecting and Interpreting Qualitative Materials $3^{\text {rd }}$ Ed., edited by N. K. Denzin and Y. S. Lincoln. London, UK: SAGE Publications.

Foreign Affairs, Trade and Development Canada. 2013. Global Markets Action Plan: The Blueprint for Creating Jobs and Opportunities for Canadians Through Trade. Retrieved January $13^{\text {th }}, 2014$ (http://international.gc.ca/global-markets-marchesmondiaux/assets/pdfs/plan-eng.pdf).

Foss, Mark. 2007. "Dirty Business, Dirty Practices: How the Federal Government Supports Canadian Mining, Oil and Gas Companies Abroad." Canadian Network for Corporate Accountability. Retrieved July $2^{\text {nd }}, 2015$ (http://www.halifaxinitiative.org/sites/halifaxinitiative.org/files/DirtyPractices.pdf ) .

Ghosh, Biswajit. 2009. "NGOs, Civil Society and Social Reconstruction in Contemporary India." Journal of Developing Societies 25(2), 229-252.

Gibson, William and Andrew Brown. 2009. Working with Qualitative Data. London, UK: SAGE Publications.

Gill, Lesley. 1997. "Power lines: the political context of nongovernmental organization (NGO) activity in El Alto, Bolivia." Journal of Latin American Anthropology 2(2), 144-169.

Gupta, Saurabh. 2014. "From Demanding to Delivering Development: Challenges of NGO-Led Development in Rural Rajasthan, India." Journal of South Asian Development 9(2), 121-145.

Haluza-DeLay, Ralph and Heather Fernhout. 2011. "Sustainability and social inclusion? Examining the frames of Canadian English-speaking environmental movement organizations." Local Environment 16(7), 727-745.

Hammami, Rema. 2000. "Palestinia NGOs Since Oslo: From NGO Politics to Social 
Movements?" Middle East Report 214, 1-7.

Herzog, Hanna. 2008. "Re/visioning the women's movement in Israel." Citizenship Studies 12(3), 265-282.

Jacobsson, Kerstin and Steven Saxonberg. 2013. "Introduction: The Development of Social Movements in Central and Eastern Europe." Pp. 1-26 in Beyond NGOization: The Devleopment of Social Movements in Central and Eastern Europe edited by K. Jacobsson and S. Saxonberg. Surrey, England: Ashgate Publishing.

Jad, Islah. 2007. "NGOs: between buzzwords and social movements" Development in Practice 17(4-5), 622-629.

Jamal, Manal. 2015. "Western Donor Assistance and Gender Empowerment in the Palestinian Territories and Beyond." International Feminist Journal of Politics 17(2), 232-252.

Jalali, Rita. 2013. "Financing Empowerment? How Foreign Aid to Southern NGOs and Social Movements Undermines Grass-Roots Mobilization." Sociology Compass 7(1), 55-73.

Junge, Benjamin. 2012. "NGOs as shadow pseudopublics: Grassroots community leaders' perceptions of change and continuity in Porto Alegre, Brazil." American Ethnologist 39(2), 407-424.

Kamphuis, Charis. 2012. "Canadian Mining Companies and Domestic Law Reform: A Critical Legal Account." German Law Journal 13(9), 1456-1486.

Kapoor, Dip. 2013. "Social Action and NGOization in Contexts of Development Dispossession in rural India: Explorations into the Un-civility of Civil Society." Pp. 45-74 in NGOization: Complicity, Contradictions and Prospects, edited by A. Choudry and D. Kapoor. New York, NY: Zed Books.

Keil, Roger, Melissa Ollevier and Erica Tsang. 2009. "Why Is There No Environmental Justice in Toronto? Or Is There?" Pp. 65-80 in Speaking for Ourselves: Environmental Justice in Canada, edited by R. Haluza-DeLay, P. O'Riley, P. Cole and J. Agyeman. Vancouver, BC: UBC Press.

Kirchhoff, Denis and Leonard J.S. Tsuji. 2014. "Reading between the lines of the 'responsible resource development' rhetoric: The use of omnibus bills to 'streamline' Canadian environmental legislation." Impact Assessment and Project Appraisal 32(2), 108-120.

Kneen, Brewster. 2013. "Alignment and Autonomy: Food Systems in Canada.” Pp. 207226 in NGOization: Complicity, Contradictions and Prospects, edited by A. Choudry and D. Kapoor. New York, NY: Zed Books. 
Kuttab, Eileen. 2008. "Palestinian Women’s Organizations: Global Cooption and Local Contradiction.” Cultural Dynamics 20(2), 99-117.

Lang, Sabine. 2013. NGOs, Civil Society, and the Public Sphere. New York, NY: Cambridge University Press.

Lang, Sabine. 1997. “The NGOization of Feminism.” Pp. 101-120 in Transitions, Environments, Translations: Feminisms in International Politics, edited by J.W. Scott, C. Kaplan, D. Keates. New York, NY: Routledge.

Laplante, J.P and Catherin Nolin. 2014. "Consultas and Socially Responsible Investing in Guatemala: A Case Study Examining Maya Perspectives on the Indigenous Right to Free, Prior, and Informed Consent." Society and Natural Resources 27, 231248.

Laurie, Nina, Robert Andolina and Sarah Radcliffe. 2005. "Ethnodevelopment: Social Movements, Creating Experts and Professionalising Indigenous Knowledge in Ecuador." Antipode, 470-496.

Lavalle, Adrian Gurza and Natalia S. Bueno. 2011. "Waves of Change within Civil Society in Latin America: Mexico City and Sao Paulo.” Politics \& Society 39(3), 415-450.

Lebon, Nathalie. 1993. "The Brazilian Feminist Movement in the Post-Constitutional Era: Assessing the Impact of the Rise of Feminist Non-Governmental Organizations." Florida Journal of Anthropology 18, 17-26.

Lounsbury, Michael. 2005. "Institutional variation in the evolution of social movements: competing logics and the spread of recycling advocacy groups." Pp. 73-95 in Social Movements and Organization Theory, edited by G.F. Davis, D. McAdam, W. Richard, S. Mayer, and N. Zald. New York, NY: Cambridge University Press.

Macdonald, Laura. 1995. "A Mixed Blessing: The NGO Boom in Latin America." NACLA Report on the Americas 28(5), 30-35.

Markowitz, Lisa and Karen W. Tice. 2002. "Paradoxes of Professionalization: Parallel Dilemmas in Women's Organizations in the Americas." Gender \& Society 16(6), 941-958.

Martens, Kerstin. 2006. "Institutionalizing societal activism within global governance structure: Amnesty International and the United Nations system." Journal of International Relations and Development 9, 371-395.

Mauthner, Natasha and Andrea Doucet. 2003. "Reflexive Accounts and Accounts of Reflexivity in Qualitative Data Analysis.” Sociology 37(3), 413-431. 
McCarthy, John and Mayer Zald. 1977. "Resource Mobilization and Social Movements: A Partial Theory." American Journal of Sociology 82(6), 1212-1241.

McCarthy, John and Mayer Zald. 2002. "The Enduring Vitality of the Resource Mobilization Theory of Social Movements.” Pp. 533-565 in Handbook of Sociological Theory, edited by J.H. Turner. New York, NY: Plenum Publishers.

Meyer, David and Sidney Tarrow. 1998. "A Movement Society: Contentious Politics for a New Century." Pp. 1-28 in The Social Movement Society: Contentious Politics for a New Century, edited by D. S. Meyer and S. Tarrow. New York: Rowman and Littlefield.

Mining Watch. 2013. "Backgrounder: A Dozen Examples of Canadian Mining Diplomacy." Retrieved July $3^{\text {rd }}, 2015$ (http://www.miningwatch.ca/article/backgrounder-dozen-examples-canadianmining-diplomacy).

Minter, Tessa, Victor De Brabander, Jan Van der Ploeg, Gerard Persoon and Terry Sunderland. 2012. "Whose Consent? Hunter-Gatherers and Extractive Industries in the Northeastern Philippines." Society and Natural Resources 25, 1241-1257.

Mishra, Neeraj. 2011. “Unravelling Governance Networks in Development Projects: Depoliticization as an Analytical Framework." Environment and Urbanization ASIA 2(2), 153-168.

Mitlin, Diana. 2001. "Civil society and urban poverty - examining complexity." Environment \& Urbanization 13(2), 151-173.

Moser, Annalise. 2004. "Happy Heterogeneity? Feminism, Development, and the Grassroots Women's Movement in Peru." Feminist Studies 30(1), 211-241.

Mueller-Hirth, Natascha. 2009. "South African NGOs and the public sphere: between popular movements and partnerships for development." Social Dynamics 35(2), 423-435.

Natural Resources Canada. 2013. Mining Sector Performance Report 1998-2012. Retrieved November 15, 2013 (http://www.nrcan.gc.ca/sites/www.nrcan.gc.ca/files/mineralsmetals/files/pdf/MS P-report-eng.pdf).

Nazneen, Sohela and Maheen Sultan. 2009. "Struggling for Survival and Autonomy: Impact of NGO-ization on women's organizations in Bangladesh." Development 52(2), 193-199.

Oliver, Pamela and Hank Johnston. 2005. "What a Good Idea! Ideologies and Frames in Social Movement Research.” Pp. 185-204 in Frames of Protest: Social 
Movements and the Framing Perspective edited by H. Johnston and J.A. Noakes. Lanham, MD: Rowman \& Littlefield Publishers.

Petras, James and Henrey Veltmeyer. 2011. Social Movements in Latin America: Neoliberalism and Popular Resistance. New York, NY: Palgrave Macmillan.

Petras, James. 1997. "Imperialism and NGOs in Latin America." Monthly Review 49(7), $10-27$.

Pithouse, Richard. 2013. "NGOs and urban movements: notes from South Africa." City $17(2), 253-257$.

Power, Grant, Matthew Maury and Susan Maury. 2002. “Operationalising bottom-up learning in international NGOs: barriers and alternatives." Development in Practice 12(3-4), 272-284.

Rahman, Sabeel. 2006. "Development, Democracy, and the NGO Sector: Theory and Evidence from Bangladesh.” Journal of Developing Societies 22(4), 451-473.

Routledge, Paul. 2011. “Translocal Climate Justice Solidarities.” Pp. 384-398 in Oxford Handbook of Climate Change and Society, edited b J.S. Dryzek, R.B. Norgaard, and D. Schlosberg. New York, NY: Oxford University Press.

Saunders, Sakura. 2013. "In Pictures: Protesters mock Peter Munk as Barrick Gold share price plummets." Retrieved July $3^{\text {rd }}, 2015$

(http://toronto.mediacoop.ca/photo/protesters-mock-peter-munk-barrick-goldshare-pric/17281).

Schlosberg, David. 2013. "Theorising environmental justice: The expanding sphere of a discourse." Environmental Politics, 22(1), 37-55.

Schneiberg, Marc and Sarah A. Soule. 2005. "Institutionalization as a contested, multilevel process: the case of rate regulation in American fire insurance." Pp. 122-160 in Social Movements and Organization Theory, edited by G.F. Davis, D. McAdam, W. Richard, S. Mayer, and N. Zald. New York, NY: Cambridge University Press.

Sinwell, Luke. 2013. "From Radical Movement to Conservative NGO and Back Again? A Case Study of the Democratic Left Front in South Africa." Pp. 102-117 in NGOization: Complicity, Contradictions and Prospects, edited by A. Choudry and D. Kapoor. New York, NY: Zed Books. 
Sloan, Art and Brian Bowe. 2014. "Phenomenology and hermeneutic phenomenology: the philosophy, the methodologies, and using hermeneutic phenomenology to investigate lecturers' experiences of curriculum design." Quality and Quantity 48, 1291-1303.

Snow, David and Robert Benford. 2005. "Clarifying the Relationship between Framing and Ideology." Pp. 205-212 in Frames of Protest: Social Movements and the Framing Perspective edited by H. Johnston and J.A. Noakes. Lanham, MD: Rowman \& Littlefield Publishers.

Snow, David. 2004. "Framing Processes, Ideology, and Discursive Fields.” Pp. 380-412 in The Blackwell Companion to Social Movements edited by D.A. Snow, S.A. Soule, and H. Kriesi. Malden, MA: Blackwell Publishing.

Solomon, Evan and Kristen Everson. 2014. "7 environmental charities face Canada Revenue Agency audits.” Retrieved July $4^{\text {th }}, 2015$ (http://www.cbc.ca/news/politics/7-environmental-charities-face-canada-revenueagency-audits-1.2526330).

Stanley, Anna. 2009. "Just space or spatial justice? difference, discourse, and environmental justice". Local Environment, 14(10), 999-1014.

Stavrianakis, Anna. 2012. "Missing the Target: NGOs, global civil society and the arms trade." Journal of International Relations and Development 15, 224-249.

Tarrow, Sidney. 2011. Power in Movement: Social Movements and Contentious Politics $\left(3^{\text {rd }}\right.$ Ed.). New York, NY: Cambridge University Press.

Tsikata, Dzodzi. 2009. “Women's Organizing in Ghana since the 1990s: From individual organization to three coalitions." Development 52(2), 185-192.

van Manen, Max. 2014. Phenomenology of Practice: Meaning-Giving Methods in Phenomenological Research and Writing. Walnut Creek, CA: Left Coast Press.

Veltmeyer, Henry and Paul Bowles. 2014. "Extractivist resistance: The case of the Enbridge oil pipeline project in Northern British Columbia" The Extractive Industries and Society, 1, 59-68.

Veltmeyer, Henry. 2013. "The political economy of natural resource extraction: a new model or extractive imperialism?" Canadian Journal of Development Studies 34(1), 79-95.

Veltmeyer, Henry. 2012. "The Natural Resource Dynamics of Postneoliberalism in Latin America: New Developmentalism or Extractivist Imperialism?" Studies in Political Economy 90, 57-85. 
Walker, Gordon. 2009. Globalizing environmental justice: The geography and politics of frame contextualization and evolution. Global Social Policy, 9(3), 355-382. 